\title{
LIFE-CYCLE COSTING
}

FOR ENERGY GONSERVATION IIN BULLDINGS: ISTUDENT'S MANUAL

Rosalie T. Ruegg

Stephen R. Petersen

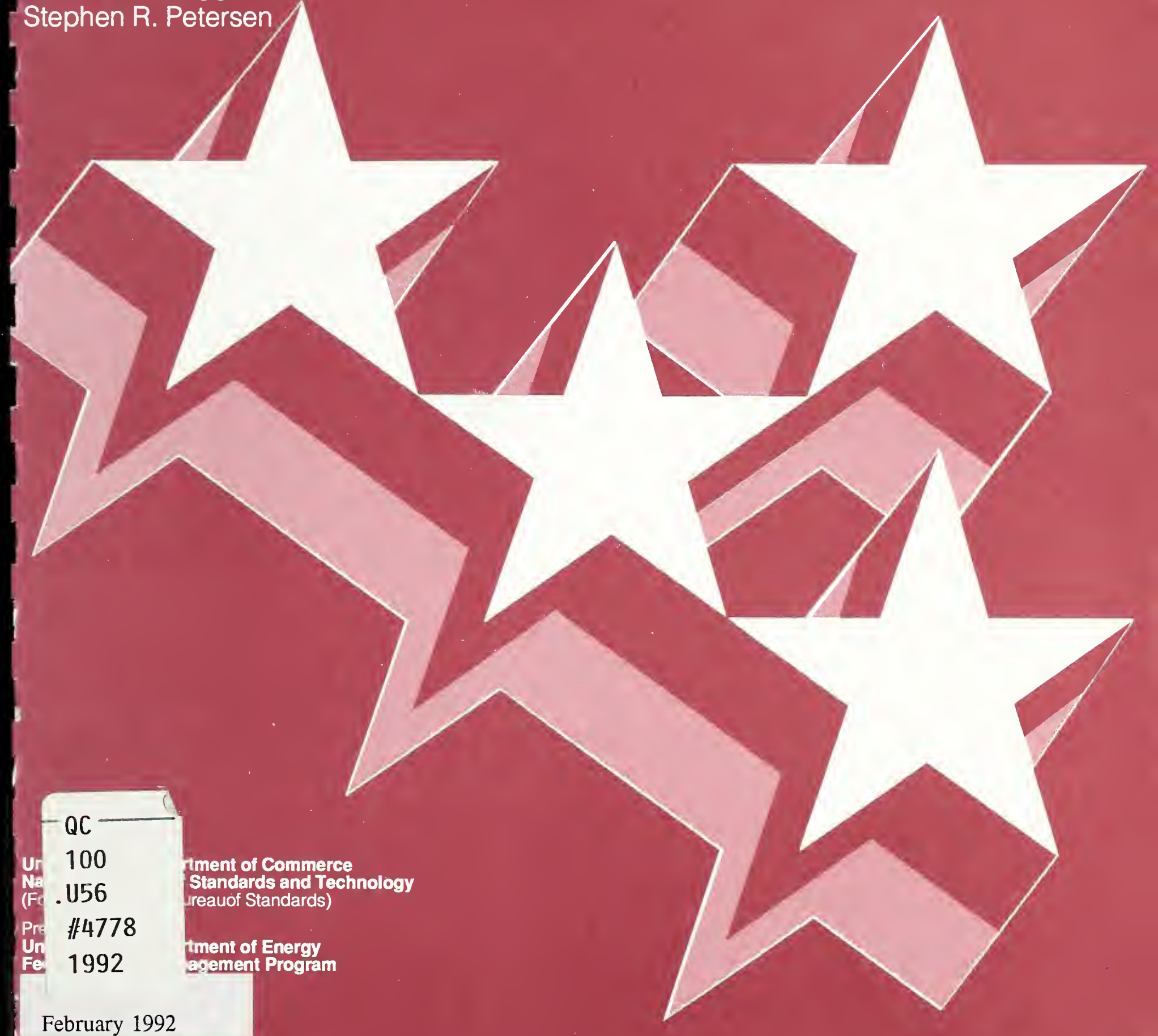

February 1992 



\section{LIFE-CYCLE COSTING FOR ENERGY CONSERVATION IN BUILDINGS: STUDENT'S MANUAL}

Rosalie T. Ruegg

Stephen R. Petersen

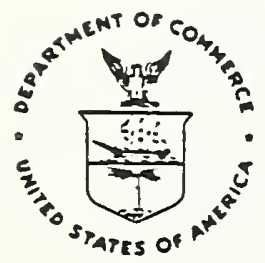

UNTTED STATES DEPARTMENT OF COMMERCE Natlonal institute of Standards and Technology (Formerly National Bureau of Standards)

Applled Economics Group Center for Computing and Applled Mathematics Gatthersburg, MD 20899

Prepared for.

U.S. Department of Energy Ottlice of the Assistant Secretary for Conservation and Renewable Energy

Federal Programs Office

Washington, D.C. 20585 


\title{
LIFE-CYCLE COSTING
}

\author{
TABLE OF CONTENTS
}

PAGE

COURSE OVERVIEW. . . . . . . . . . . . . . . . . . . . . vi

COURSE AGENDA. . . . . . . . . . . . . . . . . . . . . vii

COURSE OBJECTIVES. . . . . . . . . . . . . . . . . . . viii

INTRODUCTION. . . . . . . . . . . . . . . . . . . . . . . . . 1

A. ECONOMICS CAN IMPROVE DECISIONS. . . . . . . . . . . . . . 3

Slides. . . . . . . . . . . . . . . . . . . . .4

Examples of Decisions . . . . . . . . . . . . 13

Economic Efficiency Concepts. . . . . . . . . . . 14

LCC Profiles of Energy-Related Systems. . . . . . . 17

Overview of Economic Methods. . . . . . . . . . 18

B. WhAT YOU NEED TO GET STARTED. . . . . . . . . . . . 31

Slides. . . . . . . . . . . . . . . . . . . 32

Design or Retrofit Alternatives... . . . . . 37

Relevant Effects. . . . . . . . . . . . 37

Estimating Cash Flows . . . . . . . . . . . . 38

Setting the Study Period. . . . . . . . . . . . . 40

Exercise B-1. . . . . . . . . . . . . . . . . . . 41

Exercise B-2................ . . 43

C. ADJUSTING CASH AMOUNTS FOR TIME OF OCCURRENCE. . . . . 44

Slides. . . . . . . . . . . . . . . . . . 45

Cash-Flow Modeling. . . . . . . . . . . . . 65

Time Value of Money Concept . . . . . . . . . 66

What to Do About Inflation. . . . . . . . . . 68

Exercise $\mathrm{C}-1$. . . . . . . . . . . . . . 73 


\section{LIFE-CYCLE COSTING}

TABLE OF CONTENTS

(Continued)

D. CALCULATING LIFE-CYCLE COSTS, NET SAVINGS, SAVINGS-TO-INVESTMENT RATIO, ADJUSTED INTERNAL RATE OF RETURN, AND TIME TO PAYBACK . . . . . . . . . . . . . 76

Slides. . . . . . . . . . . . . . 77

Federal Criteria. . . . . . . . . . . . 93

Worksheets... . . . . . . . . . . 100

Calculations. . . . . . . . . . . . . . 100

Problem D-1... . . . . . . . . . . . . 101

E. LCC COMPUTER PROGRAMS. . . . . . . . . . . . . . 102

Overview of FBLCC and NBSLCC. . . . . . . . . . . 103

Getting Acquainted With the Software. . . . . . .116

Supplement to FBLCC User's Guide. . . . . . . . . .132

Supplement to NBSLCC User's Guide. . . . . . . . . 148

Problem-Solving Using FBLCC and NBSLCC. . . . . . .167

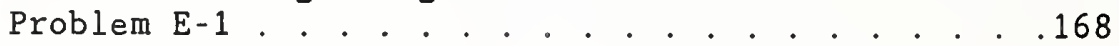

F. DESIGNING AND SIZING INDEPENDENT \& INTERDEPENDENT SYSTEMS.

Review. . . . . . . . . . . . . . .171

Slides. . . . . . . . . . . . . . . . . . . . . . . . . . . . . . .

Independent Systems . . . . . . . . . . . . . . 194

Interdependent Systems . . . . . . . . . . .195

Problem F-1... . . . . . . . . . . . . . 197

G. DETERMINING PROJECT PRIORITY . . . . . . . . . . 198

Slides. . . . . . . . . . . . . . . . . . 199

SIR Useful for Assigning Priority . . . . . . . .211

Limitations of SIR for Assigning Priority . . . . .213

Allocating a Budget Among Projects of Variable

Design/Size . . . . . . . . . . . . . . 214

Problem G-1............ . . . . . . . . . . . . . 17

H. UNCERTAINTY. . . . . . . . . . . . . . . 218

Slides. . . . . . . . . . . . . . 221

Sources of Uncertainty . . . . . . . . . . . . . . 227

Consequences of Uncertainty . . . . . . . . . . . . . . . . . 227

What to Do About Uncertainty. . . . . . . . . . 227

Problem H-1... . . . . . . . . . . 231 


\section{LIFE-CYCLE COSTING}

TABLE OF CONTENTS

(Continued)

I. REVIEW . . . . . . . . . . . . . . . . . . .232

J. COMPUTER LAB: USING FBLCC \& NBSLCC. . . . . . . . . . . 234 Problem J-1 . . . . . . . . . . . . . .235

Problem J-2 . . . . . . . . . . . . . . .236

APPENDIX A. ADDITIONAL PROBLEMS . . . . . . . . . . . . 237

Problem 1. Building Design Problem . . . . . . . .239

Problem 2. Sizing and Ranking Problem. . . . . . .241

APPENDIX B. ENERGY PRICES AND DISCOUNT FACTOR TABLES

SAMPLE. . . . . . . . . . . . . . . . . . . . . . . . . . . 243

SPW Factors (Discount Rates of 78 and 108). . . . .245

UPW Factors (Discount Rates of 78 and 108). . . . . 246

UPW* Discount Factors Adjusted for Average Fuel

Price Escalation by End-Use Sector and

Major Fuel (Discount Rate of 78 ). . . . . . . . . 248

1988 Projected Average Fuel Prices Indices

(Tables $\mathrm{Ca}-1$ through $\mathrm{Ca}-5$ ). . . . . . . . . . . 253

1988 Projected Average Fuel Price Escalation

Rates (Tables $\mathrm{Cb}-1$ through $\mathrm{Cb}-5$ ). . . . . . . . . 264

EVALUATION FORMS. . . . . . . . . . . . . . . . . 269 


\title{
LIFE-CYCLE COSTING
}

\author{
COURSE OVERVIEW
}

\section{DAY ONE}

The course begins with practical illustrations to demonstrate how life-cycle costing and related methods can improve energy-related decisions. Brief overviews are given of five methods of economic evaluation. Each method is described, examples of its use are given, and its limitations are discussed. Then, the major elements in performing a life-cycle cost evaluation are explained. Emphasis is placed on clarifying those issues which often confuse practitioners. Issues include why it is necessary to adjust cash flows for time and how to do it, how to estimate costs and benefits, and what to do about inflation. Sample exercises are provided. Students are shown, step-by-step, how to compute lifecycle costs, net savings, savings-to-investment ratio, adjusted internal rate of return, and time to payback. Federal criteria for performing economic evaluations of energy-related choices are presented. Students are asked to solve a sample problem. Then two computer programs, FBLCC for Federal applications and NBSLCC for non-Federal applications, are introduced. Students get acquainted with the software by performing a simple life-cycle cost evaluation using microcomputers.

\section{DAY TWO}

The second day broadens coverage to solution of more complex problems: designing and sizing independent and interdependent building systems, and allocating limited budgets among competing projects. The issue of uncertainty is discussed and guidance is provided on what to do about it. A computer laboratory in which students are given sample problems to solve concludes the two-day course on life-cycle costing. 


\section{LIFE-CYCLE COSTING}

COURSE AGENDA

\section{DAY 1}

TOPIC

A. ECONOMICS CAN IMPROVE DECISIONS

B. WHAT YOU NEED TO GET STARTED

C. ADJUSTING CASH AMOUNTS FOR TIME OF OCCURRENCE

D. CALCULATING LIFE-CYCLE COSTS, NET SAVINGS, SAVINGS-TO-INVESTMENT RATIO, OVERALL RATE OF RETURN, AND TIME TO PAYBACK

E. LCC COMPUTER PROGRAMS

DAY 2

F. DESIGNING AND SIZING INDEPENDENT AND INTERDEPENDENT PROJECTS

G. DETERMINING PROJECT PRIORITY

H. UNCERTAINTY

I. REVIEW

J. COMPUTER LAB: USING FBLCC \& NBSLCC
TIME ALLOTTED

50 minutes

50 minutes

100 minutes

75 minutes

90 minutes

75 minutes

60 minutes

60 minutes

75 minutes

150 minutes 


\section{LIFE-CYCLE COSTING}

\section{COURSE OBJECTIVES}

AT THE CONCLUSION OF THE TWO-DAY COURSE, THE STUDENT WILL BE ABLE TO:

Perform life-cycle cost analyses of energy-related building systems in order to make economic decisions.

AT THE CONCLUSION OF THE TOPIC, THE STUDENT WILL BE ABLE TO:

TOPIC A - ECONOMICS CAN IMPROVE DECISIONS (50 minutes)

Give examples of decisions affecting energy consumption which can be improved by economic evaluation, and explain the concepts of economic efficiency, cost-effectiveness, economic optimization, and incremental analysis.

TOPIC B -- WHAT YOU NEED TO GET STARTED (50 minutes)

Define alternatives to be evaluated, specify data requirements, and identify sources of data.

TOPIC C -- ADJUSTING CASH AMOUNTS FOR TIME OF OCCURRENCE (100 minutes)

Calculate the present value of (1) a single future amount (such as a replacement cost or residual value), (2) a uniform series of future amounts (such as routine maintenance and repair costs), and (3) a series of future amounts changing over time at specified rates (such as energy costs).

TOPIC D - CALCULATING LIFE-CYCLE COSTS, NET SAVINGS, SAVINGS-TOINVESTMENT RATIO, ADJUSTED INTERNAL RATE OF RETURN, AND TIME TO PAYBACK (75 minutes)

Calculate life-cycle costs, net savings, savings-to-investment ratio, adjusted internal rate of return, and time to payback for a Federal energy conservation project and, on the basis of those measures, decide whether to accept or reject the project. 


\section{LIFE-CYCLE COSTING}

COURSE OBJECTIVES (Continued)

TOPIC E -- ICC COMPUTER PROGRAMS (90 minutes)

Run the FBLCC or NBLCC computer program; enter data inputs for a sample problem; and read the results from a screen printout.

TOPIC F - DESIGNING AND SIZING INDEPENDENT \& INTERDEPENDENT SYSTEMS (75 minutes)

Find the cost-effective size of an energy-related building component, such as the level of attic insulation; and find the, cost-effective combination of interdependent projects, such as the level of attic insulation and heating system efficiency.

TOPIC G - DESIGNING PROJECT PRIORITY (60 minutes)

Use the SIR method to allocate a budget among independent projects.

TOPIC H - UNCERTAINTY (60 minutes)

Perform sensitivity analysis, and make decisions under uncertainty.

TOPIC I - REVIEW (60 minutes)

Summarize principal steps in performing economic evaluations, describe five methods of economic evaluation, and explain how each method is used to guide energy-related decisions.

TOPIC J - COMPUTER LAB: USING FBLCC \& NBSLCC (150 minutes)

Use FBLCC or NBSLCC to size a building system and establish funding priority among competing projects. 


\section{LIFE - CYCLE COSTING}

\section{INTRODUCTION}

\section{Why This Course?}

The energy crises of the 1970's, the threat of new shortages, and environmental concerns have focused attention on a critical need for energy conservation and reduced reliance on fossil fuels. Energy has become a crucial element in the art of building. The Federal government as the owner and operator of nearly a half-million buildings, and the nation's largest user of energy, has a leadership role in improving the energy efficiency of buildings.

Principles of microeconomic theory and engineering economics can be applied to determine the economically efficient balance of energy and other resources used in buildings. Finding the balance enables us to lower the long-run costs of owning and operating buildings.

Congress and the President, through legislation and executive order, have recognized the importance of cost-effective energy conservation. They have directed Federal agencies to make their buildings life-cycle cost effective, taking into account life-cycle energy costs. They also have instructed the Federal government to make available to the private sector, methods, computational tools, and data developed in the Federal energy management effort.

This course has three main goals: (1) to instruct Federal engineers, architects, and managers in using life-cycle cost analysis for making decisions affecting energy consumption in Federal buildings; (2) to instruct contractors and consultants who work on Federal projects in evaluating projects according to Federal requirements; and (3) to provide members of the building community at large the methods, tools, and data for evaluating energy conservation and renewable energy projects in residential, commercial, and institutional buildings. 


\section{LIFE - CYCLE COSTING}

INTRODUCTION, continued

\section{Scope}

The principles of economic evaluation taught in the course are widely applicable to investment decisions in both the public and private sectors. They apply to the decisions of an individual, as well as to those of organizations, including state and Federal governments, nonprofit institutions; companies and corporations. In the examples, principles are applied to energy conservation and renewable energy investments in Federal buildings.

\section{About this Manual}

This Manual is intended as both an in-class workbook and as a future source for reference and review. Like the course, the Manual is divided into 10 major modules which group material on each respective topic. Each module begins with the topic title, time, teaching techniques, and learning objectives. Next are paper copies of the set of instructional slides used for that topic. The copies are provided to assist you to concentrate on the presentation and with note taking. Following the slides is information to supplement your notes. It is provided for future reference and review. 


\section{ECONOMICS CAN IMPROVE}

\section{DECISIONS}

MODULE A

50 Minutes
Lecture and Discussion

OBJECTIVES

By the conclusion of this module, you are expected to be able to

- give examples of decisions affecting energy consumption which can be improved by economic evaluation; and

- explain the concepts of economic efficiency, cost effectiveness, economic optimization, and incremental analysis. 
MODULE A, CONTINUED

EXAMPLES OF DECISIONS

SLIDE $A-1$

\section{ECONOMICS CAN IMPROVE DECISIONS}

o to accept or reject?

- which design?

o what size?

- what combination?

o what priority?

NOTES : 


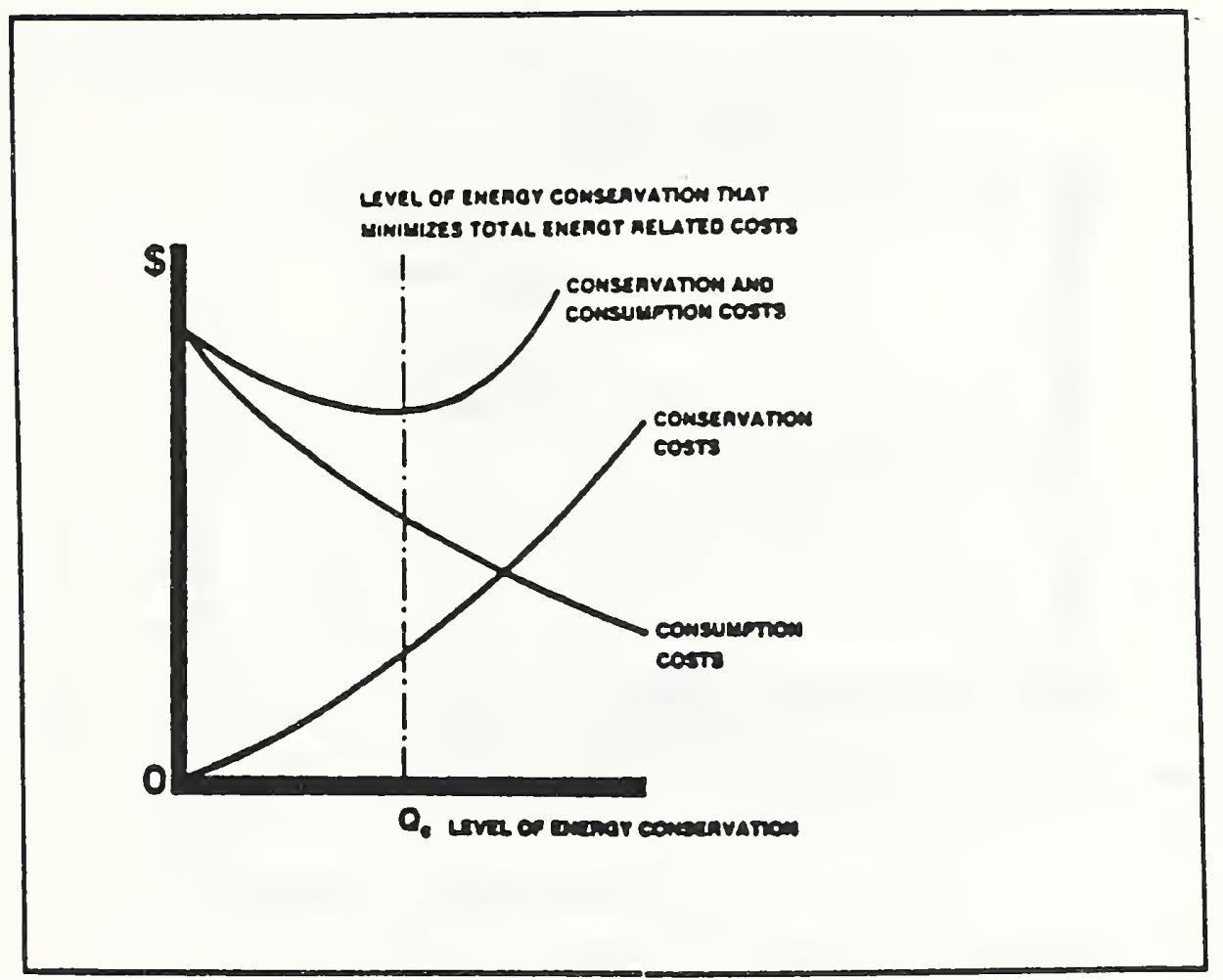

NOTES: 
SLIDE A-3

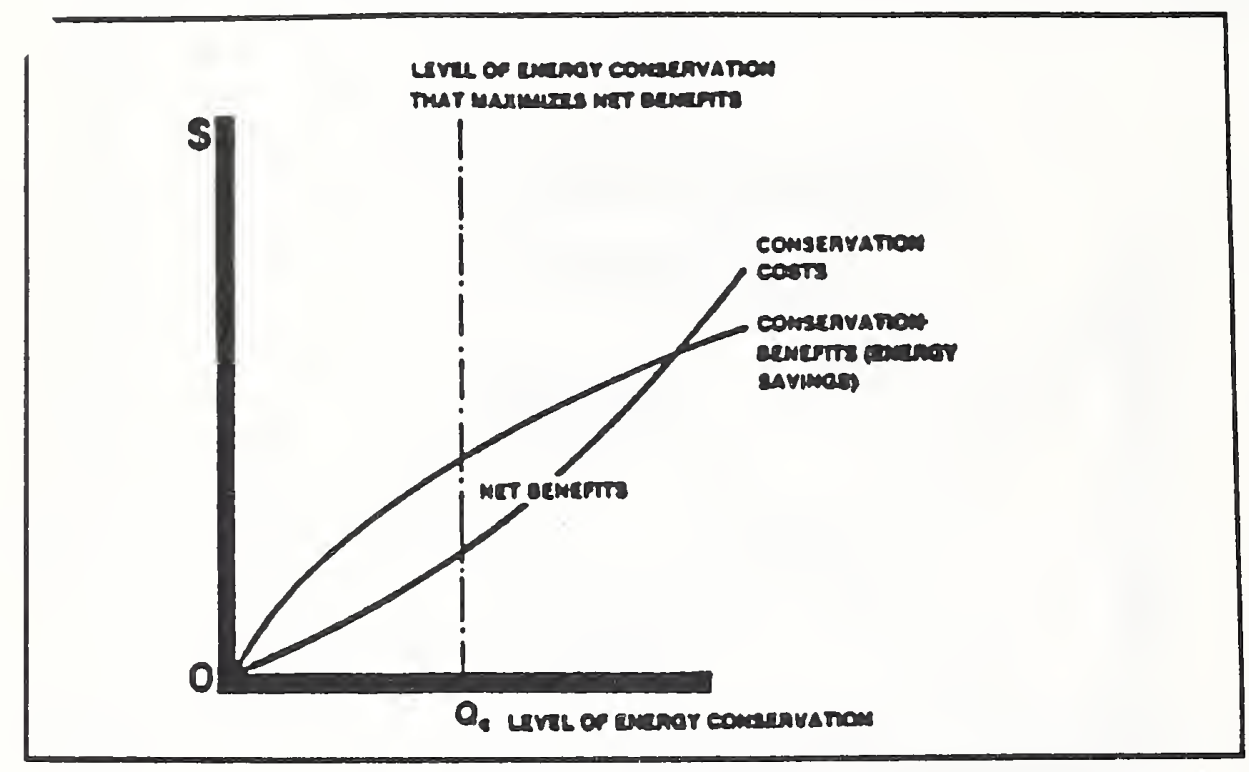

NOTES : 


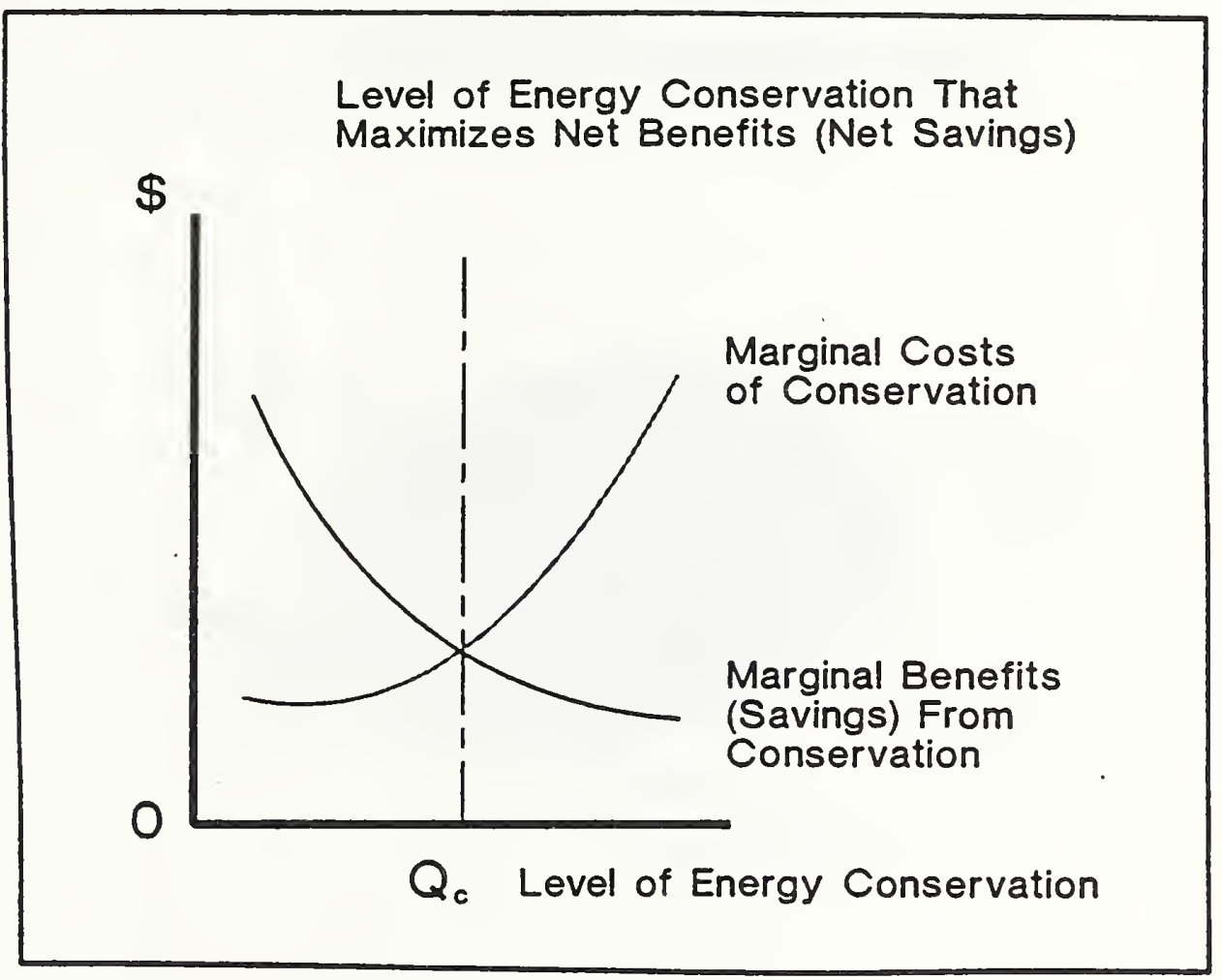

NOTES : 
MODULE A, CONTINUED

SLIDE $A-5$

\section{Life-Cycle Costs of a Motor}

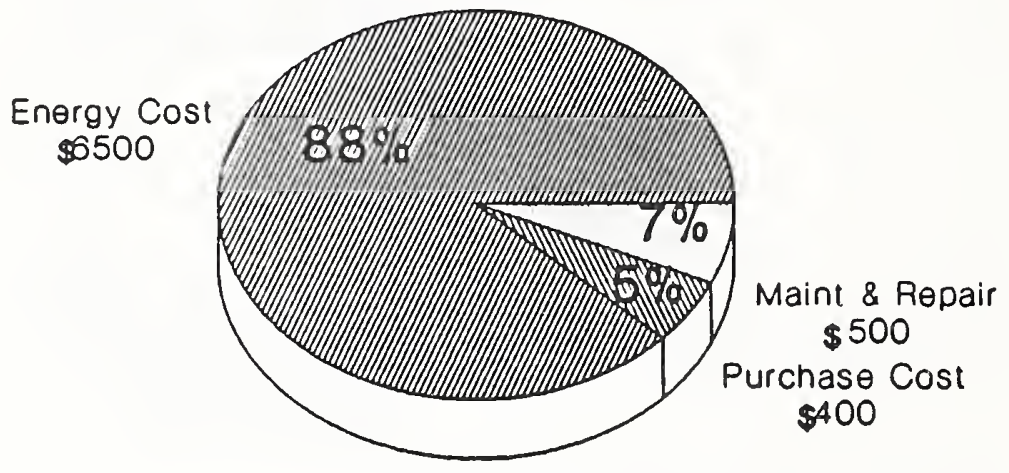

NOTES : 
MODULE A, CONTINUED

SLIDE A-6

\section{Life-Cycle Costs of a Heating System}

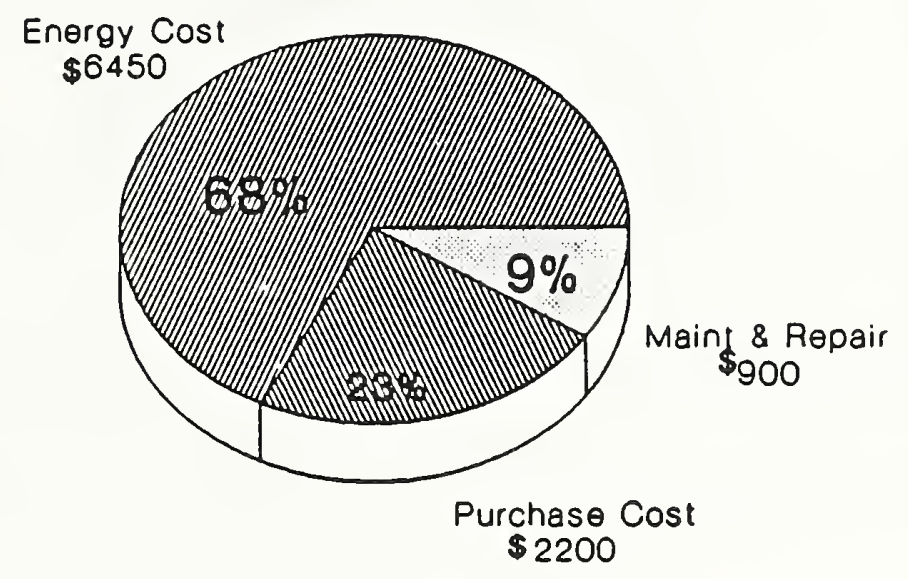

NOTES: 
SLIDE A-7

\begin{tabular}{|ll|} 
& ECONOMIC EVALUATION METHODS \\
$\circ \quad$ & Life-Cycle Cost (LCC) \\
$\circ \quad$ Savings-to-Investment Ratio (SIR) \\
$\circ \quad$ Net Savings (NS) \\
Adjusted Internal \\
Rate-of-Return (AIRR) \\
$\begin{array}{l}\text { Payback Period (PB) } \\
\text { Discounted \& Simple (DPB \& SPB) }\end{array}$ \\
\hline
\end{tabular}

NOTES: 


\section{KEY FEATURES OF LCC METHOD}

- takes into account

- first costs

--future costs ( $\&$ benefits)

- adjusts for time of occurrence

- useful for making energy-related decisions

NOTES: 
MODULE A, CONTINUED

SLIDE A-9

\section{HOW TO PERFORM LCC ANALYSIS}

- compute LCC for each alternative

- - identify relevant effects

- estimate in dollars

- adjust $\$$ amounts for time

-- sum time-equivalent amounts

- compare LCCs

- select alternative with lowest LCC

(alts must satisfy performance requirements)

NOTES : 
MODULE A, CONTINUED

\section{EXAMPLES OF DECISIONS}

Economic analysis is a powerful decision tool. It can be used to--

- Maximize net benefits (or profit) from a building investment.

- Find how much to spend on energy conservation to

minimize lifetime building costs given a level of building performance.

- Achieve the largest possible savings for a given energy conservation budget.

- Meet a targeted reduction in energy costs for the lowest budget.

Slide A-1 lists types of decisions to which economic analysis can be usefully applied. Examples of these decisions are:

- Whether to add a computer control system to an HVAC system in an office building.

- Whether to add a solar energy hot water system to a launderette.

- Whether to select heating system of design A, B, or $C$ for Building 1.

- Whether to install single-, double-, or triple-glazed windows in a new house in Bismarck, North Dakota; in Columbus, Ohio; in Atlanta, Georgia.

- What kind of insulation (e.g., cellulose or fiberglass), and how much, should be added to the walls, floors, and attic of houses in Madison, Wisconsin; in Washington, D.C.; and in Dallas, Texas.

- Whether to replace the furnace, add insulation, or do both in combination in existing housing?

- Which cost-effective projects to do first, given there are insufficient funds to do all of them. 
MODULE A, CONTINUED

\section{ECONOMIC EFFICIENCY CONCEPTS}

Improving the economic efficiency or cost effectiveness of buildings by taking into account the long-run costs of both energy consumption and conservation is at the heart of this course. Before going further, you should understand the concepts of economic efficiency, cost-effectiveness, and optimization. This will help you master the course material, diagnose economic problems, and select and apply economic methods correctly.

Economic Efficiency:

Economic efficiency means making decisions which result in maximum net benefits (excess of benefits over costs).

Cost Effectiveness:

Cost effectiveness is a term often used in place of "economic efficiency" when a choice is to be made among alternatives which differ in costs, but are considered equal in meeting performance requirements. It is a more restrictive term than economic efficiency, but the terms are frequently used interchangeably by practitioners.

Optimization:

Optimization is the process by which economic analysis is applied to determine the economically efficient or cost-effective choice among alternatives. 
MODULE A, CONTINUED

Graphical Illustration:

The concepts of economic efficiency, cost effectiveness, and optimization are illustrated in the three graphs shown in slides $\mathrm{A}-2, \mathrm{~A}-3$, and $\mathrm{A}-4$. The decision is what level of energy conservation (e.g., resistance level or "Rvalue" of insulation) to choose for a given building. In each graph, the physical quantity of inputs to conserve energy is measured on the horizontal axis. Dollars are measured on the vertical axis.

The graphs provide three ways of looking at the same problem, and they support the same decision: choose $Q_{c}$ as the economically-efficient (or ' cost-effective) level of energy conservation.

The optimal investment level of conservation is the level at which the difference between total costs and benefits (or savings) is greatest. The difference is greatest at level Qc. This method is called the "net benefits" or "net savings" method.

Slide A-2 shows the costs of conservation added to the costs of energy consumption and finds the level of energy conservation for which total longrun costs are minimum. Costs reach their minimum at level Qc. This method is appropriate if all the levels of energy conservation considered satisfy building performance requirements and compete primarily on the basis of their costs. The method is the "life-cycle cost" method.

Slide A-3 compares the costs of conservation as more is purchased, with the corresponding benefits (or savings). The total costs of conservation rise slowly at first but then more sharply as additional inputs of conservation 
MODULE A, CONTINUED

Graphical Illustration, continued:

are added and difficulties begin to be experienced in carrying out further conservation. The total conservation cost curve for a building investment typically bends upward at an increasing rate. The total savings curve also rises, but at a decreasing rate.

Slide A-4 shows how incremental or "marginal analysis" can be used to find the optimal level of conservation, i.e., the level which will yield the largest net benefits (net savings) or the lowest life-cycle costs. It shows changes in the total benefits or savings curve and in the total cost curye of slide A-2 as the inputs of energy conservation are increased, (i.e., slide A-4 shows the derivatives of slide A-2). The point of intersection of the two marginal curves indicates the most profitable level of energy conservation, level Qc. This is the level at which the costs of adding one more unit of conservation are just equal to the corresponding additional benefits in terms of energy savings; that is, the level for which "marginal costs" equal "marginal benefits" or "marginal savings."

For lower levels of conservation, the additional benefits or savings from increasing conservation by another unit are greater than the additional costs, and it pays to invest more. For higher levels of conservation, the costs of additional conservation exceed its benefits or savings causing the level of total net benefits to fall.

Note the correspondence between the optimal solution reached by (1) finding the minimum life-cycle costs, (2) finding the maximum net benefits or savings, and ( 3 ) using marginal analysis to find the point of equality between marginal costs and marginal benefits, i.e., where marginal net benefits equal zero. 
MODULE A, CONTINUED

\section{LCC PROFILES OF ENERGY-RELATED SYSTEMS}

Making choices on the basis of first costs among building systems and equipment that either consume energy directly or affect the consumption of energy, without regard to energy efficiency, can increase long-run costs. Only a small part of the long-run costs of most energy-consuming equipment is attributable to initial purchase price. The larger part is usually attributable to on-going support, energy, and maintenance costs.

The pie charts shown in slides A-5 and A-6 demonstrate the importance ' of taking into account energy efficiency in purchasing equipment.

The pie chart in slide A-5 shows the estimated costs over 20 years of owning and operating a 10-horsepower motor. Purchase costs comprise only $5 \%$ of the overall costs of the motor over its expected life of 20 years. Maintenance and repair are estimated to comprise another 78. Energy costs comprise 888 of life-cycle costs. Increasing the efficiency of the motor from 0.75 to 0.90 is estimated to add about 258 to purchase price, or about $\$ 100$, but to reduce life-cycle costs by about $\$ 1,000$.

The pie chart in slide A-6 shows estimated costs over 15 years of owning and operating an oil-fired furnace to heat a 2,000 square foot house in the Washington, D.C., area. Purchase costs make up about onefourth the long-run costs; maintenance and repair, about 10\%; and fuel oil, about two-thirds of the total. 


\section{OVERVIEW OF ECONOMIC METHODS}

Five closely related methods for evaluating the economic consequences of decisions are described here. The first treated, the life-cycle cost (LCC) method, is appropriate for addressing many energy conservation decisions and is the method emphasized in this course. But the other methods are needed for certain kinds of decisions and are therefore also treated. Since all of these methods are widely used, a working knowledge of all of them is important for communication.

\section{Life-Cycle Cost Method:}

\section{ABBREVIATION: LCC}

DESCRIPTION: LCC is a method of evaluation which sums all significant timeequivalent dollar costs attributable to a given building design, system, or component. Positive cash flows, such as salvage values ${ }^{1}$, are treated as negative costs which are time-adjusted and subtracted from the total.

"The term "salvage value" is used here to include resale value, reuse value, scrap value, or residual value remaining when the life of an asset exceeds the study period. 
MODULE A, CONTINUED

GENERAL FORMULA:

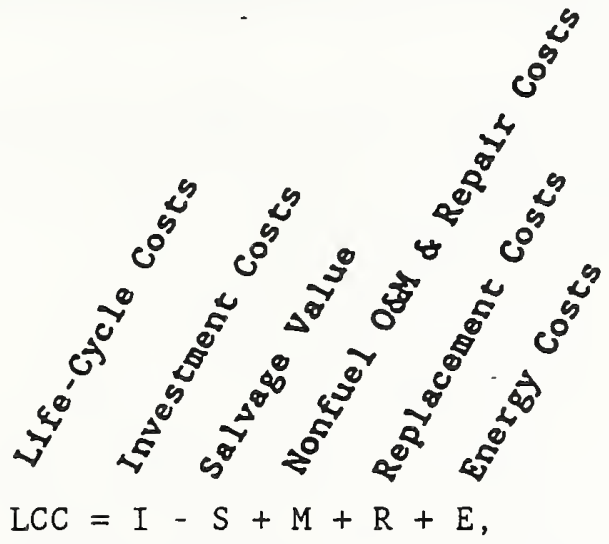

where all amounts are expressed as present-value ${ }^{1}$ dollars.

USE: (1) Determine a project's cost effectiveness.

Use the LCC method to determine project cost effectiveness by computing LCC for the proposed project and LCC for the base case. ${ }^{2}$ A building design, system, or component that results in a lower LCC than the base case while meeting the same or higher performance requirements is generally held to be cost effective. (Note that unquantified costs or benefits may be important to the decision.)

(2) Compare new building designs.

Use the LCC method to determine the cost-effective building design by computing LCCs for each of the alternative designs which meets requirements. The design alternative with minimum LCC is the cost-effective choice.

${ }^{1}$ The present value concept is treated in Module $C$.

${ }^{2}$ The base case should be a viable alternative with lowest first costs. 
MODULE A, CONTINUED

(3) Compare sizes or designs of a building system (e.g., alternative thickness of insulation for a given wall or alternative designs of a heating system).

Use the LCC method to determine the cost-effective design or size of a building system by computing LCCs for each of the alternatives and finding the design/size for which LCC is minimum.

Net Savings Method:

ABBREVIATION: NS

DESCRIPTION: NS is a method of evaluation which calculates the difference, between the LCC of the base case and the LCC of the alternative building system. (See equation (2).)

NS may also be calculated as present value savings attributable to a project, less present value costs attributable to it. This acond approach does not require the prior calculation of LCC for the base case and for the alternative, but rather, works directly from differences in individual cash flows. (See equation (3).)

The NS method is a variation of the Net Benefits (NB) method. It is used instead of the NB method when benefits occur primarily in the form of cost reductions.

GENERAL FORMULAS:

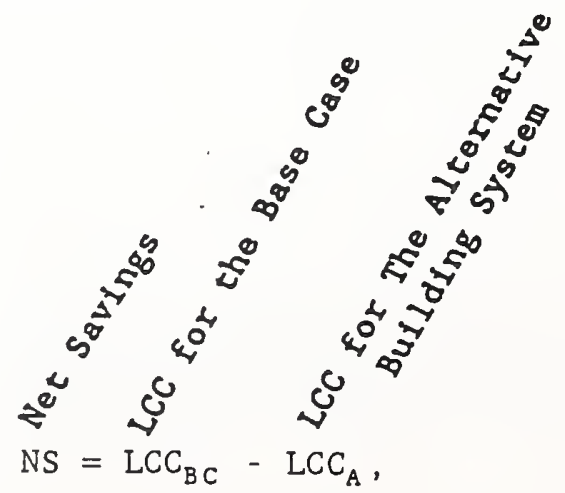


where all amounts are expressed in present value dollars, the subscript "BC" designates the base case, and the subscript "A" designates the alternative building system.

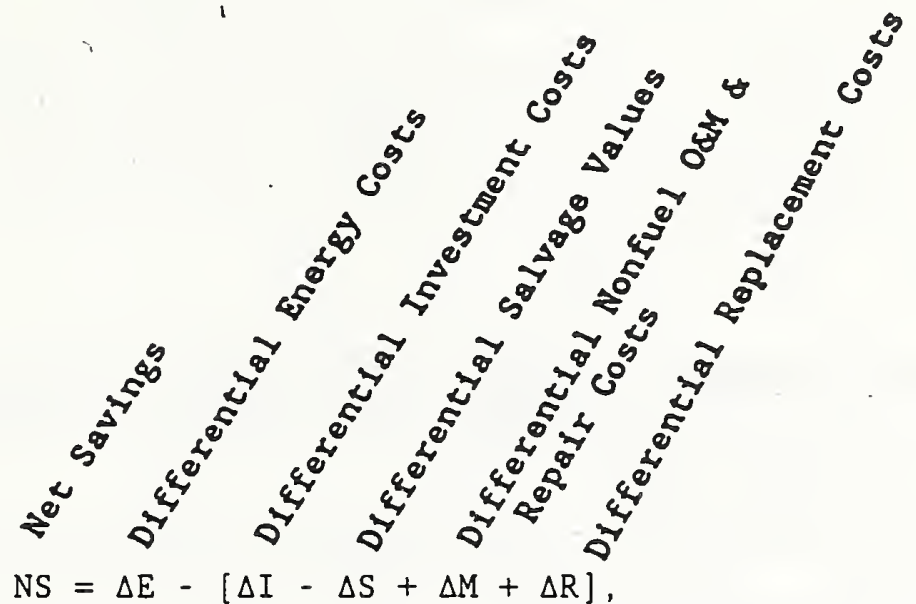

where all amounts are expressed in present value dollars, and the values in equation (3) are as defined below in equations (3.1)-(3.5).

The delta symbol, $\Delta$, used above in equation (3) and below in equations (3.1)-(3.5) signifies the taking of differences, where again the subscripts $B C$ and $A$ designate the base case and the alternative building system, respectively. The $\Delta$ terms are defined as follows:

$$
\begin{array}{ll}
\text { Differential Present Value Energy Costs: } & \Delta E=\left(E_{B C}-E_{A}\right) \\
\begin{array}{l}
\text { Differential Present Value Investment Costs: } \\
\text { Differential Present Value Salvage Value }
\end{array} & \Delta I=\left(I_{A}-I_{B C}\right) \\
\text { Net of Disposal Costs: } & \Delta S=\left(S_{A}-S_{B C}\right) \\
\begin{array}{l}
\text { Differential Present Value Nonfuel Operation } \\
\text { and Maintenance (O\&M) and Repair Costs: }
\end{array} & \Delta M=\left(M_{A}-M_{B C}\right) \\
\text { Differential Present Value Replacement Costs: } & \Delta R=\left(R_{A}-R_{B C}\right)
\end{array}
$$

Note that it is important to preserve the appropriate signs when entering the resulting values in the equations for NS, SIR, and PB: 
MODULE A, CONTINUED

USE: (1) Determine a project's cost effectiveness.

A positive NS generally means a project is cost effective. For example, an NS value of $\$ 50,000$ for an alternative building system means the system is estimated to save over the study period an amount equivalent to a lump-sum amount today of $\$ 50,000$, over and above the minimum acceptable rate of return.

(2) Compare designs or sizes of a building system (e.g., alternative thickness of insulation for a given wall, or alternative designs of a heating system).

Use the NS method to identify the design or size alternative of a building, system which maximizes net savings.

Note that choosing project design or size with the highest NS is consistent with choosing the project design or size with the lowest LCC.

Savings-to-Investment Ratio Method:

ABBREVIATION: SIR

DESCRIPTION: The SIR is a method of evaluation which expresses the ratio of savings to costs. The numerator of the ratio is the reduction in energy costs, minus any increase (or plus any decrease) in nonfuel operation, maintenance, and repair costs. The denominator is the increase in investment cost, plus any increase (or minus any decrease) in replacement costs, and minus any increase (or plus any decrease) in salvage values.

The SIR method is a variation of the Benefit-to-Cost Ratio (BCR) method. It is used instead of the BCR method when benefits occur primarily as cost reductions. 
MODULE A, CONTINUED

GENERAL FORMULA:

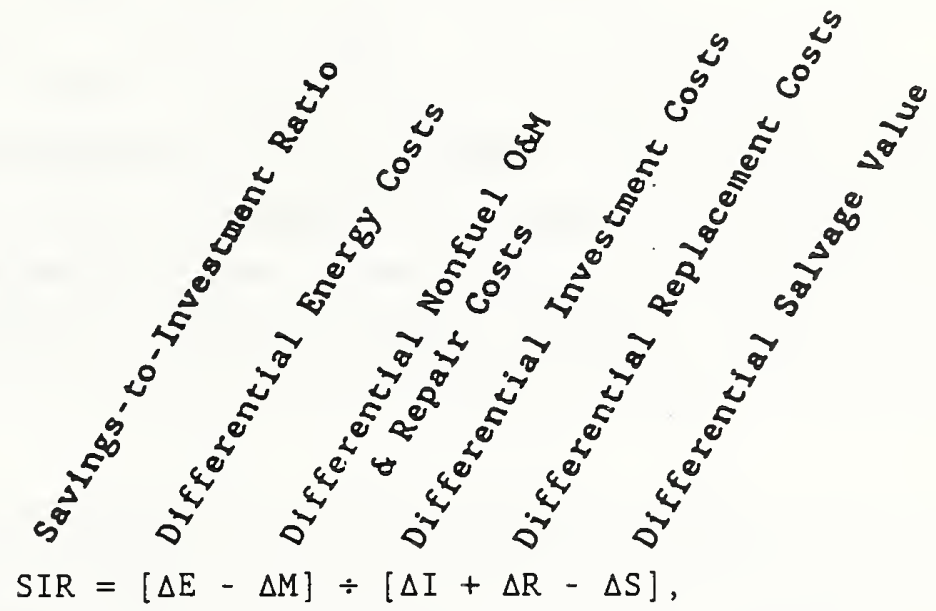

where all amounts are expressed as present value dollars.

USE: (1) Determine a project's cost effectiveness.

An SIR greater than one generally means a project is cost effective. The higher the ratio, the greater the dollar savings per dollar spent. For example, an SIR of 4 computed for an alternative system relative to the base means that the alternative building system is estimated to save $\$ 4$ on the average for every $\$ 1$ invested, over and above the minimum acceptable rate of return.

(2) Rank nonmutually exclusive projects to determine their relative priorities.

The SIR is recommended for setting priority among nonmutually exclusive projects when the budget is insufficient to do all cost-effective projects. The approach is to rank projects in descending order of their SIRs. This ranking will provide a reliable guide to choosing the group of independent projects which will maximize overall net savings for the budget, provided 
MODULE A, CONTINUED

the budget can be used up exactly. Ranking of projects is treated further in Module G.

If project costs are "lumpy," so that the budget cannot be used up exactly by adhering strictly to SIR rankings, it may be necessary to depart from the SIR ranking in order to maximize overall NS from the budgeted expenditure. In this case, overall NS can be computed for trial combinations of projects to find the set that maximizes overall NS and stays within the confines of the budget.

Note that the SIR method is not reliable for designing and sizing alternative building systems unless the analysis is based on incremental SIRs. This is because SIRs computed on total savings and costs tend to fall before the most cost-effective design or size is reached. For example, the SIR on attic insulation of R11 versus RO will tend to be higher than the SIR on R19 versus RO, but the incremental SIR on increasing insulation to R19 from R11 may nevertheless exceed one, indicating that the additional amount of insulation is cost effective. (Because of the tendency to misuse the SIR, the FEMP LCC Rule does not recommend its use for designing and sizing alternative building systems.)

Adjusted Internal Rate of Return Method:

ABBREVIATION: AIRR

DESCRIPTION: The AIRR method calculates the return on investment as a compound annual yield. The yield is calculated by subtracting 1 from the Nth root of the ratio of the terminal value of savings to the present value of costs. (See equation (5).) The compound yield is compared against the 
MODULE A, CONTINUED

investor's minimum acceptable rate of return (MARR) to measure economic performance. If it is lower than the MARR, the project is uneconomic; if higher, it is economic. The MARR is equal to the discount rate.

The AIRR is a replacement for the traditionally used internal rate of return (IRR). It makes an explicit assumption about the reinvestment of savings in each time period. The AIRR is preferred to the IRR because it avoids computational problems of the IRR and, unlike the IRR, provides a technically correct measure of the yield over the decision maker's study period.

GENERAL FORMULA:

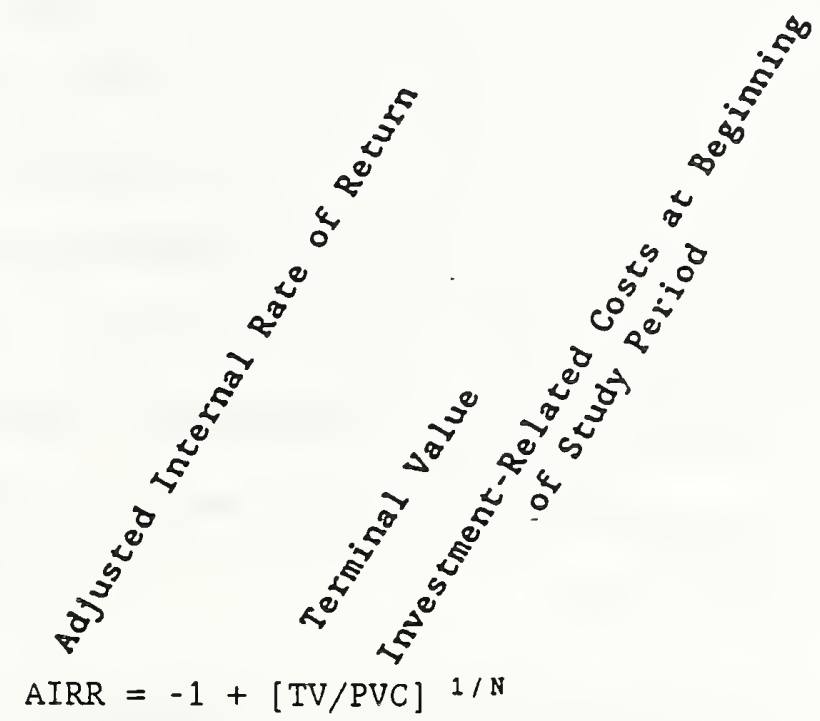


Adjusted Internal Rate of Return Method, continued:

where,

TV = value of all energy savings less increase in nonfuel operation, maintenance and repair costs as of the end of the study period (called "terminal value"), found by reinvesting net savings at rate $r$, i.e., $T V=\sum_{j=1}^{N}\left(\Delta \bar{E}_{j}-\Delta \bar{M}_{j}\right)(1+r)^{N-j}$, where $\Delta \bar{E}_{j}$ and $\Delta \bar{M}_{j}$ are differential

energy costs and nonfuel operation, maintenance, and repair costs, respectively, as defined in equations (3.1) and (3.4), except that they are amounts in year $j$, not yet discounted to present values;

$r=$ the reinvestment rate, i.e., the rate at which interim net savings earn a return until the end of the study period, which is set equal to the discount rate;

PVC = present value of investment-related costs (FEMP defines this as including future replacement costs and net of salvage values, i.e., $P V C=\Delta I+\Delta R-\Delta S$ )

USE: (1) Determine a project's cost effectiveness.

An AIRR measure greater than the MARR generally means a project is cost effective. 
MODULE A, CONTINUED

Adjusted Internal Rate of Return Method, continued:

(2) Rank nonmutually exclusive projects to determine their relative priorities.

The AIRR is a substitute for the SIR for ranking. The approach is to rank projects in descending order of their AIRRs. When used for ranking, the AIRR is subject to the same limitations as the SIR. When the budget cannot be exhausted by taking projects in descending order of their AIRRs (i.e., project costs are "lumpy"), it may be necessary to depart from the AIRR' ranking in order to maximize overall NS from the budgeted expenditure. Like the SIR, the AIRR is not reliable for designing and sizing unless the analysis is based on incremental AIRRs. [It is used optionally in the FEMP Program as a supplementary measure for managers who prefer the economic worth of a project expressed as a percentage rate of return.]

Payback Period Method:

ABBREVIATION: $P B$ for payback; $D P B$ for discounted payback, and SPB for simple payback.

DESCRIPTION: The PB method finds how long it takes a project to just break even, in the sense of recovering investment costs. The measure is calculated as the elapsed time between the initial investment and the time at which 
MODULE A, CONTINUED

cumulative savings, net of accrued costs, are just sufficient to offset investment costs.

If cash flows are expressed as time-equivalent values, the method is called "discounted payback" (DPB). If this is not done, that is, the opportunity cost is assumed to be zero--generally, a poor assumption--the method is called "simple payback" (SPB).

GENERAL FORMULA:

Find minimum value of $y$, years, for which

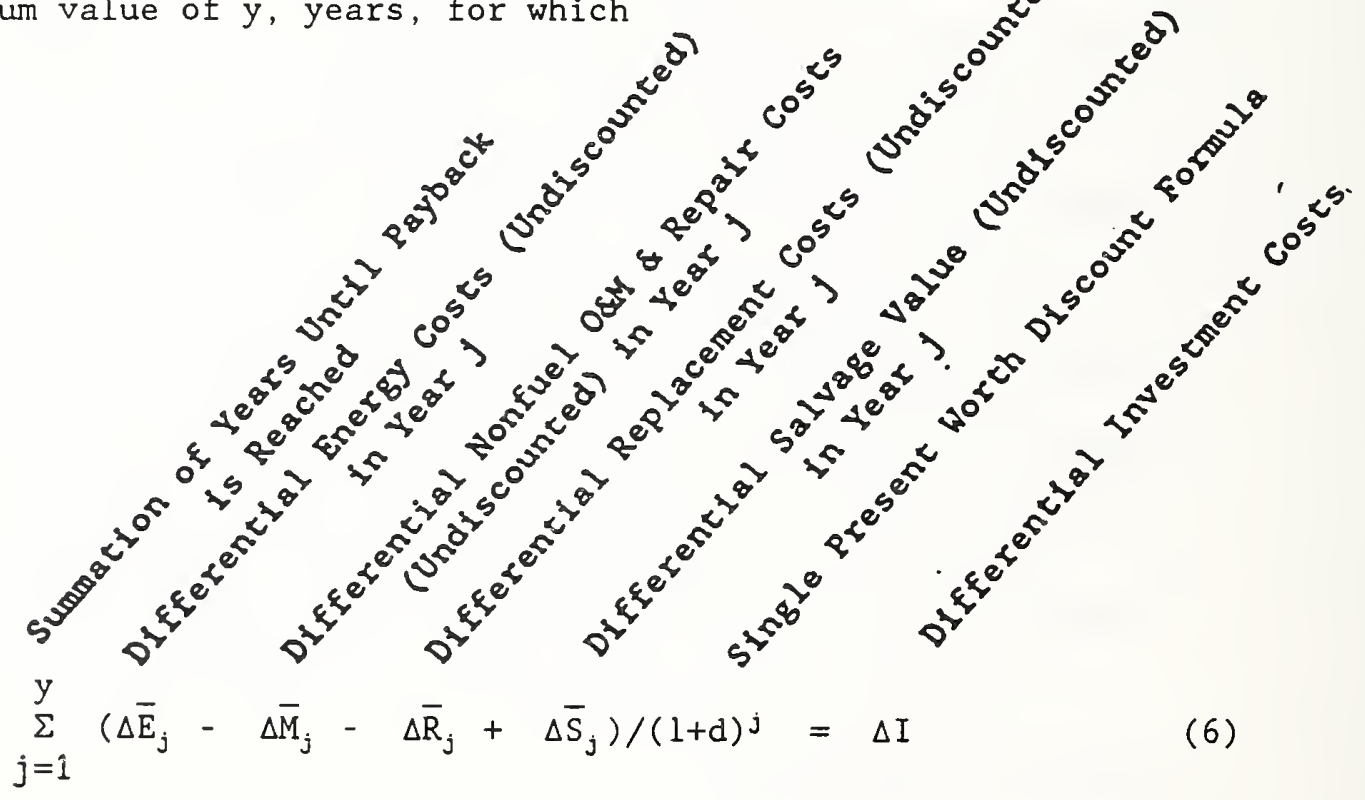

where $\Delta \bar{E}_{j}, \Delta \bar{M}_{j}, \Delta \bar{R}_{j}$, and $\Delta \bar{S}_{j}$ are, respectively, differential energy costs, nonfuel operating, maintenance and repair costs, replacement costs, and salvage value as defined in equations (3.1) through (3.5), except that they are amounts in year $j$, not discounted to present values prior to being entered into equation (6); $d=$ the discount rate. If $d \neq 0, y=D P B$, and if $\mathrm{d}=0, \mathrm{y}=\mathrm{SPB}$.

SIMPLIFIED SPB FORMULA: If future savings net of future costs are estimated to occur in an even amount from year to year, such that 
$\left(\Delta \bar{E}_{j}-\Delta \bar{M}_{j}-\Delta \bar{R}_{j}+\Delta \bar{S}_{j}\right)=$ AS (a constant), and investment costs are assumed to occur as a lump-sum initial amount, the following simple formula can be used to determine SPB:

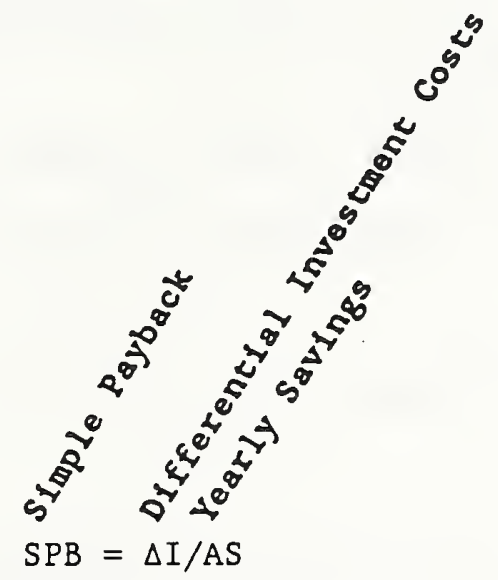

DPB can be approximated from SPB using graphs or discount factor tables, as explained in NBS Special Publication 709 and as illustrated in the example in Module D.

USE: (1) Supplementary measure.

Care is urged in using the $P B$ method because it is subject to misuse and erroneous interpretation. A project design or size with a shorter payback period may be a poorer investment than a design or size with a longer payback period. For example, a level of R19 insulation may take longer to recover its investment cost than a level of R11, but that does not mean that the insulation level should be limited to R11. The simple version of payback has the added disadvantage of not indicating the correct time to payback because it ignores the cost of money. For these reasons, the PB method has limited application in project evaluation.

Primary advantages of the PB method are its simplicity, its usefulness in assessing the minimum required project life, and the insight it provides to protecting initial investment funds in the face of uncertainty over time. 
MOdULE A, CONTINUED

Focus on LCC

The LCC method is particularly designed for evaluating cost-reducing investments, and for measuring costs over the long run. These characteristics make it well suited for energy-related decisions.

Slide A-8 lists key features of the LCC method. Slide A-9 outlines how LCC is performed. We will examine each of these subjects further in coming modules. 


\title{
WHAT YOU NEED TO GET STARTED
}

MODULE B

\author{
50 Minutes \\ Lecture, Discussion, and Exercises
}

\section{OBJECTIVES}

At the conclusion of this module, you are expected to be able to

- define alternatives to be evaluated;

- specify data requirements; and

- identify sources of data. 
MODULE B, CONTINUED

DESIGN/RETROFIT ALTERNATIVES

SLIDE B-1

\section{CHOOSE ALTERNATIVES}

- good alternatives ESSENTIAL

- must meet performance requirements

o credit if benefits exceed requirements?

NOTES : 
MODULE B, CONTINUED

\section{RELEVANT EFFECTS}

SLIDE B-2

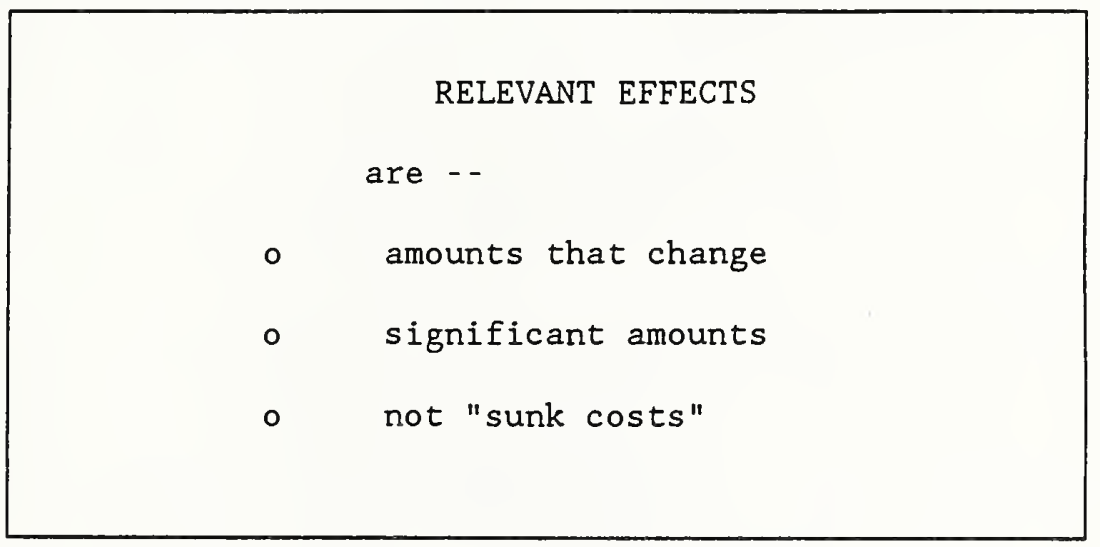

NOTES: 
MOdUle B, CONTINUED

SLIDE B-3

$\begin{array}{|ll|} & \text { RELEVANT EFFECTS } \\ \text { may include - } & \\ 0 & \text { acquisition costs } \\ 0 & \text { energy costs } \\ 0 & \text { maintenance costs } \\ 0 & \text { repair costs } \\ 0 & \text { replacement costs } \\ 0 & \text { residual value } \\ 0 & \text { revenue } \\ 0 & \text { other }\end{array}$

NOTES: 
MODULE B, CONTINUED

ESTIMATING CASH FLOWS

SLIDE B-4

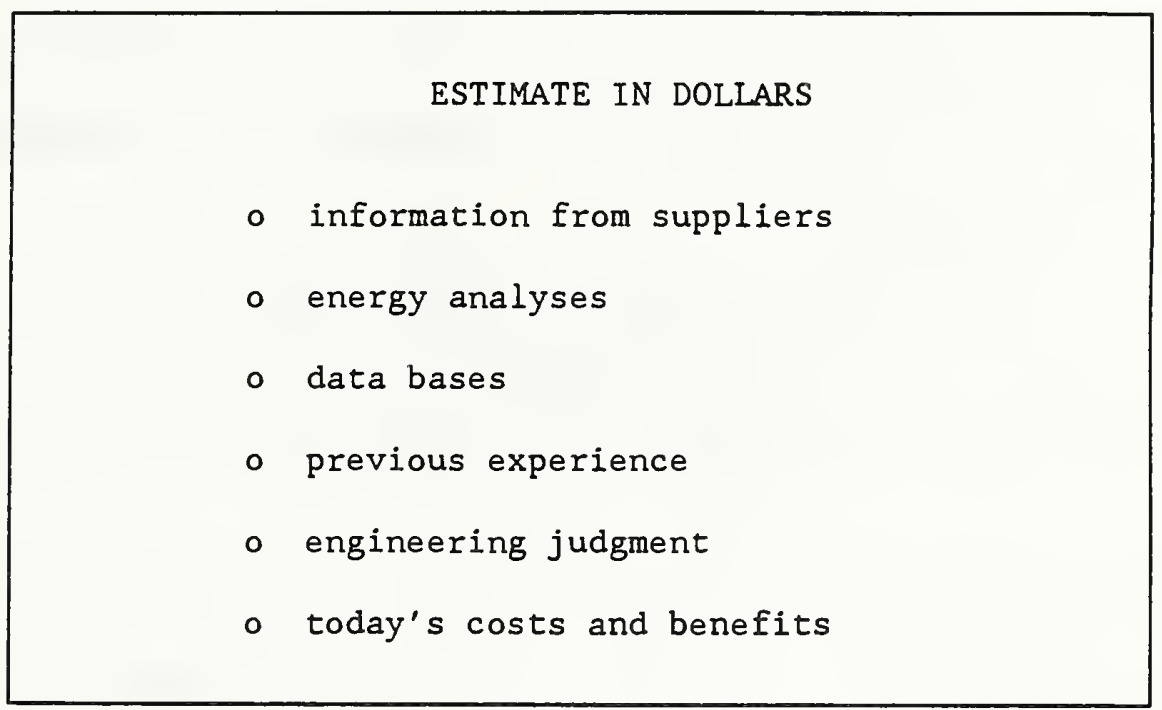

NOTES: 


\begin{tabular}{|c|}
\hline STUDY PERIOD \\
should- - \\
$0 \quad$ be same length for alternatives \\
if compared using LCC or NS \\
$0 \quad \begin{array}{c}\text { correspond with time perspective of } \\
\text { investor } \\
\text { not exceed imposed limit }\end{array}$ \\
\end{tabular}

NOTES: 
MODULE B, CONTINUED

\section{DESIGN/RETROFIT ALTERNATIVES}

Slide B-1 lists three key points in choosing alternatives. The most important is to remember that your decision can be no better than the best alternative you consider, no matter how good your economic evaluation. The second point is to consider only alternatives which satisfy performance standards. Take into account constraints such as availability of energy sources, building code requirements, and local suppliers in identifying feasible alternatives. It is a waste of time evaluating alternatives which will not qualify on other grounds.

The third point concerns what to do if an alternative exceeds minimum performance standards. In this case, you need to determine if the additional benefits are important to your organization. Some organizations specify their performance standards tightly and give no credit to performance in excess of the standards. But others credit alternatives which exceed minimum performance standards with additional benefits.

\section{RELEVANT EFFECTS}

Slide B-2 gives characteristics of effects which are relevant to decisions and should be taken into account. Data requirements for making an economic decision are not identical to those for keeping an accounting system. To make a decision which is economically efficient, it is important to measure the economic consequences of alternatives. Only significant changes which are expected to result from a decision are relevant to making that decision. In making a decision, try to ignore "sunk costs," i.e., costs resulting from past decisions. 
MODULE B, CONTINUED

Relevant effects often include acquisition costs, energy costs, non-fuel operation, maintenance and repair costs, replacement costs, and salvage or residual value, and sometimes revenue and other benefits, as listed in slide $B-3$.

\section{ESTIMATING CASH FLOWS}

The economic evaluation methods--LCC, NS, SIR, AIRR, and PB--require inputs expressed in dollars. Effects not expressed in dollars are not included in the measure of economic performance. But effects not in dollars may be of critical importance, and should not be overlooked in making a decision.

Slide B-4 lists possible sources of data. Suppliers may provide cost quotes for off-the-shelf systems. Cost estimating guides may help in developing conceptual estimates of construction costs. Do not wait for a detailed take-off of quantities based on engineering specifications to do economic analysis. To wait means missing the best opportunities for using economic analysis to influence design decisions.

Estimating quantities of energy saved is the topic of the follow-on course (ASEAM). This course focuses on assigning present and future prices to energy. We use DOE forecasts of energy prices. Sample energy price data are in appendix $B$.

Three sets of data are provided to estimate energy prices: (1) yearly price indices, (2) average annual escalation rates for five-year intervals, and (3) uniform present worth discount factors modified to include yearly price escalation. We will use the data later in the course to do economic analysis. 
MODULE $B$, CONTINUED

The Army Corps of Engineer's Construction Engineering Research Laboratory (CERL) has developed an extensive data base for estimating maintenance and repair costs for a 25 year period. The database covers four major building systems: (1) architectural, (2) electrical, (3) plumbing, and (4) HVAC. Each is divided into components.

For example, architectural is divided into exterior and interior wall finishes, roofing, flooring, windows, and doors. Alternatives for flooring include ceramic tile, quarry tile, brick, wood parquet, linoleum, vinyl tile, concrete surfaces, terrazzo, and carpet. For each alternative, maintenance and repair cost indices are given in tables. By applying your labor and equipment rates, quantities, and location to the indices you can develop estimates of maintenance and repair costs.

Additional information on the database can be obtained by contacting:

Facility System Division

Construction Engineering Research Laboratory

Corps of Engineers

U.S. Department of the Army

P.O. Box 4005

Champaign, Illinois 61820-1305

Previous experience with similar systems can shed light on what values to use. One reason it is important to document LCC studies is that they may be useful in providing data for future studies. Engineering judgment is another source of data.

Today's costs and benefits can provide a useful starting point for estimating future costs and benefits. For example, suppose we know that a replacement would cost $\$ 100$ if made today, and we need to know what the replacement will cost in five years. By estimating the rate of price change 
during the interval, and applying that rate to the cost today we can estimate the future amount. More will be said about this topic in Module $C$.

\section{SETTING THE STUDY PERIOD}

The study period is the time over which the effects of a decision are of interest to the decision maker. For very long investments, the study period may be set for a selected period. For example, the Federal government uses a maximum study period of 25 years from the beneficial occupancy date.

Although there is some flexibility in choosing the study period, there are also rules. Slide B-5 gives three guidelines for setting the study period. Note especially the first: The same study period must be used when comparing alternatives in present value dollars with the LCC or NS method. 


\section{EXERCISE $B-1$}

\section{Relevant Effects}

Suppose you want to evaluate whether it is cost effective to replace an existing HVAC system with a new system. Assume that the existing system can continue to meet heating and cooling requirements over the remaining 10 years that the owner plans to occupy the building. From the following list, check the data you need:

1. Original land costs

2. Original site improvements

3. Initial construction costs

4. Purchase and installation costs of the existing HVAC system

5. Duct work for the existing HVAC system

6. Modification of the existing duct work to meet requirements of the new HVAC system

7. Purchase and installation costs of the new HVAC system

8. Maintenance cost of the existing HVAC

9. Maintenance cost of the new HVAC

10. Heating efficiency/cooling COP of existing system

11. Heating efficiency/cooling COP of new system

12. Current price of energy used by the existing system

13. Current price of energy used by the new system

14. Projected rate of change in price of energy used by existing system

15. Projected rate of change in price of energy used by new system

16. Building heating load (annual)
$\$ 100,000$

$\$ 50,000$

$\$ 5,000$

$\$ 10,000$

$\$ 10,000$

$\$ 2,000$

$\$ 50,000$

$\$ 2,000 /$ year

$\$ 2,000 /$ year

$0.65 / 2.0$

$0.80 / 3.0$

$\$ 25.00 / \mathrm{MBtu}$

$\$ 22.00 / \mathrm{MBtu}$

$7 \% /$ year

$58 /$ year

3,000 MBtu 
MODULE B, CONTINUED

Exercise B-1, continued

17. Building cooling load (annual)

4,000 MBtu

18. Existing HVAC system's current resale, less removal costs

$\$ 5,000$

19. New HVAC system's resale, less removal costs, at the end of its 30 year service life

20. Replacement costs of existing system at end of its 15 year remaining service life

21. Replacement of new system at the end of end of its 30 year service life

22. The amount the new system will add to resale value of the building in 10 years

23. The new system operates more quietly than the existing system 


\section{EXERCISE B-2}

Setting the Study Period

Choose a study period for each of the following situations:

1. A building owner wants to evaluate the cost effectiveness of an automatic thermostat control which will last 15 years. The building will be used indefinitely.

2. A designer wishes to perform an LCC comparison of two solar window films. Film A lasts five years; film B lasts 10 years. The building will be used indefinitely.

3. A state government sets a limit of 25 years on its LCC studies. An analyst is evaluating alternative roofing systems, one of which lasts 15 years and one of which lasts 30 years. 


\section{ADJUSTING CASH AMOUNTS FOR TIME OF OCCURRENCE}

MODULE C

100 MINUTES

Lecture, Discussion, Slides, and Exercises

\section{OBJECTIVES}

At the conclusion of this module, you are expected to be able to

- calculate the present value of

- a single future amount,

- a uniform series of future amounts, and

- - a series of future amounts changing over time at specified rates. 
MODULE C, CONTINUED

CASH-FLOW MODELING

SLIDE $\quad C-1$

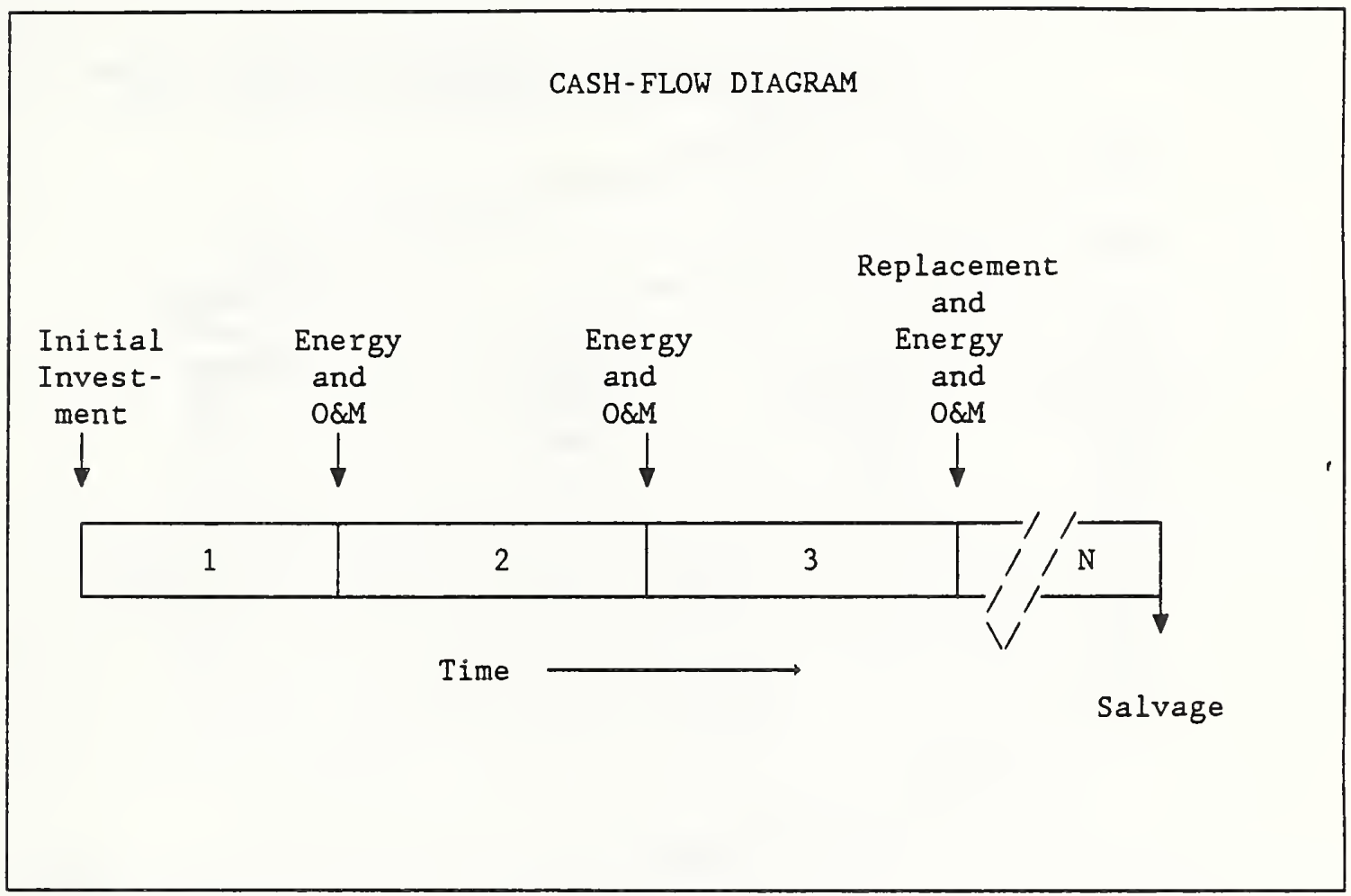

NOTES : 
SLIDE $\quad$ - -2

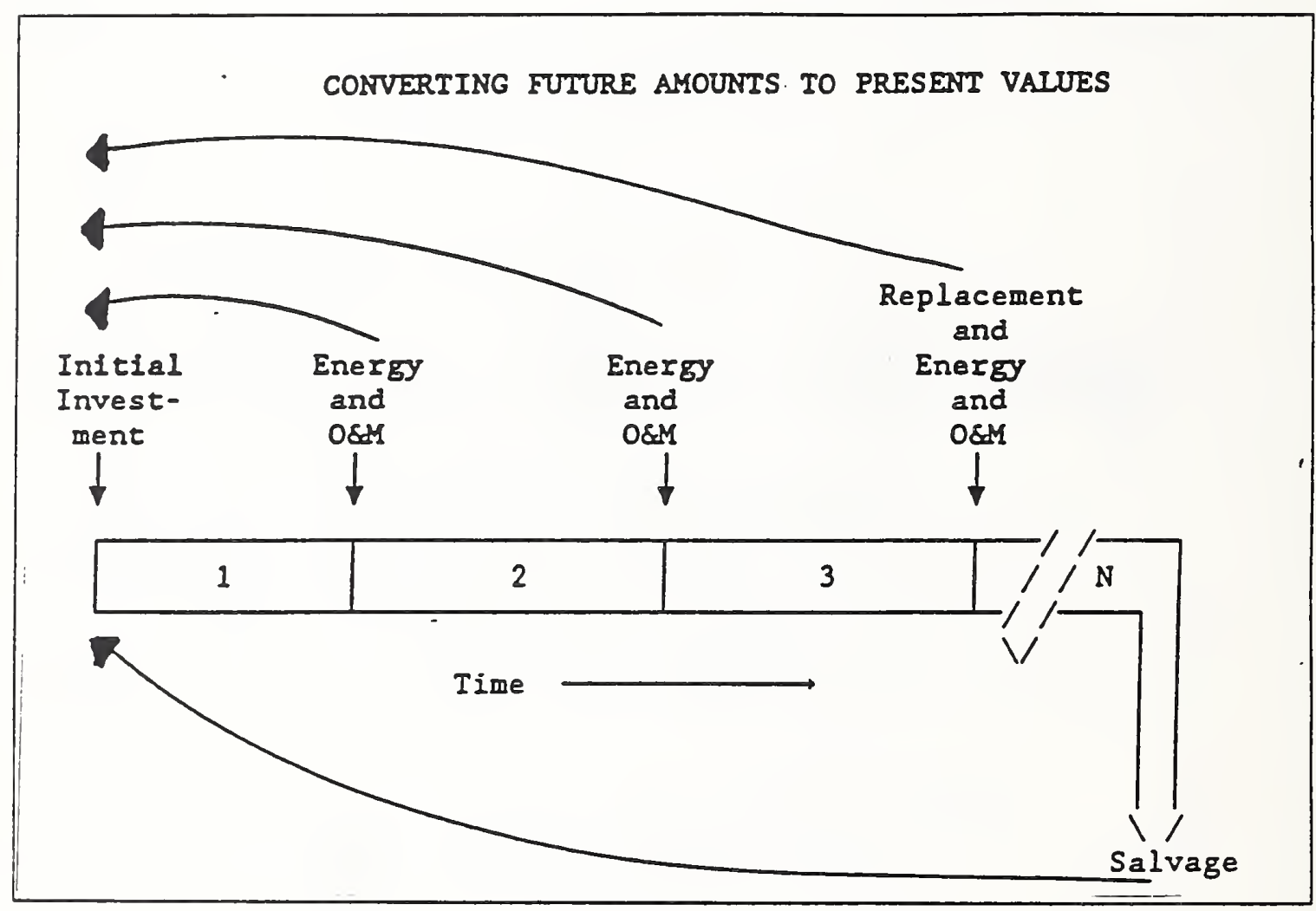

NOTES : 
MODULE C, CONTINUED

TIME VALUE OF MONEY

NOTES : 


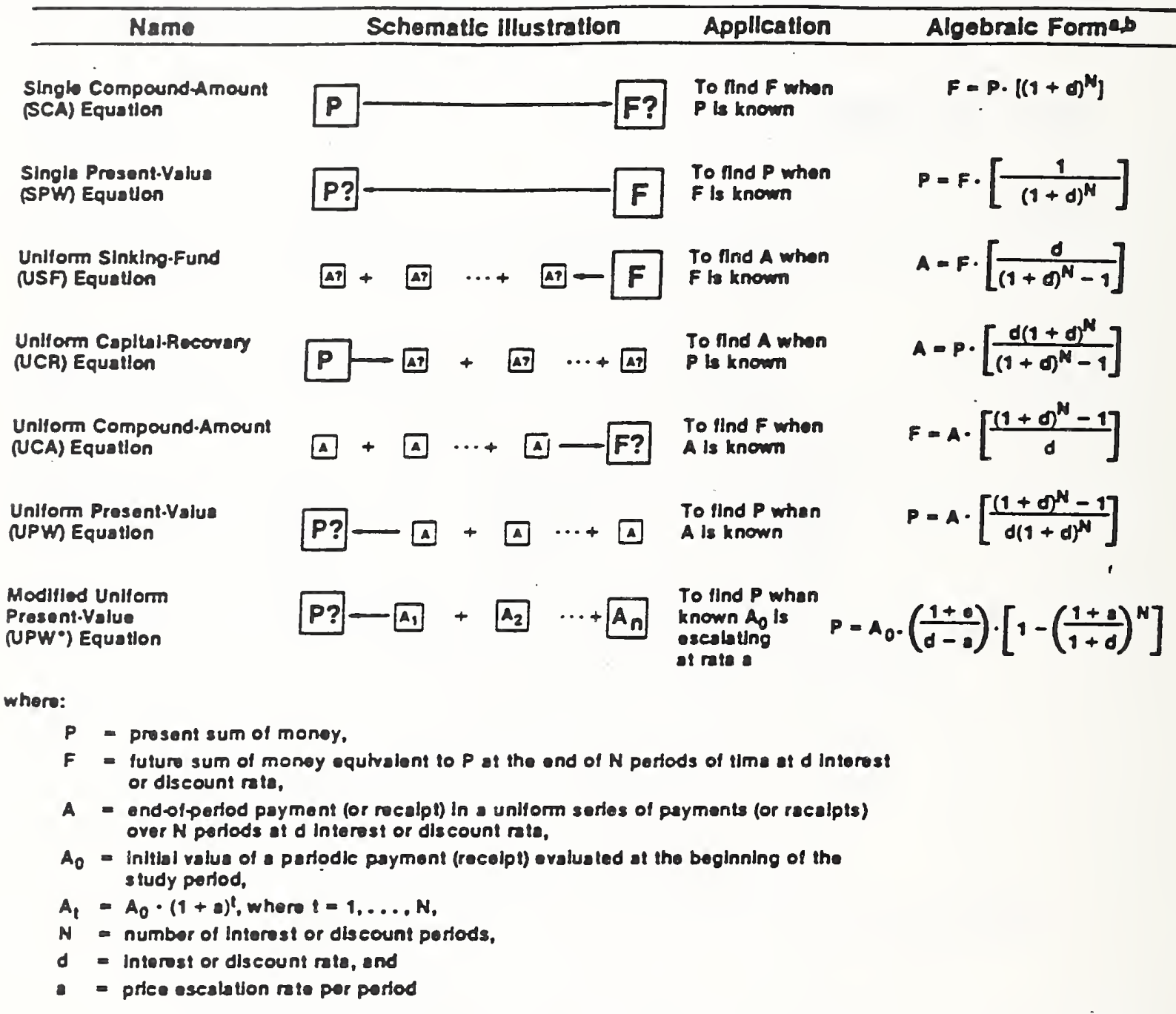

- Nota that the USF, UCR, UCA, and UPW equatlons yleld undeflned answers when $d=0$. The correct algebrake forms for this speclal case would be as follows: USF formula, A = FN; UCR formula, A \& PIN; UCA formula, F \& A - N. The UPW• -quation also yields an undeflined answer whan $a=d$. In this case, $P=A_{0} \cdot N$.

${ }^{b}$ The terms by which the known values are multiplied th these aquatlons are the formulas for the factors found in discount factor tables. Using acronyms to represent the factor formulas, the discounting equaflons can elso be written es $F=P \cdot S C A, P=F \cdot S P W, A=F \cdot U S F, A=P \cdot U C R, F=U C A_{1} P=A \cdot U P W$, and $P=A_{0} \cdot U P W^{\circ}$. 


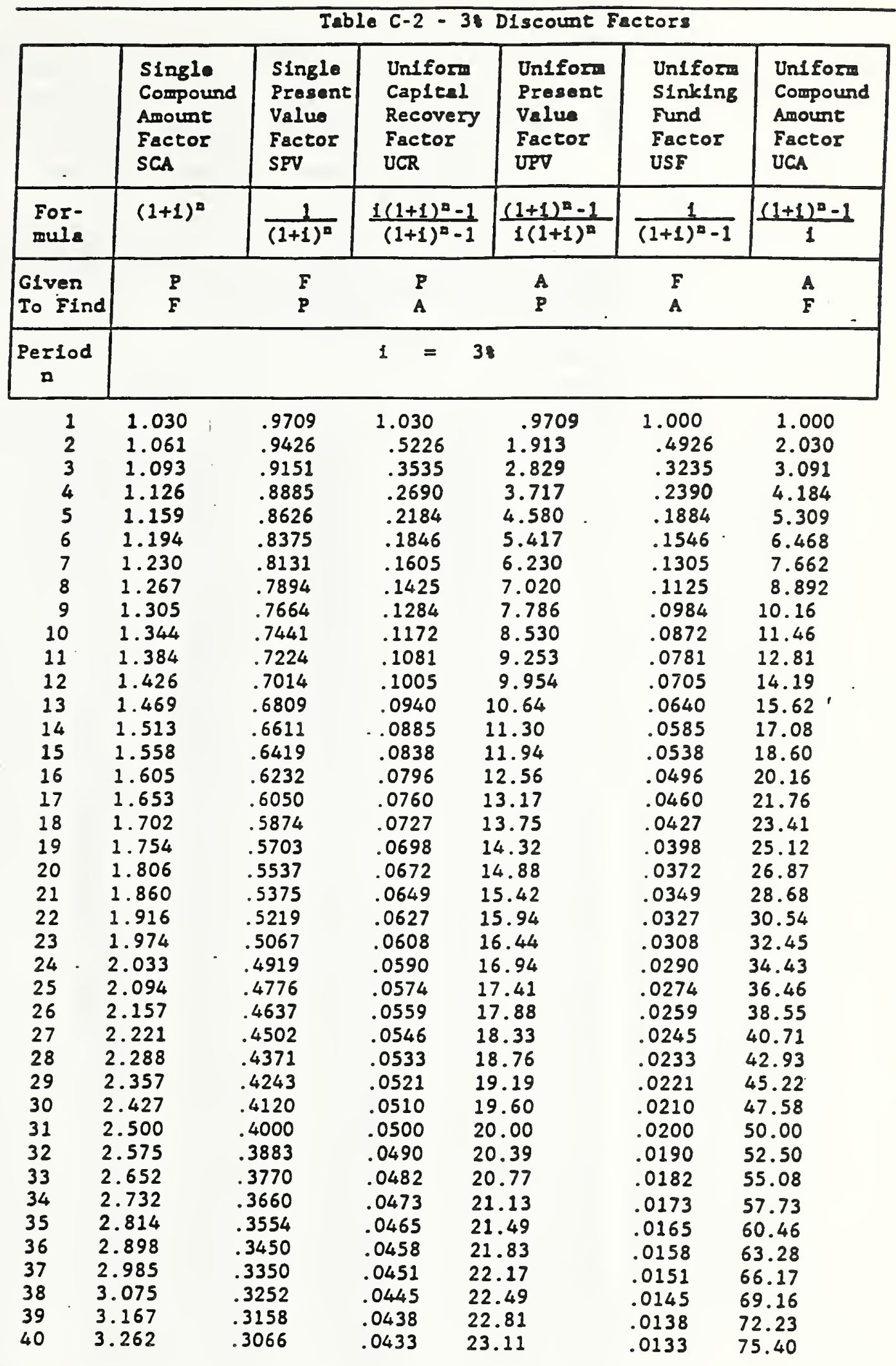

- All formulas assume end-of-period payments.

$P=a$ present sum of money; $F=$ a future sum of money, equivalent to $P$ at the end of $n$ periods of time at discount rate of $1 ; A=$ an end-of-period payment (or receipt) in a uniform serfes of payments (or recelpts) over $n$ perlods at interest rate of 1 .

Note: table nomenclature uses i for interest rate or discount rate. 
MODULE C, CONTINUED

Tablo C-3 - 9: D1scoune Factors

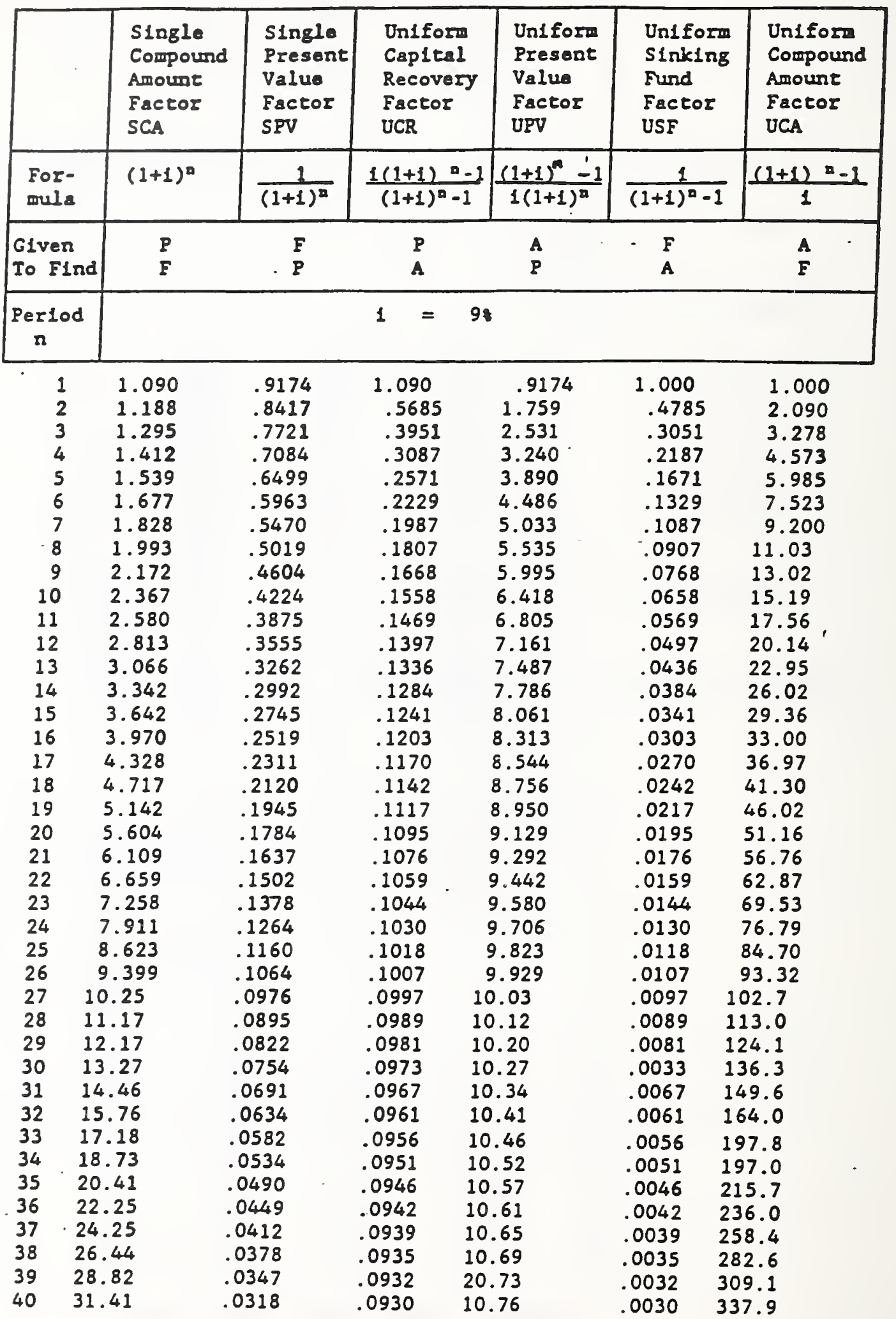

- All formulae assume end-of-period payments.

$P=a$ present sum of money: $F=a$ future sum of money, equivalent to $P$ at the end of $n$ perlods of time at discount rate of $1 ; A=$ an end-of-period payment (or receipt) in a uniform serles of payments (or recelpts) over $n$ perlods at 1 interese rate. 
MODULE $C$, CONTINUED

\begin{tabular}{|c|c|c|c|c|c|c|c|c|c|c|}
\hline \multirow[b]{2}{*}{ Year } & \multirow{2}{*}{\multicolumn{2}{|c|}{$\begin{array}{l}\text { Table } \\
28\end{array}$}} & \multicolumn{4}{|c|}{$\begin{array}{r}\text { C-4 - 68 UNIFORM PRESENT VALUE } \\
\text { FOR ESCALATION } \\
\text { Rate of Escalation }\end{array}$} & \multirow{2}{*}{$\begin{array}{c}\text { FACTORS } \\
7 \%\end{array}$} & \multirow{2}{*}{$\begin{array}{c}\text { MODIFIED } \\
88\end{array}$} & \multirow[b]{2}{*}{98} & \multirow[b]{2}{*}{108} \\
\hline & & & 38 & 48 & 58 & 68 & & & & \\
\hline 1 & .9528 & .9623 & .9717 & .9811 & .9906 & 1 & 1.009 & 1.019 & 1.028 & 1.038 \\
\hline 2 & 1.861 & 1.888 & 1.916 & 1.944 & 1.972 & 2 & 2.028 & 2.057 & 2.086 & 2.115 \\
\hline 3 & 2.726 & 2.779 & 2.883 & 2.888 & 2.944 & 3 & 3.057 & 3.115 & 3.173 & 3.232 \\
\hline 4 & 3.550 & 3.637 & 3.725 & 3.815 & 3.907 & 4 & 4.095 & 4.192 & 4.291 & 4.392 \\
\hline 5 & 4.335 & 4.462 & 4.591 & 4.724 & 4.860 & 5 & 5.143 & 5.290 & 5.441 & 5.595 \\
\hline 6 & 5.084 & 5.256 & 5.433 & 5.616 & 5.805 & 6 & 6.201 & 6.409 & 6.623 & 6.844 \\
\hline 7 & 5.727 & 6.019 & 6.251 & 6.491 & 6.741 & 7 & 7.269 & 7.549 & 7.839 & 8.140 \\
\hline 8 & 6.476 & 6.755 & 7.046 & 7.350 & 7.668 & 8 & 8.347 & 8.710 & 9.089 & 9.485 \\
\hline 9 & 7.124 & 7.462 & 7.818 & 8.192 & 8.586 & 9 & 9.435 & 9.893 & 10.37 & 10.88 \\
\hline 10 & 7.740 & 8.143 & 8.568 & 9.019 & 9.496 & 10 & 10.53 & 11.10 & 11.70 & 12.33 \\
\hline 11 & 8.328 & 8.798 & 9.298 & 9.830 & 10.40 & 11 & 11.64 & 12.33 & 13.06 & 13.83 \\
\hline 12 & 8.888 & 9.428 & 10.01 & 10.63 & 11.29 & 12 & 12.76 & 13.58 & 14.45 & 15.39 \\
\hline 13 & 9.422 & 10.03 & 10.69 & 11.41 & 12.17 & 13 & 13.89 & 14.89 & 15.89 & 17.01 \\
\hline 14 & 9.930 & 10.62 & 11.36 & 12.17 & 13.05 & 14 & 15.03 & 16.15 & 17.37 & 18.69 \\
\hline 15 & 10.41 & 11.18 & 12.01 & 12.92 & 13.92 & 15 & 16.18 & 17.48 & 18.89 & 20.43 \\
\hline 16 & 10.88 & 11.72 & 12.65 & 13.66 & 14.78 & 16 & 17.35 & 18.82 & 20.45 & 22.24 \\
\hline 17 & 11.32 & 12.24 & 13.26 & 14.38 & 15.63 & 17 & 18.52 & 20.20 & 22.06 & 24.12 \\
\hline 18 & 11.73 & 12.74 & 13.86 & 15.09 & 16.47 & 18 & 19.70 & 21.60 & 23.71 & 26.07 \\
\hline 19 & 12.13 & 13.22 & 14.44 & 15.79 & 17.31 & 19 & 20.90 & 23.03 & 25.41 & 28.09 \\
\hline 20 & 12.51 & 13.69 & $15.00^{\circ}$ & 16.47 & 18.13 & 20 & 20.10 & 24.48 & 27.16 & 30.19 \\
\hline 21 & 12.88 & 14.13 & 15.55 & 17.14 & 18.95 & 21 & 23.32 & 25.96 & 28.96 & 32.36 \\
\hline 22 & 13.22 & 14.56 & 16.08 & 17.80 & 19.76 & 22 & 24.55 & 27.47 & 30.80 & 34.62 \\
\hline 23 & 13.55 & 14.97 & 16.59 & 18.45 & 20.57 & 23 & 25.79 & 29.01 & 32.70 & 36.97 \\
\hline 24 & 13.87 & 15.37 & 17.10 & 19.08 & 21.36 & 24 & 27.05 & 30.57 & 34.66 & 39.40 \\
\hline 25 & 14.16 & 15.75 & 17.58 & 19.70 & 22.15 & 25 & 28.31 & 32.17 & 36.67 & 41.92 \\
\hline 26 & 14.45 & 16.12 & 18.06 & 20.31 & 22.93 & 26 & 29.59 & 33.79 & 38.43 & 44.54 \\
\hline 27 & 14.72 & 16.47 & 18.52 & 20.91 & 23.71 & 27 & 30.88 & 35.45 & 40.86 & 47.26 \\
\hline 28 & 14.98 & 16.81 & 18.97 & 21.49 & 24.48 & 28 & 32.18 & 37.14 & 43.04 & 50.08 \\
\hline 29 & 15.22 & 17.14 & 19.40 & 22.07 & 25.24 & 29 & 33.49 & 38.86 & 45.29 & 53.01 \\
\hline 30 & 15.46 & 17.46 & 19.82 & 22.64 & 25.99 & 30 & 34.81 & 40.61 & 47.60 & 56.05 \\
\hline 31 & 15.68 & 17.76 & 20.23 & 23.19 & 26.73 & 31 & 36.15 & 42.39 & 49.97 & 59.20 \\
\hline 32 & 15.90 & 18.05 & 20.53 & 23.73 & 27.47 & 32 & 37.50 & 44.45 & 53.83 & 62.47 \\
\hline 33 & 16.10 & 18.33 & 21.02 & 24.27 & 28.20 & 33 & 38.87 & 46.07 & 54.93 & 65.87 \\
\hline 34 & 16.29 & 18.60 & 21.40 & 24.79 & 28.93 & 34 & 40.24 & 47.95 & 57.51 & 69.39 \\
\hline 35 & 16.48 & 18.87 & 21.76 & 25.30 & 29.65 & 35 & 41.63 & 49.88 & 60.17 & 73.05 \\
\hline 36 & 16.65 & 19.12 & 22.12 & 25.81 & 30.36 & 36 & 43.03 & 51.84 & 62.90 & 76.84 \\
\hline 37 & 16.82 & 19.36 & 22.47 & 26.30 & 31.06 & 37 & 44.45 & 53.83 & 65.71 & 80.78 \\
\hline 38 & 16.98 & 19.59 & 22.80 & 26.79 & 31.76 & 38 & 45.88 & 55.87 & 68.59 & 84.87 \\
\hline 39 & 17.13 & 19.81 & 23.13 & 27.26 & 32.45 & 39 & 47.32 & 57.94 & 71.56 & 89.11 \\
\hline 40 & 17.28 & 20.03 & 23.44 & 27.73 & 33.13 & 40 & 48.78 & 60.05 & 74.62 & 93.51 \\
\hline
\end{tabular}


MODULE C, CONTINUED

\section{DISCOUNTING FORMULAS}

Amount to be discounted

single future amount

recurring annual amount

changing annual amount
Formula

$P=F \times S P W$

$P=A \times U P W$

$P=A_{0} \times$ UPW*

where:

SPW = Single Present Worth factor

UPV = Uniform Present Worth factor

UPV*= Modified Uniform Present Worth factor

NOTES : 
SIIDE C-4

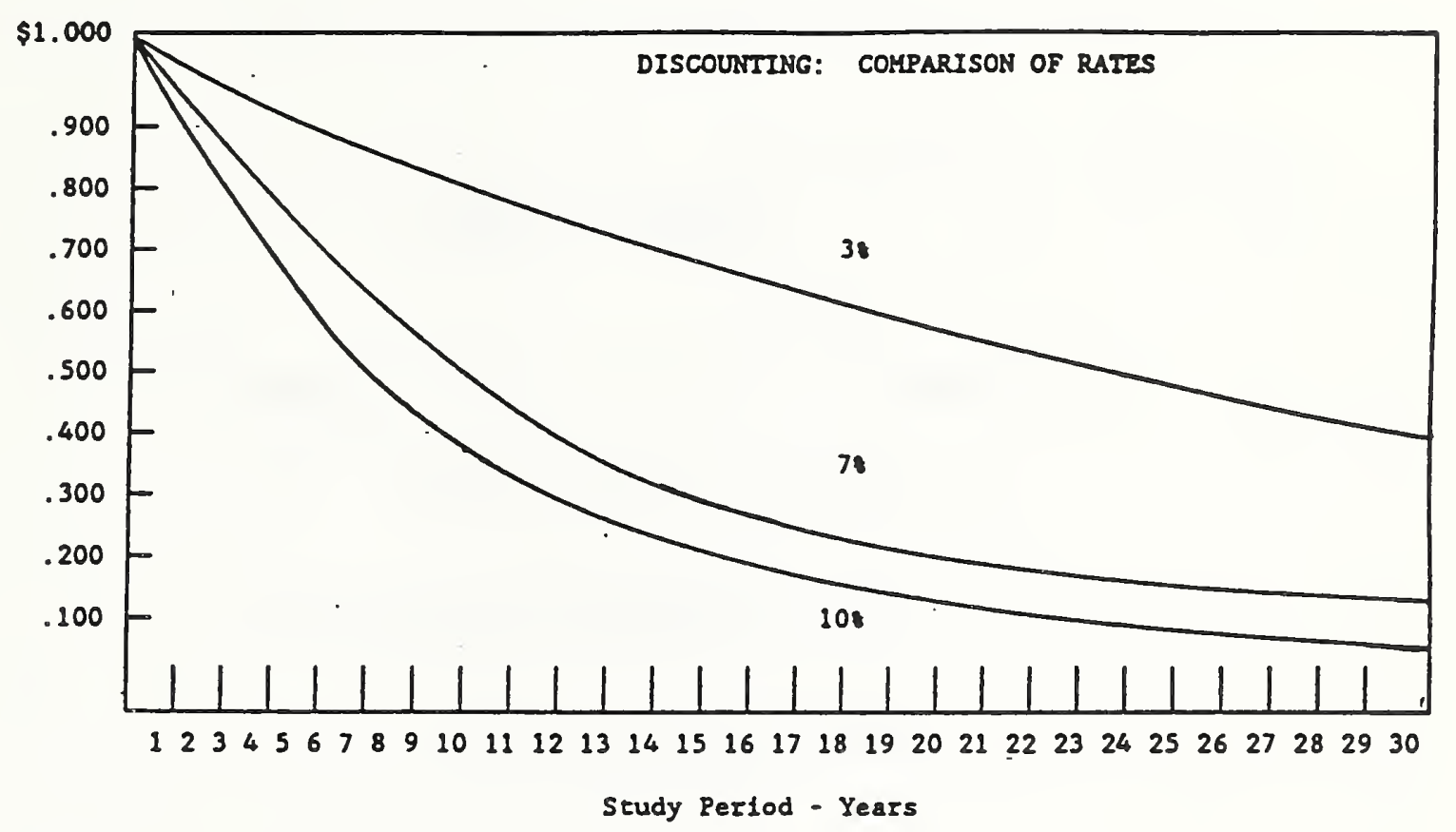

NOTES: 
MODULE C, CONTINUED

SLIDE C-5

\section{DISCOUNTING EXAMPLE}

Find present value (P) of a future replacement cost (F)

- replacement cost: $\$ 10,000$

- time of replacement: end of year 6

- discount rate: 38

NOTES : 
MODULE $C$, CONTINUED

SLIDE C-6

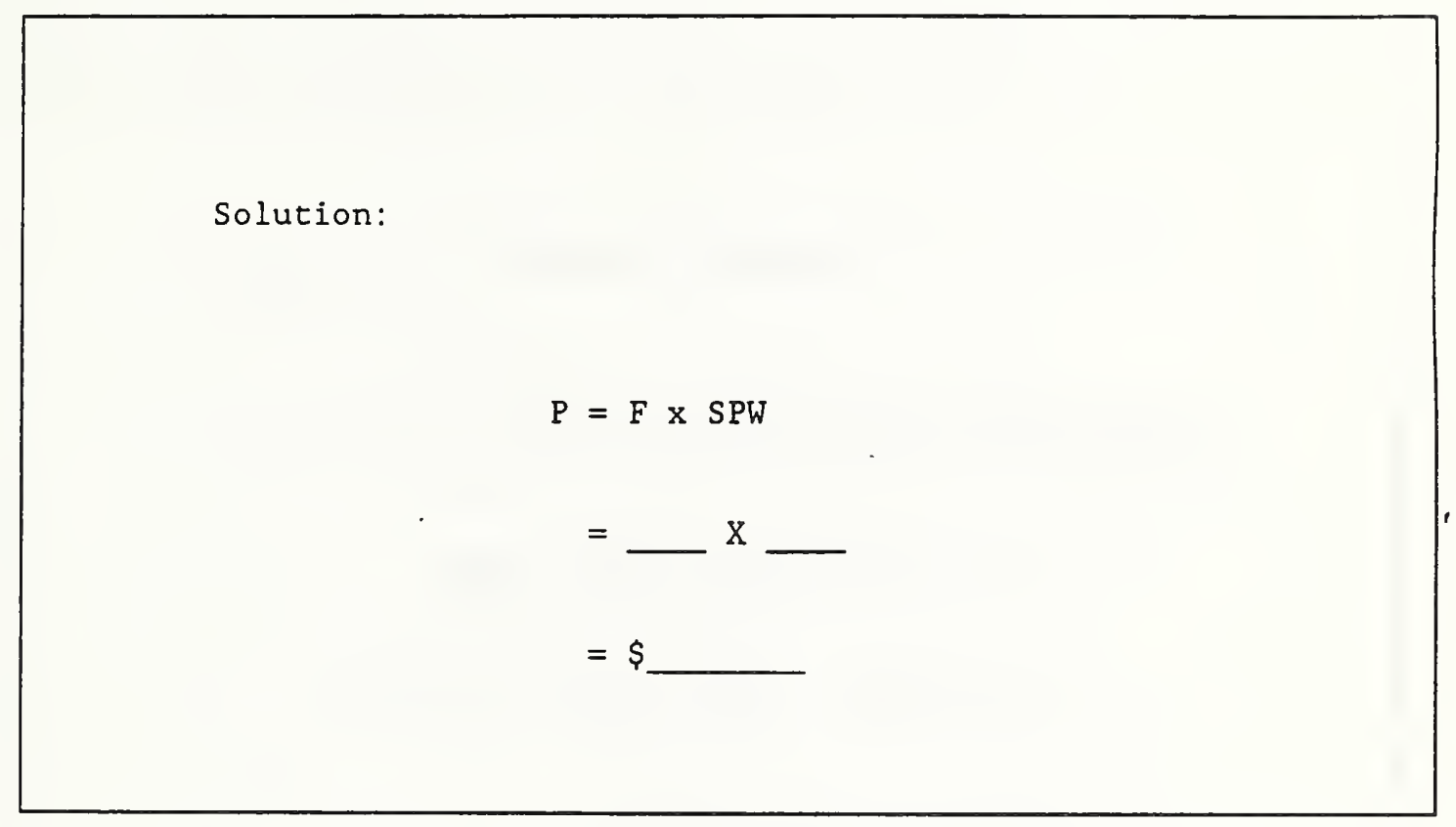

NOTES : 
MODULE $C$, CONTINUED

SLIDE $C-7$

\section{DISCOUNTING EXAMPLE}

Find present value (P) of an annually recurring maintenance cost (A)

- annual maintenance cost: $\$ 200$

- occurrence: end of each of 12 years

- discount rate: 98

NOTES : 
MODULE C, CONTINUED

SLIDE $\quad$ - 8

Solution:

$P=A \times U P W$

$=\$$

NOTES: 
MODULE C, CONTINUED

SLIDE $\quad$-9

\section{DISCOUNTING EXAMPLE}

Find present value ( $P$ ) of energy costs which are changing at a constant rate

- annual energy cost at today's price

$\left(A_{0}\right): \$ 25,000$

- occurrence: end of years 1-7

- discount rate: 68

- projected annual rate of change: 28

NOTES : 
MODULE C, CONTINUED

SLIDE C-10

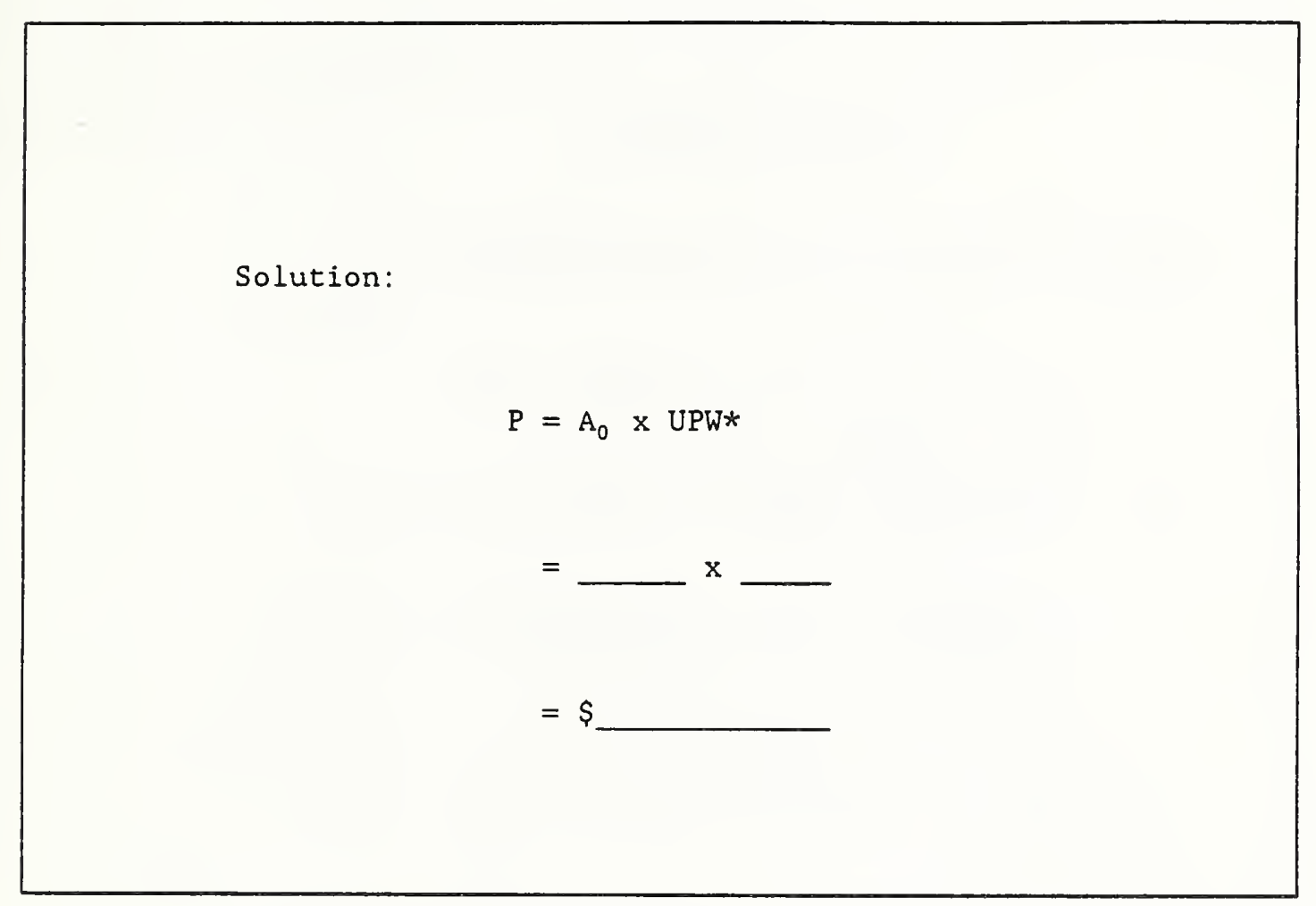

NOTES: 
MODULE C, CONTINUED

SLIDE C-11

\section{DISCOUNTING EXAMPLE}

Find present value (P) of energy costs which are changing at annual rates projected by DOE

- annual energy cost at today's price

$\left(A_{0}\right): \$ 50,000$

- occurrence: beginning 1988 and continuing over 25 years

- building location: Federal office building in Atlanta

- energy type: natural gas

- DOE 1988 energy price projections

NOTES : 
MODULE C, CONTINUED

SLIDE $\quad C-12$

Solution:

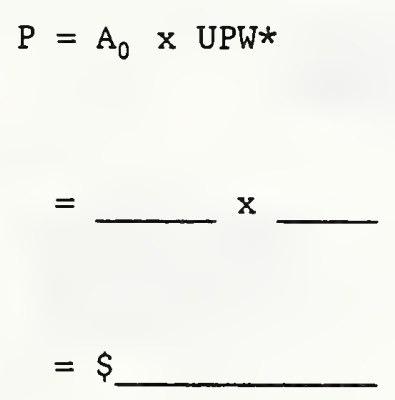

NOTES : 
MODULE C, CONTINUED

SIIDE $C-13$

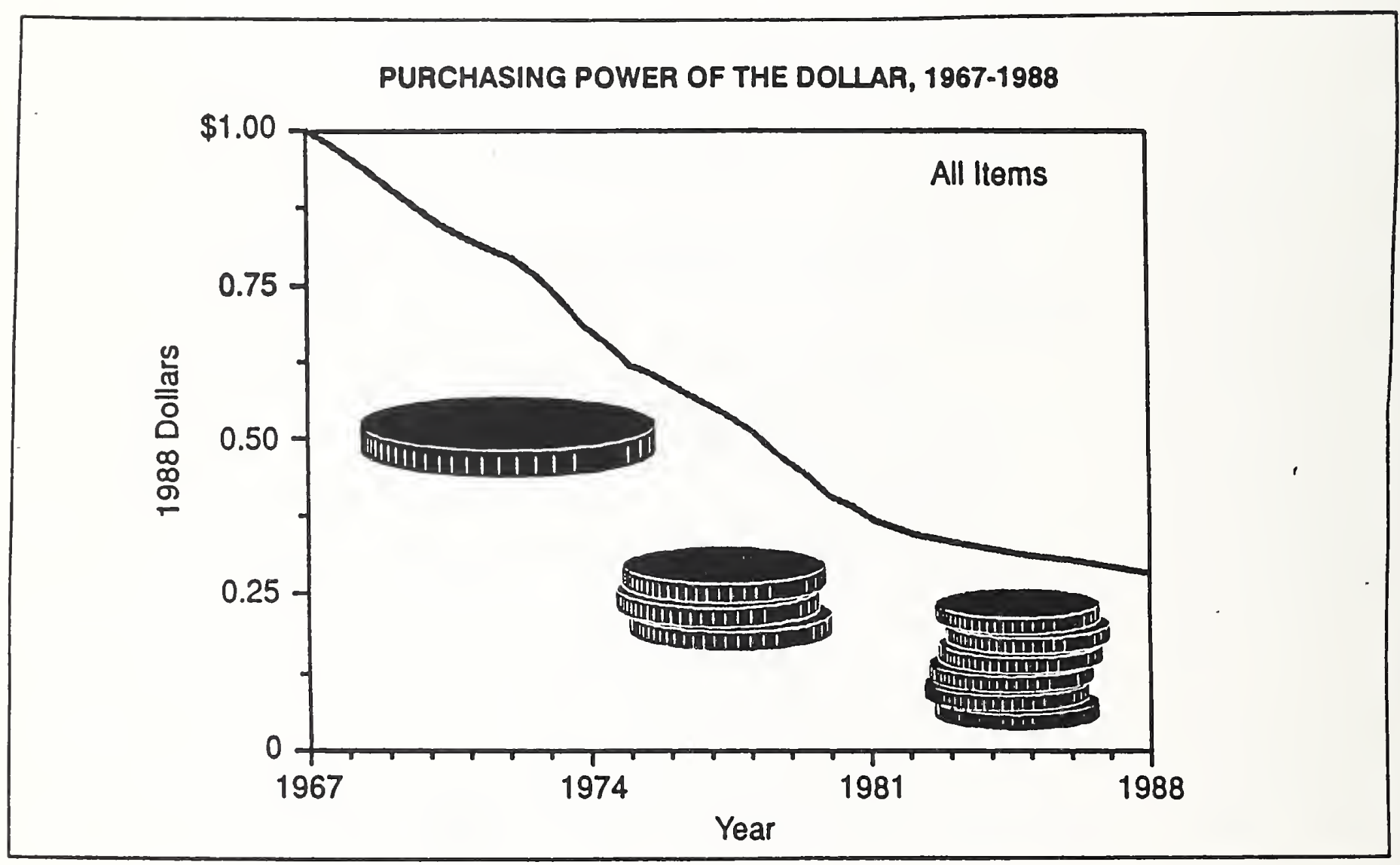

NOTES: 
MODULE C, CONTINUED

SLIDE C-14

(serles a to d)

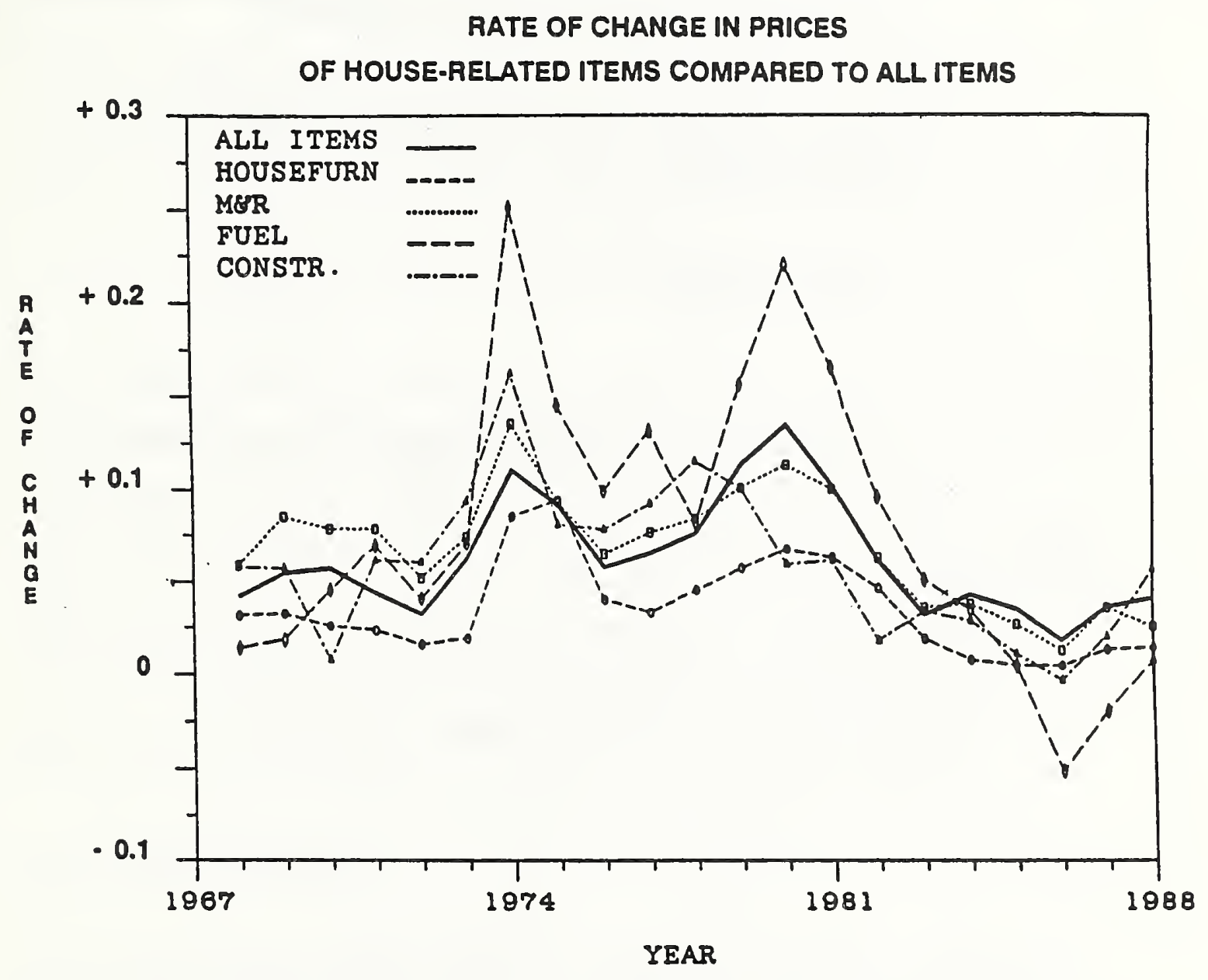

NOTES : 
MODULE $C$, CONTINUED

SLIDE $\quad C-15$

Two approaches for dealing with inflation

1. work in absolute terms (current $\$ \&$ nominal discount rate)

2. work in relative terms (constant $\$ \&$ real discount rate)

NOTES : 
MODULE $C$, CONTINUED

\section{CASH-FLOW MODELING}

\section{Cash-Flow Diagram:}

Slide C-1 shows a cash-flow diagram. Diagraming cash flows provides a visual checklist of relevant effects including their timing. It organizes data. It helps others grasp the problem quickly. It is easy to do, because it is usually more of a sketch than a formal drawing.

\section{Cash-Flow Modeling:}

It is common practice in economics to model cash amounts which occur at varying times within the year as though they occur either at the beginning of the year, middle of the year, end of the year, or continuously throughout the year, rather than exactly as each amount actually is paid. Additionally, cash amounts which are more or less repeating are typically modeled as a uniformly recurring series. The effort to describe exactly the timing of costs and benefits is generally not worthwhile. Complex flows of costs and benefits can be represented in simple form with little sacrifice in accuracy.

\section{Common-time Convention:}

Once the patterns of cash flows are established, the next step is to convert them all to a common time. In fact, the main reason we lay them out in the diagram is because it helps identify how they must be moved. 
MODULE C, CONTINUED

The common time can be

(1) the present, whereby all cash amounts are converted to an equivalent lump-sum value occurring now, i.e., a present value (this conversion is illustrated by slide $(-2)$;

(2) annually, whereby all cash amounts are converted to an equivalent value occurring in a uniform amount each year over the study period, i.e., an annual value; and

(3) the future, whereby all cash amounts are converted to an equivalent lump-sum value occurring at some common time in the future, i.e., a future value.

[For uniformity, Federal agencies use present values.]

\section{TIME VALUE OF MONEY CONCEPT}

"Opportunity cost" is the return that could be realized if funds were used for the best alternative use instead of for the use at hand.

If an investor cannot realize a rate of return greater than the opportunity cost, there is no economic reason to undertake the investment at hand. That is, the opportunity cost is the investor's "minimum acceptable rate of return" or MARR.

The implication of opportunity cost for energy-related decisions is that the higher the investor's opportunity cost, the less willing the investor is to forego present investment dollars for future energy savings. 
MODULE C, CONTINUED

When the MARR is used to find the present-value equivalent of a future amount, such as the present value of a stream of energy savings, it is called a "discount rate." Hence, the discount rate equals the investor's MARR and reflects the investor's opportunity cost.

\section{Time Relationships:}

You can calculate a person's or organization's MARR if you know a future amount which the person or organization is willing to trade for a present amount. Likewise, if you know the MARR, you can calculate the future amount for which a person or organization is willing to trade a present, amount; or the present amount for which a person or organization is willing to trade a future amount.

To solve for MARR, when $F$ and $P$ are given:

$$
\operatorname{MARR}=-1+(F / P)^{1 / n}
$$

To solve for $F$, when $P$ and MARR are given:

$$
F=P(1+\text { MARR })^{n}
$$

To solve for $P$, when $F$ and $D$ are given:

$$
P=F /(1+D)^{n}
$$

where,

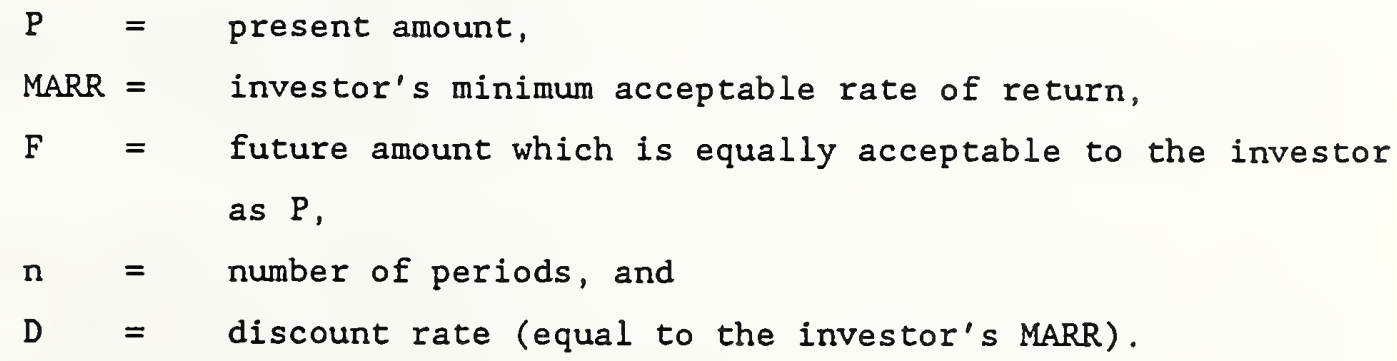


MODULE C, CONTINUED

Table C-1 lists common formulas for converting various cash flows to time-equivalent amounts.

Slide C-3 lists formulas frequently used in evaluating energy-related investments. Note that they are expressed in simplified form, using discount factors.

Tables C-2, C- 3 , and C-4 provide discount factors. Those in table C-2 are all based on a discount rate of $3 \%$; those in table $\mathrm{C}-3$ on a discount rate of 98 ; and those in table C-4 on 68 . Note that table C-4 contains only one type of factor. These are uniform present worth factors modified for escalation.

Slide C-4 shows the impact of the discount rate over time. The higher the discount rate and the longer into the future a dollar is received or paid, the lower its equivalent value today.

Slides C-5 through C-12 show examples of discounting. For reference, a set of sample problems with solutions is provided at the end of this module, just before Exercise $\mathrm{C}-1$.

\section{WHAT TO DO ABOUT INFLATION}

Just as a constant unit of measure is required to determine the physical dimensions of a building (foot or meter), so are dollars with a constant unit of measure required for measuring economic performance.

Inflation reduces the purchasing power of the dollar as illustrated by slide C-13. This changes the unit for measuring economic impact. Measuring economic effects in inflating or deflating dollars, without adjustment, is meaningless. 
MODULE C, CONTINUED

There are two correct (and equivalent) ways to deal with inflation:

(1) Include estimated general price inflation in cost and benefit estimates and in the discount rate, such that "current" dollar cash flows are discounted using a "nominal" discount rate which cancels out general price inflation.

With this approach, for example, projections of benefits and costs include the absolute (actual) change in prices of individual items (shown in Slide $\mathrm{C}-14$ ), and the discount rate includes the absolute change in the average price of all items.,

(2) Include in estimates of cost and benefits only those changes which are expected to be faster or slower than the general price inflation rate, and discount the "constant" dollar cash flows using a "real" discount rate which also excludes general price inflation.

With this approach, for example, projections of benefits and costs include only the "differential change" in prices of individual items relative to the change in the average price of all items, and the discount rate excludes the absolute change in the average price of all items.

Slide C-15 lists the two approaches to treating inflation. 
MODULE C, CONTINUED

Relationships of "Real" and "Nominal" Rates

$$
\begin{aligned}
& e=(1+E) /(1+I)-1 \\
& E=(1+e)(1+I)-1 \\
& d=(1+D) /(1+I)-1 \\
& D=(1+d)(1+I)-1
\end{aligned}
$$

where,

$$
\begin{aligned}
& e=\text { "real" rate of change, excluding inflation; } \\
& E=\text { "nominal" rate of change, including inflation; } \\
& d=\text { "real" discount rate, excluding inflation; and } \\
& D=\text { "nominal" discount rate, including inflation. }
\end{aligned}
$$


MODULE $C$, CONTINUED

Discounting Formulas and Sample Problems with Solutions:

Find $F$, given $P$

$F=P(1+M A R R)^{n}$

$F=P \times S C A$ factor

$$
\begin{aligned}
& \text { Given } P=\$ 10,000 \\
& \text { MARR }=98 \\
& n=10 \text { years } \\
& F=\$ 10,000 \times(1+0.09)^{10} \\
& F=\$ 10,000 \times 2.3674 \\
& =\$ 23,674
\end{aligned}
$$

Find $P$, given $F$

$P=F\left[1 /(1+D)^{n}\right]=F /(1+D)^{n}$

$$
\text { Given } \begin{aligned}
F & =\$ 6,000 \\
D & =88 \\
n & =4 \text { years }
\end{aligned}
$$

$P=F \times S P W$ factor

$$
\begin{aligned}
P & =\$ 6,000 \times 0.7350 \\
& =\$ 4,410
\end{aligned}
$$

\section{Find $P$, given $A$}

$P=A\left[\left((1+D)^{n}-1\right) / D(1+D)^{n}\right]$

$$
\begin{aligned}
\text { Given } A & =\$ 2,000 \\
D & =118 \\
n & =20 \text { years } \\
P & =2,000 \times 7.9629 \\
= & \$ 15,926
\end{aligned}
$$$$
P=A \times \text { UPW factor }
$$

Find $P$, given $A_{0}$ and $E$

$$
\begin{aligned}
& P=A_{0} \sum_{j=1}^{n}[(1+E) /(1+D)]^{j} \quad \text { Given } A_{0}=\$ 100 \\
& =A_{0}\left[((1+E) /(D-E))\left(1-((1+E) /(1+D))^{n}\right)\right] \\
& P=A_{0} \times \text { UPW* factor } \\
& \begin{array}{l}
D=10 \% \\
n=10 \text { years } \\
E=8 \%
\end{array} \\
& P=\$ 100 \times 11.10 \\
& =\$ 1,110
\end{aligned}
$$


MODULE C, CONTINUED

Discounting Formulas and Sample Problems with Solutions, continued:

Find $P$, given $A_{0}$ and DOE energy price projections

\begin{tabular}{|c|c|c|}
\hline$P=A_{0} \times U P W^{*}{ }_{D O E}$ & $\begin{array}{l}\text { Given } A_{0} \\
\text { Location } \\
\text { Energy Pricing } \\
\text { Energy Type } \\
\text { Future Prices } \\
n\end{array}$ & $\begin{array}{l}=\$ 10,000 \\
=\text { New York City } \\
=\text { Office Building } \\
=\text { Distillate } \\
=1988 \text { projections } \\
=15 \text { years }\end{array}$ \\
\hline
\end{tabular}


MODULE $C$, CONTINUED

\section{EXERCISE C-1 \\ Discounting Using Discount Factor Tables}

1. Find the value at the end of seven years of a present amount of $\$ 100$ which grows at a rate of 98 compounded annually. (Sketch a cash-flow diagram.)

2. Find the present value of $\$ 1,000$ to be received at the end of 20 years when the discount rate is 108 . (Sketch a cash-flow diagram.) 
MODULE C, CONTINUED

EXERCISE C-1, CONTINUED

3. You are notified that you have won the million-dollar lottery, and that you will receive the $\$ 1,000,000$ in $\$ 50,000$ installments paid at the end of each of the next 20 years. Assuming you can invest funds on hand to earn $10 \%$ per annum, what is the present value of your prize? (Sketch a cash-flow diagram.)

4. What is the estimated present value of a $\$ 10,000$ cost (in constant dollars) to be incurred five years from now, based on a 78 (real) discount rate? 
MODULE C, CONTINUED

EXERCISE $C-1$, CONTINUED

5. What is the estimated present value of a uniform annual cost of $\$ 1,000$ (in constant dollars) that is expected to recur over the next 20 years, if the discount rate is 78 (real)?

6. What is the present value of the energy savings from a retrofit project in Seattle which reduces annual electricity bills in a Federal office building by $\$ 5,000$ at today's prices, assuming that savings accrue over the next 25 years. 
CALCULATING LIFE-CYGLE COSTS, NET SAVINGS,

\author{
SAVINGS-TO-INVESTMENT RATIO,
} ADJUSTED INTERNAL RATE OF RETURN, AND

\title{
TIME TO PAYBACK
}

MODULE D

$\sqrt{10}$

\author{
75 MINUTES \\ Lecture, Discussion, and Problem Solving
}

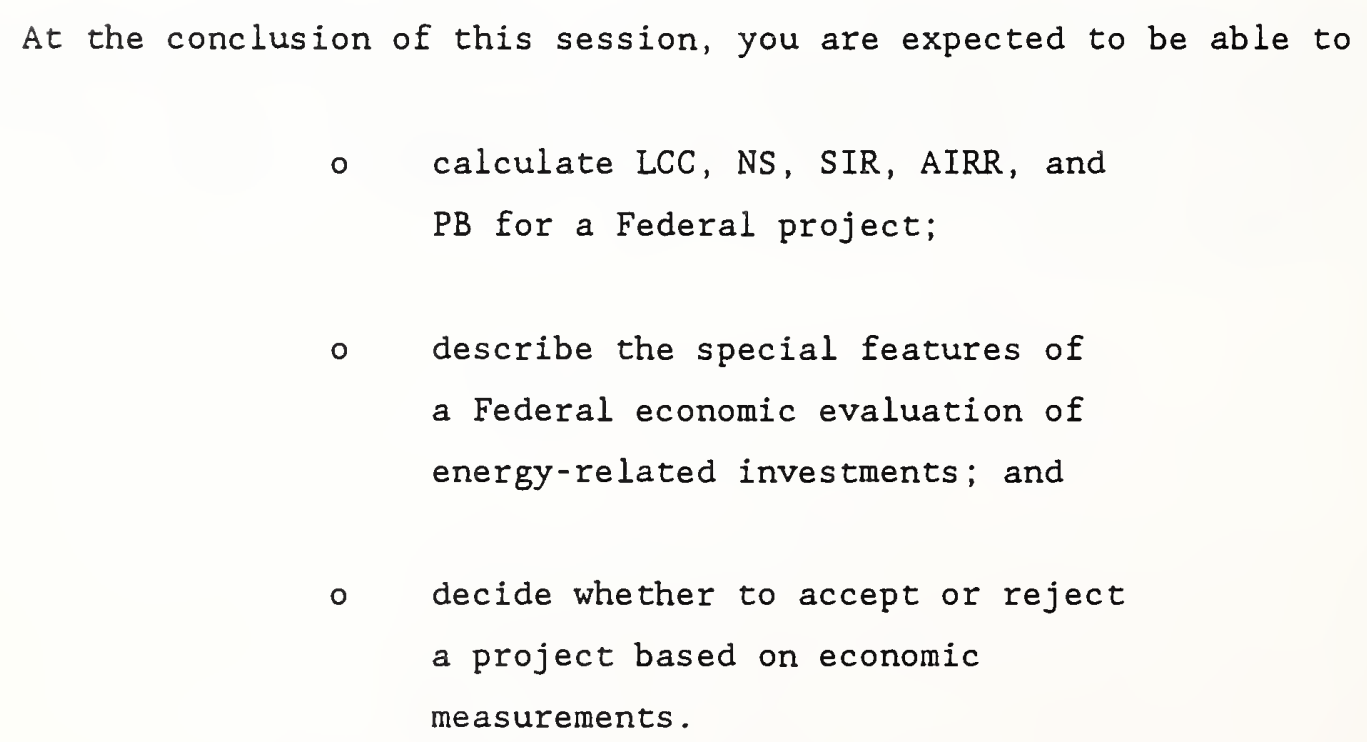


MODULE D, CONTINUED

FEDERAL CRITERIA

SLIDE D-1

\begin{tabular}{|l}
\hline FEDERAL CRITERIA \\
$\circ \quad$ DOE discount rate \\
$\circ \quad$ constant dollars \\
$\circ \quad$ present values \\
$\circ \quad$ quantity of energy at boundary \\
$\circ \quad$ actual agency energy prices \\
$\circ \quad$ DOE energy price projections \\
$\circ \quad$ instantaneous or delayed investment \\
study period 25 years \\
end-of-year or when-actually-incurred cash flows \\
no evaluation required under certain conditions
\end{tabular}

NOTES: 
MODULE D, CONTINUED

\section{WORKSHEETS}

- Retrofit Worksheets for Calculating Life-Cycle Costs, Net Savings, and Savings-to-Investments Ratio

- New Building Design Worksheets for Calculating Life-Cycle Costs

- Solar Energy Worksheets

(See Handbook 135)

NOTES : 
MODULE D, CONTINUED

\section{CALCULATIONS}

\section{SLIDE D-2}

DATA

Location: Washington, D.C.

Building: House on a military base (commercial pricing)

Performance: Both systems meet performance requirements

Discount Rate: 7\%, real

Energy Prices: Based on DOE 1988 projections

Costs stated in constant 1989 dollars.

NOTES : 
MODULE D, CONTINUED

SLIDE D-3

Base Case: Baseboard Heating System with Window Air Conditioners

- Purchase and installation costs: $\$ 1,500$

Baseboard heaters $=\$ 500$

Window air conditioners $=\$ 1,000$

- Annual maintenance $\cos t=\$ 50$

- Air conditioner repairs in year $8=\$ 400$

- Salvage value: $\$ 150$

Baseboard $=\$ 50$ (10\% of initial cost)

Window air conditioners $=\$ 100$ (10\% of initial cost)

- Annual electricity cost valued at the beginning of the study period $=\$ 1,200$

- Useful life $=15$ years

- Study period $=15$ years

NOTES : 
MODULE D, CONTINUED

SLIDE D-4

Alternative System: Heat Pump

- Purchase and installation cost $=\$ 3,000$

- Annual maintenance cost $=\$ 100$

- Compressor repair at end of year $8=\$ 600$

- Salvage value (net of disposal costs) at end of life $=\$ 250$

- Annual electricity costs, valued at the beginning of the study period $=\$ 800$

- Useful life $=15$ years

- Study period: 15 years

NOTES : 
MODULE D, CONTINUED

SLIDE D-5

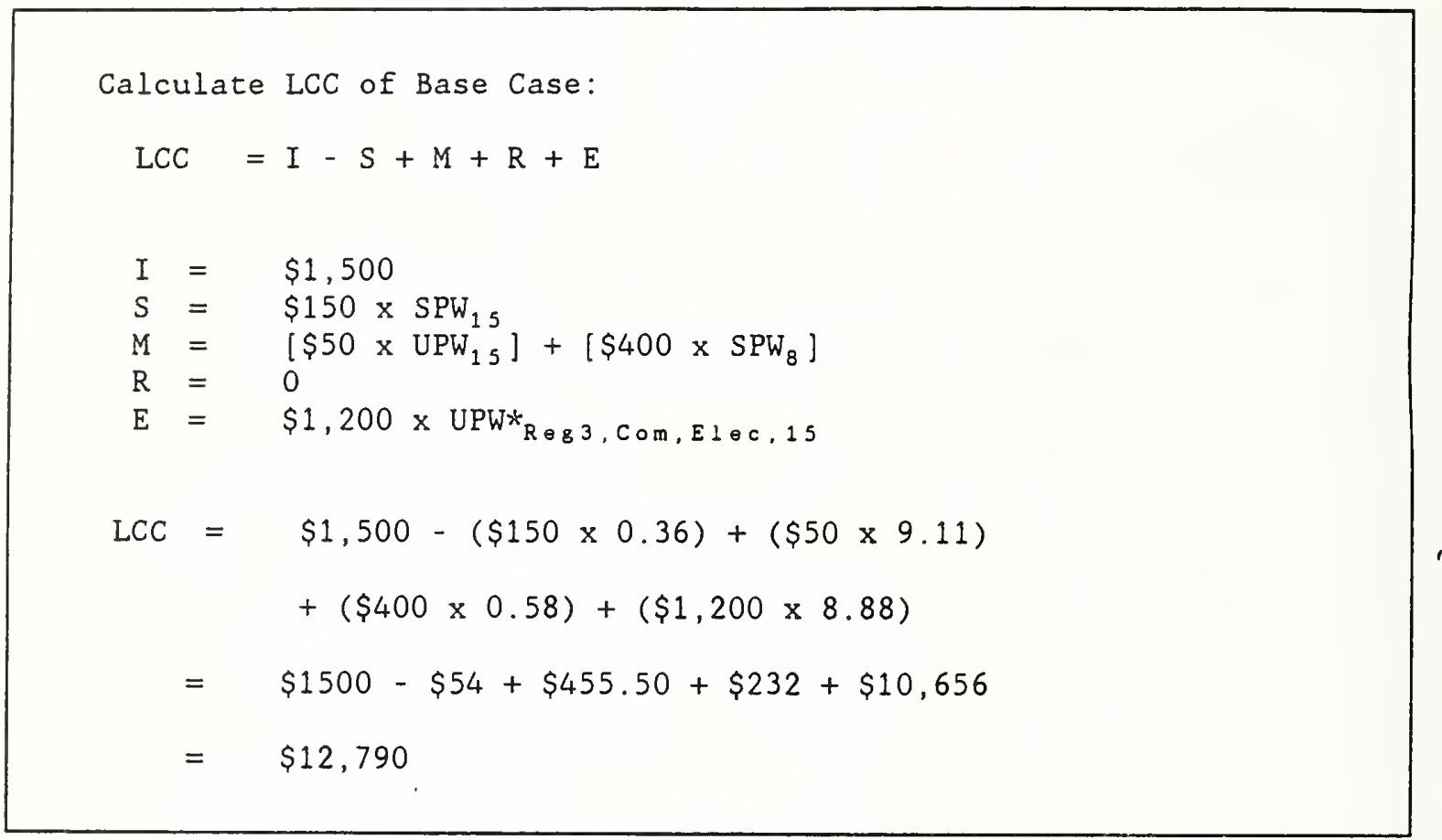

NOTES: 
MODULE D, CONTINUED

SLIDE D-6

Calculate LCC of Alternative:

$$
\begin{aligned}
& I=\$ 3,000 \\
& \mathrm{~S}=\$ 250 \times \mathrm{SPW}_{15} \\
& \mathrm{M}=\left[\$ 100 \times \mathrm{UPW}_{15}\right]+\left[\$ 600 \times \mathrm{SPW}_{8}\right] \\
& \mathrm{R}=0 \\
& E=\$ 800 \times U P W *_{R \in g}, C \circ, E 1 \in c, 15 \\
& \operatorname{LCC}=\$ 3,000-(\$ 250 \times 0.36)+(\$ 100 \times 9.11) \\
& +(\$ 600 \times 0.58)+(\$ 800 \times 8.88) \\
& =\$ 3,000-\$ 90+\$ 911+\$ 348+\$ 7,104 \\
& =\$ 11,273
\end{aligned}
$$

NOTES : 
MODULE D, CONTINUED

SLIDE D-7

Calculate NS of Heat Pump from LCCs:
\[ \begin{aligned} \text { NS } & =\text { LCC }_{\mathrm{BC}}-\text { LCC }_{\mathrm{A}} \\ & =\$ 12,790-\$ 11,273 \\ & =\$ 1,517\end{aligned} \]

NOTES : 
MODULE $D$, CONTINUED

SLIDE D-8

Calculate NS of Heat Pump by Subtracting Differences in Costs from Savings:

$$
\begin{aligned}
& \mathrm{NS}=[\Delta \mathrm{E}]-[\Delta \mathrm{I}-\Delta \mathrm{S}+\Delta \mathrm{M}+\Delta \mathrm{R}] \\
& \Delta E=(\$ 1,200-\$ 800) \times U P W x_{R \in g}, C \circ D, E \perp e c, 15 \\
& \Delta I=(\$ 3,000-\$ 1,500) \\
& \Delta S=(\$ 250-\$ 150) \times S P W_{15}
\end{aligned}
$$

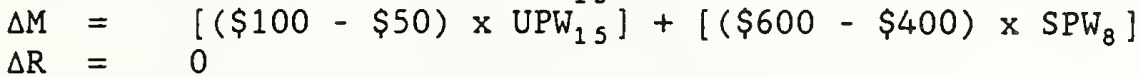

$$
\begin{aligned}
& \text { NS }=[(\$ 1,200-\$ 800) \times 8.88] \\
& \text { - }[(\$ 3,000-\$ 1,500) \\
& -(\$ 250-\$ 150) \times 0.36 \\
& +[(\$ 100-\$ 50) \times 9.11]+[(\$ 600-\$ 400) \times 0.58]] \\
& =[\$ 3,552]-[\$ 1,500-\$ 36+\$ 571.50] \\
& =\$ 1,517
\end{aligned}
$$

NOTES: 
MODULE D, CONTINUED

SLIDE D-9

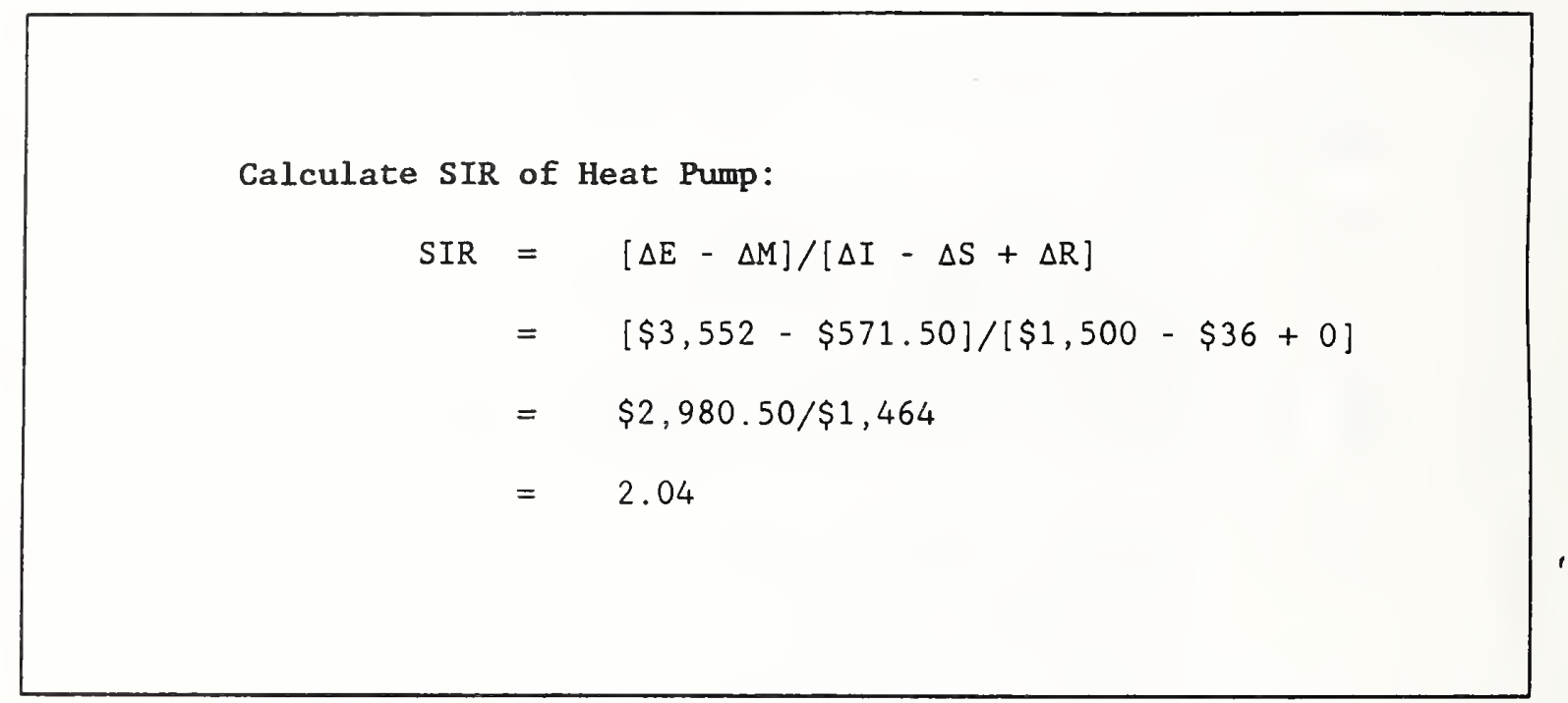

NOTES : 
MODULE D, CONTINUED

SLIDE D-10

Formula for Calculating AIRR:

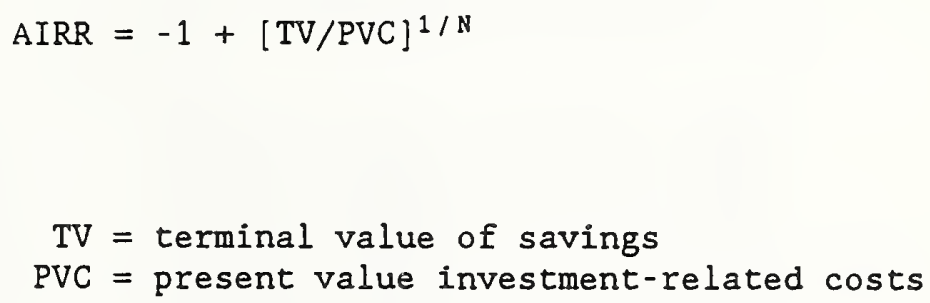

NOTES : 
MODULE D, CONTINUED

SLIDE D-11

Calculate TV Savings of Heat Pump:

$$
\begin{aligned}
& T V=\sum_{j=1}^{N}\left(\Delta \bar{E}_{j}-\Delta \bar{M}_{j}\right)(1+r)^{N-j} \\
& =[(\$ 400 \times 0.99)-\$ 50] \times(1.07)^{14}=\$ 892.17 \\
& +[(\$ 400 \times 0.98)-\$ 50] \times(1.07)^{13}=\$ 824.17 \\
& +[(\$ 400 \times 0.97)-\$ 50] \times(1.07)^{12}=\$ 761.24 \\
& +[(\$ 400 \times 0.96)-\$ 50] \times(1.07)^{11}=\$ 703.02 \\
& +[(\$ 400 \times 0.96)-\$ 50] \times(1.07)^{10}=\$ 657.03 \\
& +[(\$ 400 \times 0.95)-\$ 50] \times(1.07)^{9}=\$ 606.69 \\
& +[(\$ 400 \times 0.96)-\$ 50] \times(1.07)^{8}=\$ 573.87 \\
& +[(\$ 400 \times 0.96)-\$ 50-\$ 200] \times(1.07)^{7}=\$ 215.17 \\
& +[(\$ 400 \times 0.97)-\$ 50] \times(1.07)^{6}=\$ 507.25 \\
& +[(\$ 400 \times 0.98)-\$ 50] \times(1.07)^{5}=\$ 479.67 \\
& +[(\$ 400 \times 0.98)-\$ 50] \times(1.07)^{4}=\$ 448.29 \\
& +[(\$ 400 \times 1.00)-\$ 50] \times(1.07)^{3}=\$ 428.77 \\
& +[(\$ 400 \times 1.00)-\$ 50] \times(1.07)^{2}=\$ 400.72 \\
& +[(\$ 400 \times 1.00)-\$ 50] \times(1.07)^{1}=\$ 374.50 \\
& +[(\$ 400 \times 1.00)-\$ 50] \times(1.07)^{0}=\$ 350.00 \\
& =\$ 8,223
\end{aligned}
$$

[Note use of Energy Price Indices from appendix B, Table Ca-3, to estimate yearly cash flow.]

$r=$ reinvestment rate $=$ discount rate

NOTES : 
MODULE D, CONTINUED

SLIDE D-12

Calculate PVC of Heat Pump:
\[ \begin{aligned} \text { PVC } & =\Delta I+\Delta R-\Delta S \\ & =(\$ 3,000-\$ 1,500)+0-\$ 36 \\ & =\$ 1,464\end{aligned}, . \]

NOTES: 
MODULE D, CONTINUED

SLIDE D-13

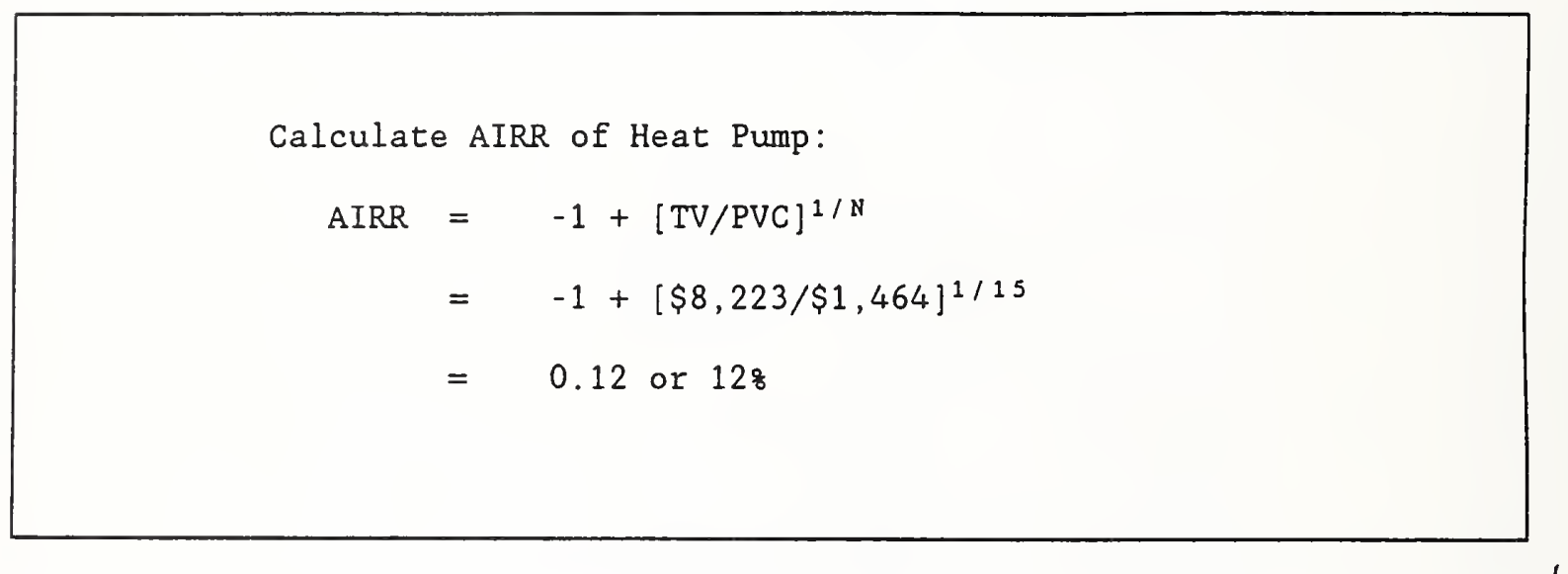

NOTES : 
MODULE D, CONTINUED

SLIDE D-14

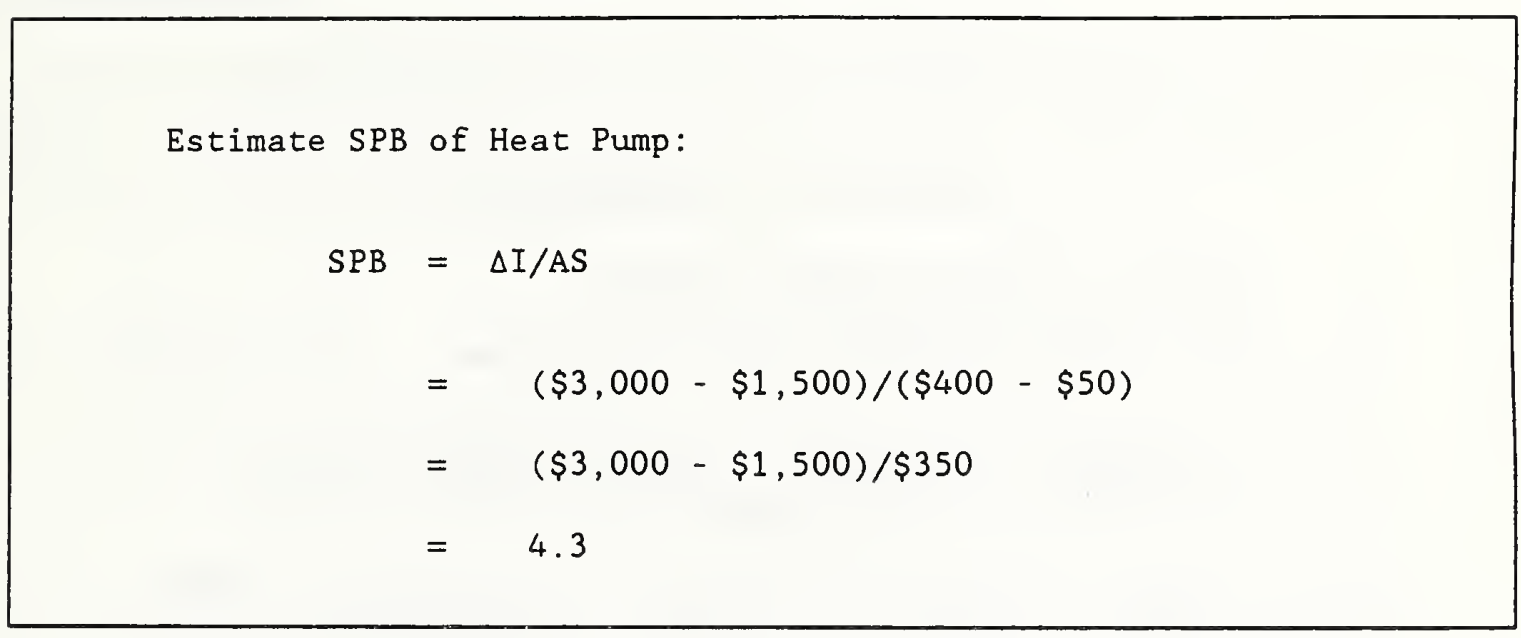

NOTES : 
MODULE D, CONTINUED

SLIDE D-15

\begin{tabular}{|c|c|c|c|c|c|}
\hline \multirow[t]{2}{*}{$\begin{array}{l}0 \\
0 \\
0\end{array}$} & \multicolumn{4}{|c|}{$\begin{array}{l}\text { find in UPW* table, ELEC column } \\
\text { find factor closest to SPB of } 4.3 \\
\text { read off corresponding year in } N \text { column } \\
\text { (Appendix B) TABLE B-3a. UPW* DISCOUNT FACTORS } \\
\text { Census Region } 3\end{array}$} & \multirow[b]{2}{*}{ COAL } \\
\hline & ELEC & DIST & RESID & NATGAS & \\
\hline 1 & 0.93 & 1.01 & 0.98 & 0.95 & 0.95 \\
\hline 2 & 1.78 & 1.97 & 1.90 & 1.84 & 1.85 \\
\hline 3 & 2.58 & 2.89 & 2.76 & 2.68 & 2.71 \\
\hline 4 & 3.31 & 3.78 & 3.57 & 3.46 & 3.53 \\
\hline 5 & 3.99 & 4.64 & 4.37 & 4.22 & 4.31 \\
\hline 6 & 4.63 & 5.49 & 5.17 & 4.94 & 5.05 \\
\hline 7 & 5.23 & 6.32 & 6.00 & 5.64 & 5.75 \\
\hline 8 & 5.79 & 7.14 & 6.85 & 6.32 & 6.42 \\
\hline 9 & 6.31 & 7.96 & 7.71 & 6.97 & 7.05 \\
\hline
\end{tabular}

NOTES : 
MODULE D, CONTINUED

\section{FEDERAL CRITERIA}

Slide D-1 lists principal criteria for performing economic evaluations in support of Federal energy conservation decisions. Each criterion is discussed in the following sections.

DOE Discount Rate:

To evaluate energy conservation or renewable energy projects, discount future amounts to present value using the rate set each year by the Secretary of DOE. It is a "real" discount rate based on current market rates. Prior to FY 1990, the discount rate for evaluating energy conservation projects was 78 (real), set by Congress. (To evaluate most other Federal projects except those specifically exempted, discount future amounts to present value or annual value using a $10 \%$ (real) discount rate.)

\section{Constant Dollars:}

Estimate all future amounts in constant dollars, with the purchasing power of the dollar fixed as of the base year. For example, if an LCC evaluation were being made in 1990, a future cost expected to occur in 1995 should be stated in 1990 dollars without an estimate for the purely inflationary/ deflationary trends that may cause the general level of prices in the economy to change between 1990 and 1995.

This approach allows for the inclusion in data estimates of "differential price changes," i.e., changes that are projected to be faster or slower than the projected rate of general price inflation, when there is a reasonable basis for estimating such changes.

Present Values:

For consistency, Federal agencies use present values for evaluating energyrelated projects. 
MODULE D, CONTINUED

\section{FEDERAL CRITERIA, continued}

Quantity of Energy at Boundary:

Estimate the quantity of energy at the building boundary. The life-cycle cost approach uses energy prices to evaluate the cost effectiveness of an investment. Because these prices already reflect the relationship of "boundary energy" to "source energy," the measure of the physical quantity of energy associated with a building or building system should be based on the quantity of energy delivered to the boundary of the Federal building for the purpose of making the LCC evaluation.

A possible exception is when fuel is used to generate electricity on site. If, in the case of on-site generation of electricity, the agency estimates the value of the electricity on the basis of the actual price of electricity to the agency, the quantity of electricity generated should be used in the LCC evaluations, not the boundary purchases of fuel to produce the electricity. If, however, the agency estimates the value of on-site electricity/steam/hot water on the basis of the input fuel plus generating and distributing costs, the quantity of the input energy should be based on the boundary purchases of the fuel.

\section{Actual Agency Energy Prices:}

Federal agencies should use the actual prices of energy to them in the base year to establish base-year energy costs or savings. When fuel is purchased by a Federal agency to produce its own electricity, steam, or hot water on site, the base-year price of energy used to make LCC evaluations should be (a) the price of the input fuel to the agency plus the costs incurred by the agency in generating and distributing the electricity/steam/hot water, or (b) for electricity only, the agency price of electricity. 
MODULE D, CONTINUED

\section{FEDERAL CRITERIA, continued}

Actual Agency Energy Prices, continued:

If the energy conservation or renewable energy investment being evaluated affects the utility pricing structure, such as through time-of-day charges or demand changes, the demand and usage components should be broken out separately in establishing base-year energy costs.

DOE Energy Price Projections:

To account for anticipated change in future energy prices, use DOE energy price projections unless specifically exempted. DOE projects the future prices of coal, fuel oil, electricity, and natural gas to rise at rates different from the rate of change in the general level of prices. These "differential energy price escalation rates" are projected by Census Region, by sector, by fuel type, and over time. The sample UPW* factors of appendix B are based on DOE 1988 projections.

The DOE energy price projections can be incorporated into LCC evaluations in any of the four following ways:

(1) Multiply the appropriate UPW* factor of appendix B (tables B-1 through B-4) times the initially valued annual energy cost or savings to calculate present value; or

(2) Apply the appropriate energy price indices of appendix B (tables $\mathrm{Ca}-1$ through $\mathrm{Ca}-4)$ to base-year prices, in the year-by-year approach described in appendix G of NBS Handbook 135; or

(3) Use the escalation rates of appendix $B$ (tables $\mathrm{Cb}-1$ through $\mathrm{Cb}-4$ ) to calculate future energy prices, apply the prices to future quantities, and discount the result to present value; or 
MODULE D, CONTINUED

\section{FEDERAL CRITERIA, continued}

DOE Energy Price Projections, continued:

(4) Use an up-to-date version of the companion FBLCC or NBSLCC Computer Program, which contains the DOE-projected rates of change in energy prices in a file on the diskette.

There are two exceptions to using the DOE energy price projections:

(1) If base-year utility prices are broken into demand and usage components, and if component-specific escalation rates are available from the energy supplier, those rates can be used in lieu of the DOE rates. (If the component-specific projections are not available, but base-year utility prices are broken into demand and usage components, the DOE projections can be applied to each of the price components for the purpose of estimating life-cycle costs or savings.)

(2) A Federal agency conducting life-cycle analyses of energy projects for Federal buildings in a foreign country should use escalation rates which are "reasonable under the circumstances," and may refer to the U.S. average DOEprojections as shown in appendix B, tables $\mathrm{B}-5 \mathrm{a}, \mathrm{B}-5 \mathrm{~b}, \mathrm{Ca}-5$, and $\mathrm{Cb}-5$.

Instantaneous or Delayed Investment:

At the discretion of the agency, investment costs, including costs of design, engineering, purchase, and installation (exclusive of sunk costs) may be treated as a lump-sum present value amount occurring at the beginning of the base year. Treating investment costs as occurring at the beginning of the base year is a simplification which allows these costs to be considered already in present value dollars without discounting. It avoids the need to adjust for the corresponding delay in the onset of other cash flows, such as energy costs. 
MODULE D, CONTINUED

FEDERAL CRITERIA, continued

Instantaneous or Delayed Investment, continued:

To assume that the initial investment costs for all projects to be evaluated in a given year occur at the beginning of that year is a simplification that gives somewhat less accurate results than a detailed analysis of actual estimated cash flows. Furthermore, it should be recognized that a detailed scheduling and accounting of costs is an important aspect of project management. However, for the purpose of making investment decisions, the difference in the results of a detailed cash-flow analysis and of the simplified approach is generally not great.

If the agency wishes, however, it can make a detailed analysis, taking into account project delays. This is, in fact, necessary when making choices among mutually exclusive project alternatives which have as a primary difference their time required for implementation. For example, if a natural gas heating system is being compared with an oil heating system for retrofit to a building which now has an electric resistance system, but access to the natural gas will not be available for three more years, the comparison relative to the existing system is between installing the oil heating system now and having it over the entire study period versus having the existing, or some other interim system, for three years and the gas system thereafter. In this example, the investment costs for the oil heating system would be treated as a lump-sum amount at the beginning of the base year, as would the costs for the interim system (either the residual value of the electric system if it is the interim system or the investment cost of some other system which might be the designated interim system). The investment costs for the gas heating system would be treated as a future amount occurring at the end of the third year. 
MODULE D, CONTINUED

FEDERAL CRITERIA, continued

Study Period 25 Years (Plus Planning/Scheduling Period):

For selecting among mutually exclusive designs and/or sizes for a given building or building system, use the same study period to evaluate all of the choices, not to exceed either 25 years or the period of intended use of the building.

When amounts are expressed in present values, it is essential that the same study period be used to evaluate mutually exclusive choices--such as alternative designs for a given building, alternative layers of glazing in, windows, alternative solar collector designs and sizes, or alternative levels of thermal insulation. Choosing different study periods will automatically cause one choice to have a different life-cycle cost or net savings than another, because its cash flows will be examined over a longer or shorter time period.

The common study period for evaluating mutually exclusive choices, not to exceed 25 years from the beneficial occupancy date of the building, may be:

(a) The period of intended use of the building, with appropriate replacement and salvage values for each alternative.

(b) The lowest common multiple of the estimated lives of the mutually exclusive alternatives, with appropriate replacements for each alternative.

To evaluate or rank a given building system for a Federally owned building, choose a study period that is the lesser of (a) 25 years, (b) the estimated life of the building system, or (c) the period of intended use of the building. 
MODULE D, CONTINUED

FEDERAL CRITERIA, continued

Study Period 25 Years (Plus Planning/Scheduling Period), continued

For evaluating energy use and related investments in a leased Federal building, choose a study period that is the lesser of 25 years or the effective remaining term of the lease (including renewal options likely to be exercised). Since Federal agencies are required to consider only those costs that accrue to the Federal government in evaluating projects for leased buildings, the study period should be the effective remaining term of the lease, not in excess of the 25 year limit. Renewal options may be taken into account, if appropriate, in setting the study period.

End-of-Year or When-Actually-Incurred-Cash Flows:

Agencies have flexibility in modeling cash flows within years. They may use end-of-year, beginning-of-year, middle-of-year, continuous, or whenactually-incurred cash-flow modeling.

\section{No Evaluation Required Under Certain Conditions:}

Presume that an alternative building system $\underline{\text { is }}$ cost effective if its investment and other costs are insignificant.

Presume that an alternative building system is not cost effective if the building is (a) occupied under a short-term lease without renewal option or with a renewal option that is not likely to be exercised, (b) occupied under a lease that includes the cost of utilities in the rent, with no passthrough to the government of energy savings, or (c) scheduled for demolition or retirement within three years. 
MODULE D, CONTINUED

\section{WORKSHEETS}

A set of worksheets have been developed with step-by-step instructions to guide you through evaluating (a) new building design alternatives, (b) retrofit building systems, and (c) solar energy systems. The use of these worksheets is discretionary, but it is required that a structured format be used for documenting the evaluation. (See Handbook 135.)

\section{CALCULATIONS}

Slides D-2 through D-15 demonstrate for a sample problem how to calculate LCC, NS, SIR, AIRR, SPB, and DPB.

- Slide D-2 gives background data.

- Slide D-3 list data for the system with the lowest first cost.

- Slide D-4 lists data for the alternative system.

- Slide D-5 shows calculation of LCC for the lower first-cost system.

- Slide D- 6 shows calculation of LCC for the alternative system.

- Slide D-7 shows calculation of NS from LCCs.

- Slide D-8 shows calculation of NS by subtracting individual items of increased costs from increased savings.

- Slide D-9 shows calculation of SIR.

- Slides D-10, D-11, D-12, and D-13 show calculation of AIRR.

- Slide D-14 shows calculation of SPB.

- Slide D-15 shows approximation of DPB from SPB. 
MODULE D, CONTINUED

\section{PROBLEM D-1 \\ Calculating LCC, NS, and SIR}

Use LCC and NS to determine if adding a solar hot water system to a military launderette is estimated to be cost-effective, and, if so, what funding priority it should receive relative to other energy conservation projects. The alternatives are to

(1) continue using the existing hot water system as it is, or

(2) add the solar hot water system and use the existing system as a backup.

Data and Assumptions:

Location: Arizona

Hot Water Load: 1,750 MBtu/year

Fraction of Load to be Supplied by Solar: $60 \%$

Existing Hot Water Heater: Electric Resistance

Today's Price of Electricity: $\$ 20 /$ MBtu

DOE Price Projections: Industrial pricing

Cost of Purchasing and Installing Solar Energy System: $\$ 140,000$

Annual Electricity to Operate

the Solar Energy System:

28 of annual load supplied by solar energy

Annual Maintenance \& Repair

Costs for the Solar Energy System: 38 of purchase and installation costs

System Lives: Both the existing system and the solar energy system are expected to last the remaining 15 years the launderette is expected to remain in use.

Salvage Value: 0 


\section{BLCC COMPUTER PROGRAM (Revised*)}

Module E

90 minutes

Lecture and computer lab

Objectives

At the end of this session you will be able to:

- run the BLCC computer program

- set up an LCC problem for solution using BLCC

o interpret the reports generated by BLCC

- use DISCOUNT for stand-alone discounting problems

\footnotetext{
This revised module supersedes module $E$ in the "Life-cycle Costing for Energy Conservation in Buildings: Students Manual," NISTIR 89-4130, National Institute of standards and Technology, Gaithersburg, MD, August 1989
} 
MODULE E, CONTINUED

\section{overview of BLCC}

slide $\mathrm{E}-1$

INTRODUCTION TO THE NIST BLCC PROGRAM

FOR BUILDING LIFE-CYCLE COST ANALYSIS

For detailed description and user's guide, see:

The NIST "Building Life-Cycle cost" (BLCC) Program (version 3.0), User's Guide and Reference Manual (NISTIR 4481)

Notes: 


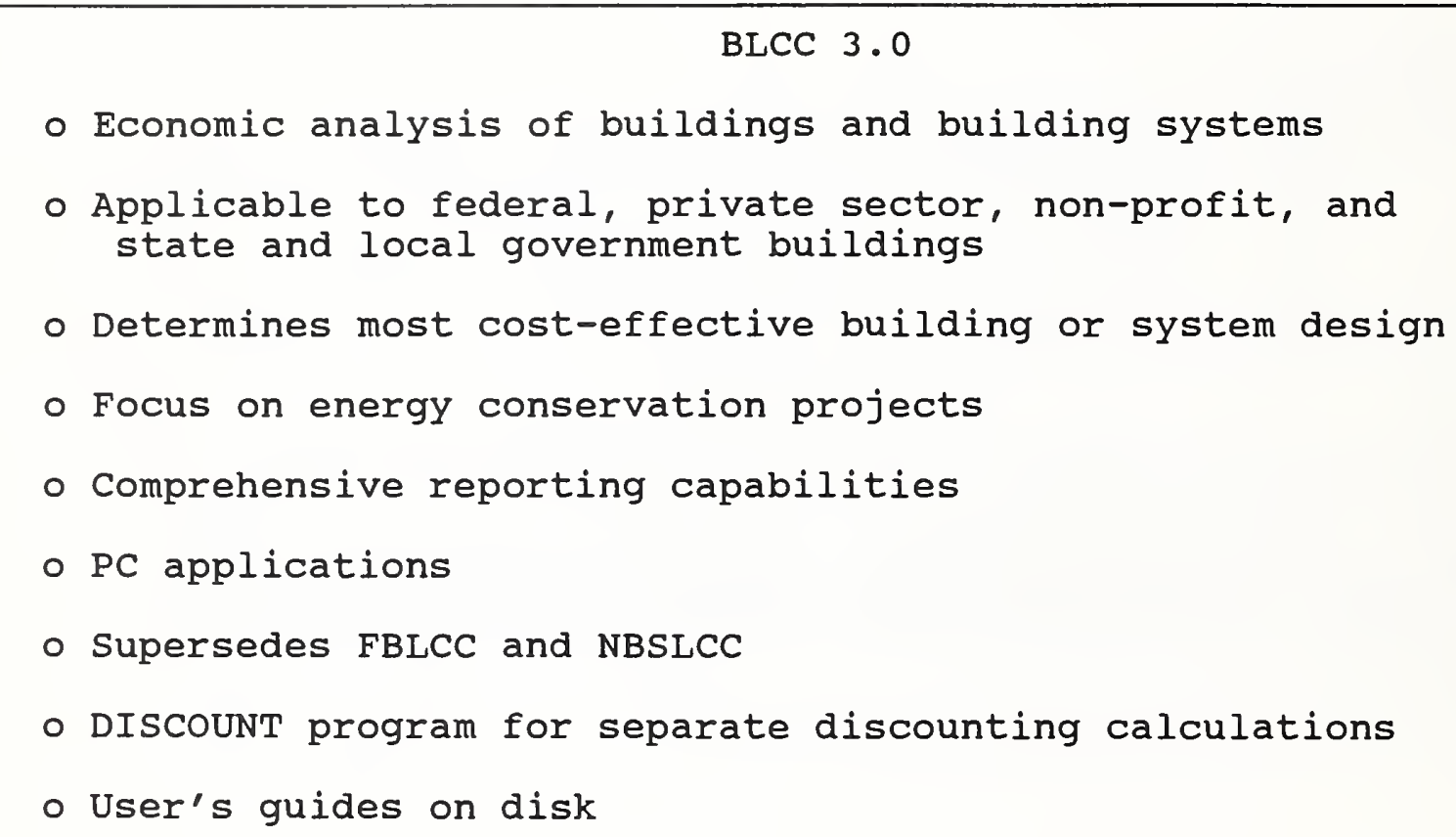

Notes: 
MODULE E, CONTINUED

slide $\mathrm{E}-3$

\section{BLCC Analysis}

- Life-cycle cost calculations

- Yearly cash flow analysis

- Lowest life-cycle cost (up to 9 alternatives)

- Comparative economic analysis (2 alternatives):

- Net savings

- SIR

- Adjusted internal rate of return

Notes: 

BLCC Reports
- Input data listing
- Summary LCC
- Detailed LCC
- Yearly cash flow analysis
- Lowest LCC analysis
- Comparative economic analysis

Notes: 
MODULE E, CONTINUED

slide $E-5$

BLCC for Federal Buildings

o Consistent with NIST Handbook 135 for energy conservation projects

- Optional use of OMB A-94 for non-energy conservation projects

- Automatically accesses DOE energy price projections from disk

- Constant dollar analysis

- No financing or tax-related computations

Notes: 
MODULE E, CONTINUED

slide E-6

BLCC for Non-Federal Buildings
- Consistent with ASTM Standards for building economics
- Taxable and non-taxable projects
- Financing analysis
- Current dollars for taxable projects
o Constant or current dollars for non-taxable projects

Notes: 
MODULE E, CONTINUED

Slide $E-7$

Typical data requirements of BLCC Analysis

General assumptions:

study Period

Planning/Construction Period

Discount rate

Tax environment

Capital asset data:

Initial cost

Annually recurring costs

Non-annually recurring costs and timing

Replacement costs and timing

Escalation rates

Tax-related data
Energy related data: Types

Annual consumptions Unit costs

Escalation rates

Usage indexes

Financing data:

Loan amounts

Mortgage life

Interest rates

Payments/year

Notes: 
MODULE E, CONTINUED

Slide E-8

Running BLCC
1. Type BLCC to start
2. Use main menu to select each step of analysis
3. Create/edit input data file for each project alternative
4. Print detailed LCC report for each alternative
5. Find alternative with lowest LCC
6. Perform comparative analysis of selected alternatives if
needed.

Notes: 
MODULE E, CONTINUED

Slide E-9

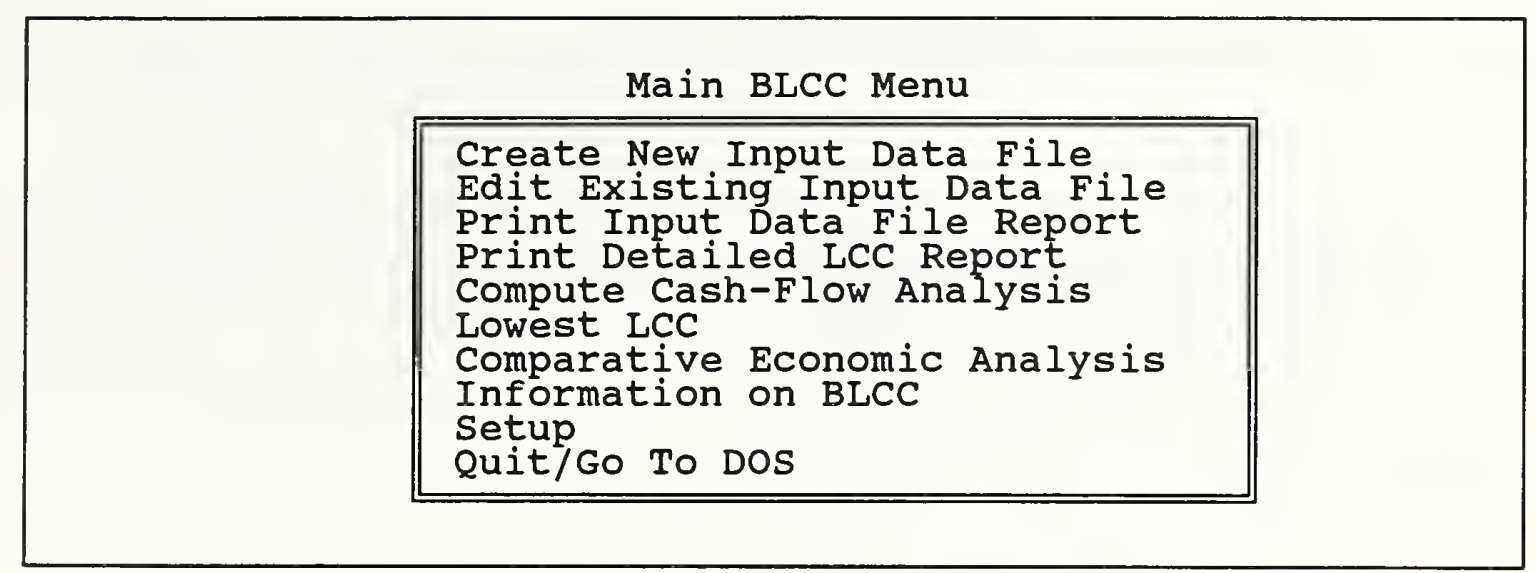

Notes: 
MODULE E, CONTINUED

\section{Slide E-10}

COMPARATIVE PRESENT-VALUE COSTS OF ALTERNATIVE PROJECTS (Shown in ascending order of initial cost, $*=$ lowest LCC)

$$
\begin{aligned}
& \text { PROJECT } \\
& \text { NAME } \\
& \text { alternative \#1 } \\
& \text { alternative \#2 } \\
& \text { alternative \#3 } \\
& \text { alternative \#4 }
\end{aligned}
$$

LCC

FILENAME

-.---

DEMO 1

DEMO2

DEMO3

DEMO4
INITIAL

$\operatorname{cosT}(P V)$

$\$ 9,527$

$\$ 10,479$

$\$ 11,432$

$\$ 14,290$
LIFE CYCLE COST (PV)

$\$ 158,876$

$\$ 145,451$

$\$ 139,382$ *

$\$ 139,532$

Notes: 
MODULE E, CONTINUED

Slide E-11

\section{PROJECT DATA:}

Project title: Storm windows

Base year (1990-2000): 1991

Study period $(2-60): 20$ Years

Planning/Construction period (0-9): 0 Year(s)

Discount rate: $7.00 \%$

Comment: This run is for demonstration purposes only

Notes: 


\section{DISCOUNT 3.0 PROGRAM MENU}

\section{SINGLE AMOUNTS}

1. PRESENT VALUE when future value is known.

2. FUTURE VALUE when present value is known.

\section{UNIFORM SERIES OF PAYMENTS}

3. PRESENT VALUE when periodic payment amount is known.

4. FUTURE VALUE when periodic payment amount is known.

5. PERIODIC PAYMENT AMOUNT when present amount is known.

6. PERIODIC PAYMENT AMOUNT when future amount is known.

NON-UNIFORM SERIES OF PAYMENTS

7. PRESENT VALUE when periodic payment amount increases at constant rate.

8. PRESENT VALUE when periodic payment amount increases at changing rate.

9. PRESENT VALUE using DOE energy price escalation rates.

Notes: 
BLCC Date Entry Screens:

Select the type of analysis:

(1) Federal Analysis--Energy Conservation Projects

(2) Federal Analysis--Projects subject to OMB A-94

(3) Private Sector--Buildings with Tax Analys is

(4) Private Sector--Owner-occupied Houses

(5) Generic LCC Analysis--No Tax Analysis

Use cursor to make selection, then press <Enter>.

(Use <EsC> to move back to previous screen.)

PROJECT DATA:

Project title:

Base year $(1990-2000): 1991$

Study period $(2-60) *$ : 0 Years

Planning/Construction period (0-9): 0 Year(s)

Discount rate: $4.70 \%$

Comment:

Use Tab and Shift-Tab to move forward and backward.

Press <PgDn> when finished, <PgUp> for previous screen.

Note: For Federal energy conservation analyses, the base year must be set to the current year.

* The STUDY PERIOD includes the Planning/Construction Period (if any). O\&M, energy, and replacement costs are not incurred during P/C Period.

Component Names

Component \#1: baseboard ht Component \#2: air condtnr 
BLCC Date Entry Screens (continued):

Component \#1: baseboard ht

CAPITAL INVESTMENT DATA:

Initial Cost (base year dollars): $\$ 500$

Expected Life (years): 15

Resale Value Factor ( $\%$ of initial cost): $10.0 \%$

Use Tab and Shift-Tab to move forward and backward.

Press <PgDn> when finished, <Pgup> for previous screen.

Component \#1: baseboard ht

Annually-Recurring operating and Maintenance Costs

(Do not include energy costs)

Amount (base year $\$$ ) : $\$ 50$

Use Tab and Shift-Tab to move forward and backward.

Press <PgDn> when finished, <Pgup> for previous screen.

Component \#1: baseboard ht

Non-Annually-Recurring operating and Maintenance costs

(Do not include Replacement Costs)

Enter year (from occupancy, e.g., $1,2, \ldots$ ) and amount in base-year $\$$

\begin{tabular}{|lllllllll|}
\hline Yr Amount & Yr Amount & Yr & Amount & Yr Amount & Ir Amount \\
\hline 8 & 400 & -- & & & & & & \\
\hline- & & & & & & & \\
\hline
\end{tabular}

Use Tab and Shift-Tab to move forward and backward.

Press F1 to delete row, F2 to insert row. Press <PgDn> when finished. Entries in years beyond the end of study period will be saved but not used. 
BLCC Date Entry Screens (continued):

Component \#1: baseboard ht Replacement cost Schedule

Year (from occupancy):

\section{Replacement: \#1}

Initial cost (base yr $\$$ ):

Expected Life (years):

Resale Value Factor:

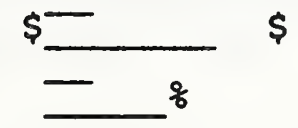

\#2

(1)

\#3 \#4

$\$$

$\$$

o

8

$\%$

Use Tab and Shift-Tab to move forward and backward.

Press F1 to delete column, F2 to insert column. Press <PgDn> when finished.

Energy-Related Cost and Use Data

(Enter up to 4 energy types)

\begin{tabular}{|c|c|c|c|c|}
\hline Energy type number: & $\# 1$ & $\# 2$ & \#3 & $\# 4$ \\
\hline $\begin{array}{l}\text { Energy Type Code }(1-7) * \text { : } \\
\text { Base Annual consumption (units): } \\
\text { Price per unit (base year } \$): \\
\text { Annual demand (or other) charge: } \\
\text { Escalation rate code }(1-3) * \star:\end{array}$ & $\begin{array}{l}1 \\
17850 \\
\$ \\
\$ 0 \\
2\end{array}$ & $\$$ & $\begin{array}{l}\$ \\
\$\end{array}$ & $\$$ \\
\hline
\end{tabular}

Use Tab and Shift-Tab to move forward and backward.

ress F1 to delete column, F2 to insert column. Press <PgDn> when finished.

Note: DOE's energy price escalation rates must be used with

Federal energy conservation projects when available.

*Energy type codes (units):

l=Electricity (kWh); 2=distillate oil (gallons); $3=$ residual oil (gallons)

$4=$ natural gas (therms); $5=\mathrm{LPG}$ (lbs); $6=$ coal (tons); 7 =other (unspecified)

**Energy price escalation rate codes:

$1=$ user enters rates; $2=$ DOE rates from disk; $3=$ user modifies DOE rates 


\section{BLCC Date Entry Screens (continued):}

DOE energy price escalation projections require the following data:

Rate Schedule Type* $(1-3): 3$

State Abbreviation (2-char): DC

\section{Press <PgDn> when complete.}

* Rate Schedule Types:

1 = Residential

2 = Commercial

3 = Industrial

DOE Projected Energy Price Escalation Rates for Electricity (Net of general inflation)

Rate type $=$ Industrial; DOE Region $=3 ;$ Projection Date: MAY 1990

\begin{tabular}{|c|c|c|c|c|c|c|c|c|c|}
\hline Year & Rate & Year & Rate & Year & Rate & Year & Rate & Year & Rate \\
\hline $\begin{array}{l}1991 \\
1992 \\
1993 \\
1994 \\
1995 \\
1996 \\
1997 \\
1998 \\
1999 \\
2000\end{array}$ & $\begin{array}{r}1.69 \\
-0.91 \\
0.85 \\
0.64 \\
-0.35 \\
0.16 \\
0.80 \\
1.29 \\
2.39 \\
0.30\end{array}$ & $\begin{array}{l}2001 \\
2002 \\
2003 \\
2004 \\
2005\end{array}$ & $\begin{array}{l}1.26 \\
0.98 \\
1.25 \\
0.80 \\
0.38\end{array}$ & & & & & & \\
\hline
\end{tabular}

These rates are shown for inspection only. Press <PgDn> to continue. To modify these rates press <Pgup> to return to energy data screen and change escalation rate type to "User modifies DOE rates". 
Yearly Energy Usage Indexes for Electricity

starting with first year of occupancy (1991) $100 \%=$ base index

Enter in pairs: Number of YEARS (duration) and corresponding INDEX. Yrs Index up to 15 pairs; total years must add to at least 15) Yrs Index Index

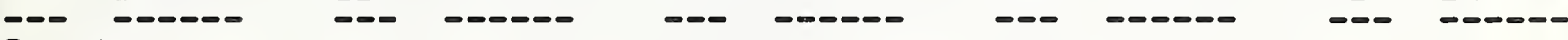

$5 \quad 100.00$

$10 \quad 95.00$

Use $\mathrm{Tab}$ and Shift-Tab to move forward and backward.

Press F1 to delete row, F2 to insert row. Press <PgDn> when finished. Indexes in years beyond end of study period will be saved but not used.

Data entry is now complete.

Save Input Data \& Compute LCC

Review Input Data File

Exit without saving

Use cursor to make selection, then press <Enter>.

(or press highlighted letter) 


\section{BLCC Lab Problem E-1 (revised)}

Selecting a Heating and cooling system

Compare the LCCs of the following two systems for heating a cooling a house on a military base in washington, D.C., based on their comparative cost effectiveness:

Baseboard Heating System with Window Air Conditioners (Base case System)

- Purchase and installation costs:

Baseboard heaters $=\$ 500$

Window air conditioners $=\$ 1000$

- Annual maintenance cost $=\$ 50$

- Air Conditioner repairs in year $8=\$ 400$

- Study Period = 15 years

- Resale value at end of study period:

Baseboard heaters $=10 \%$ of initial cost $(\$ 50)$

Window Air Conditioners $=10 \%$ of initial cost ( $\$ 100)$

- Annual Electricity Consumption $=17580 \mathrm{kWh}$

- Current Price of Electricity $=\$ 0.068$ per $\mathrm{kWh}$

Heat Pump (Alternative System)

- Purchase and installation cost $=\$ 3000$

- Annual maintenance cost $=\$ 100$

- Compressor repair in year $8=\$ 600$

- Study period $=15$ years

o Resale value at end of study period $=8.33 \%$ of initial cost $(\$ 250)$

- Annual electricity consumption $=11720 \mathrm{kWh}$

- Current Price of Electricity $=\$ 0.068$ per $\mathrm{kWh}$ 
Suggested approach for problem E-1:

(1) Select "Create New Input Data File" from the Main BLCC Menu. create a separate input data file for both the base case

(baseboard and air conditioner) and alternative (heat pump)

systems. Since much of the input data in the second file is the same as the first, it may be easier to create the second file by editing the first file after it has been saved, changing only the variables that are different, and then saving the new file under a new filename. (The input data file is automatically saved with filename extension ".DAT".)

(2) When the input data file is saved, the LCC computations are automatically completed and saved to an LCC output file which you can name. (The LCC output file is automatically saved with filename extension ". ICC".) It is generally better to give the same name to the ICC output file used for the input data file, so that related input and output data can be easily identified. since the two files will have different filename extensions, they will not be confused. This is the default filename convention.

(3) After saving each input file, you can display a summary of the ICC analysis to the screen or to a printer (If available).

(4) Check the contents of your input data files by selecting "Print Input Data File" from the main menu and highlighting the file you wish to examine. Display this file to the screen or printer (if available) and look it over to make sure that it matches your problem requirements. If there is an error, select "Edit Existing Input Data File" from the main menu and correct it. When you resave the file, the LCC will automatically be recomputed and resaved.

(5) After verifying that the base case and alternative files are correct, select "Comparative Economic Analysis" from the main menu. Your ICC filenames will show up on the screen. Tag the filenames of the two files to be compared. Display your results to the screen or printer (if available).

Note: In the edit mode for data input files, you can move to the end of the file any time by pressing <FIO>. If you cannot exit a screen in the file creation or edit mode, it is generally because one of the variables is out of the allowable bounds. If this is the case, the allowable bounds are shown at the bottom of the screen.

NOTE: Pages 122-169 have been deleted. 


\title{
DESIGNING \& SIZING I NDEPENDENT AND INTERDEPENDENT SYSTEMS
}

MODULE F

\author{
75 Minutes \\ Lecture, Discussion, and Problem Solving
}

OBJECTIVES

At the conclusion of this module, you are expected to be able to

- find the cost-effective size of an

energy-related building system; and

- find the cost-effective combination

of interdependent building systems. 
MODULE $F$, CONTINUED

\section{REVIEW}

Notes: 
MODULE $F$, CONTINUED

SLIDE F-1

\begin{tabular}{|l}
\hline DECISIONS \\
Focus of Day 2 : \\
$0 \quad$ what design or size of a given system \\
$\circ \quad$ how to combine interdependent systems \\
$\circ \quad \begin{array}{l}\text { which projects--in what design and } \\
\text { size--to fund with a limited budget }\end{array}$ \\
\end{tabular}

NOTES : 
MODULE F; CONTINUED

\section{INDEPENDENT SYSTEMS}

Assumptions

- $1200 \mathrm{ft}^{2}$ Single-Family House

- Ohio (Region 2)

- Annual Space Heating Load (AHL) $=50 \mathrm{MBtu}$

- Electric Resistance System, Efficiency $(E F F)=100 \%$

- $\triangle \mathrm{AHL}$ (MBtu) as Attic Insulation is Added:

$$
\frac{0-R 11}{-13.0} \quad \frac{R 11-R 19}{-2.1} \quad \frac{R 19-R 30}{-1.3} \quad \frac{R 30-R 38}{-0.5}
$$

- $\quad$ Insulation Cost: $\quad \$ 300 \quad \$ 150 \quad \$ 200 \quad \$ 150$

- Price of Electricity $=\$ 21.75 / \mathrm{MBtu}$

- Commercial Electricity Rates

- 1988 DOE Price Projections

- Heating Only

- Study Period: 25 years

NOTES: 
MODULE F; CONTINUED

SLIDE F-3

ANNUAL HEATING ENERGY REQUIREMENT

DEPENDS ON

LOAD \& SYSTEM EFFICIENCY:

$\mathrm{AER}=\frac{\mathrm{AHL}}{\mathrm{EFF}}=\frac{50 \mathrm{MBtu}}{1}=50 \mathrm{MBtu}$

$\mathrm{AER}=$ Annual Energy Requirement

AHL $=$ Annual Heating Load

$E F F=$ Heating System Efficiency or Seasonal Coefficient of Performance

NOTES : 
MODULE F, CONTINUED

SLIDE F-4

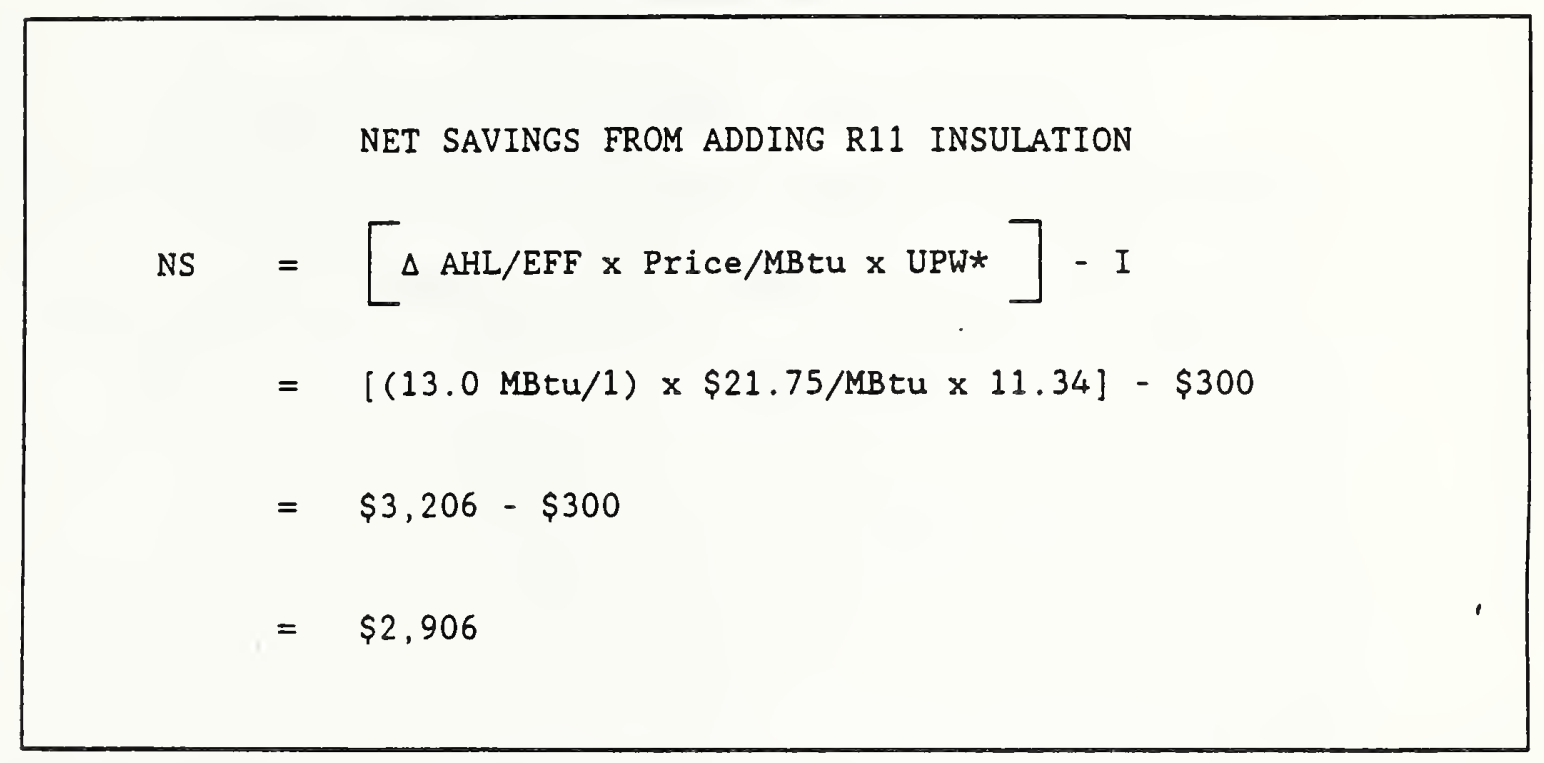

NOTES: 
MODULE F; CONTINUED

SLIDE F-5

NET SAVINGS FROM INCREASING INSULATION FROM R11 TO R19

$N S=[(2.1 \mathrm{MBtu} / 1) \times \$ 21.75 /$ MBtu $\times 11.34]-\$ 150$

$=\$ 518-\$ 150$

$=\$ 368$

NOTES : 
MODULE $F$; CONTINUED

SLIDE F-6

NET SAVINGS FROM INCREASING INSULATION FROM R19 TO R30

$\mathrm{NS}=[(1.3 \mathrm{MBtu} / 1) \times \$ 21.75 / \mathrm{MBtu} \times 11.34]-\$ 200$

$=\$ 321-\$ 200$

$=\$ 121$

NOTES : 
MODULE F; CONTINUED

SLIDE F-7

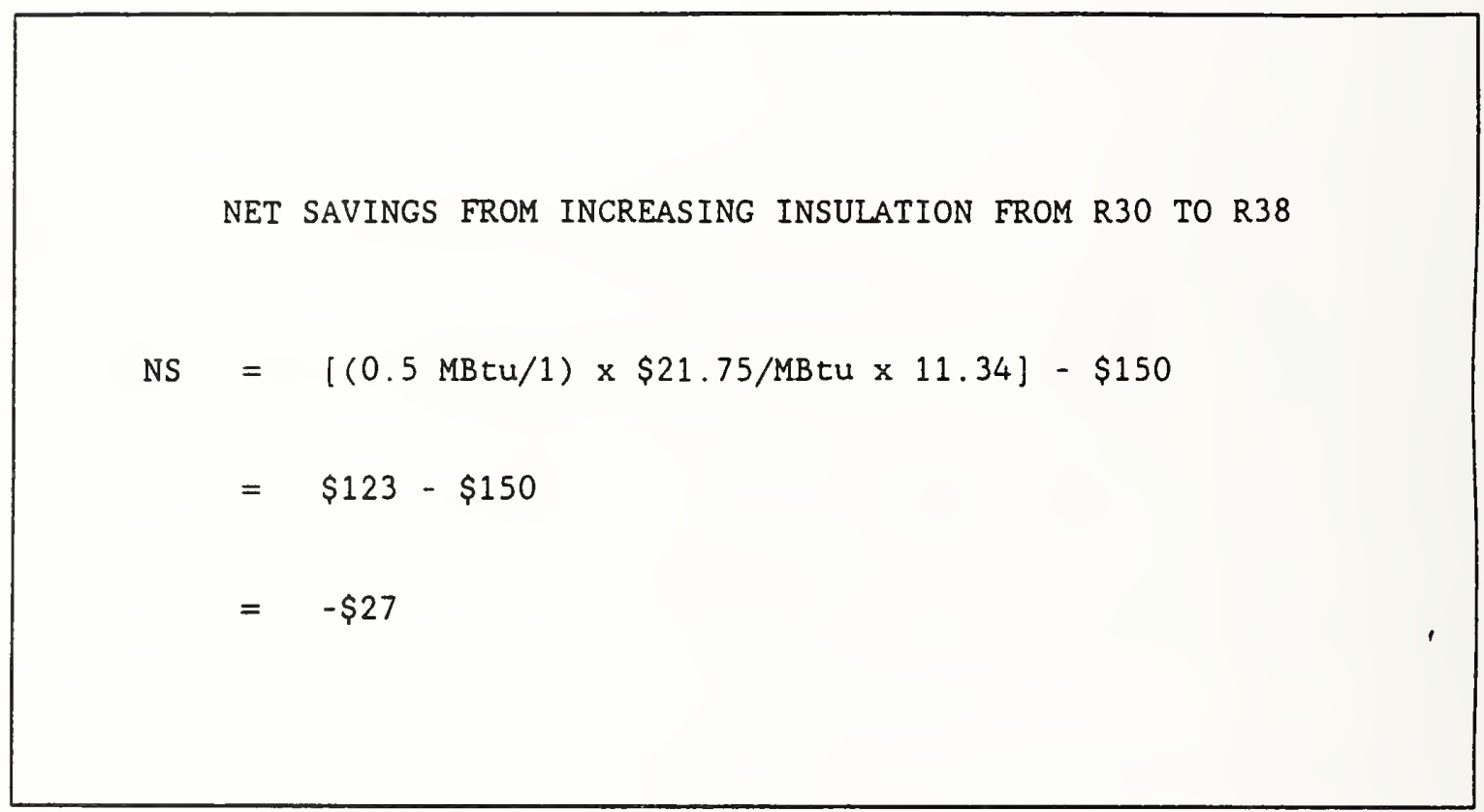

NOTES: 
MODULE F, CONTINUED

SLIDE F-8

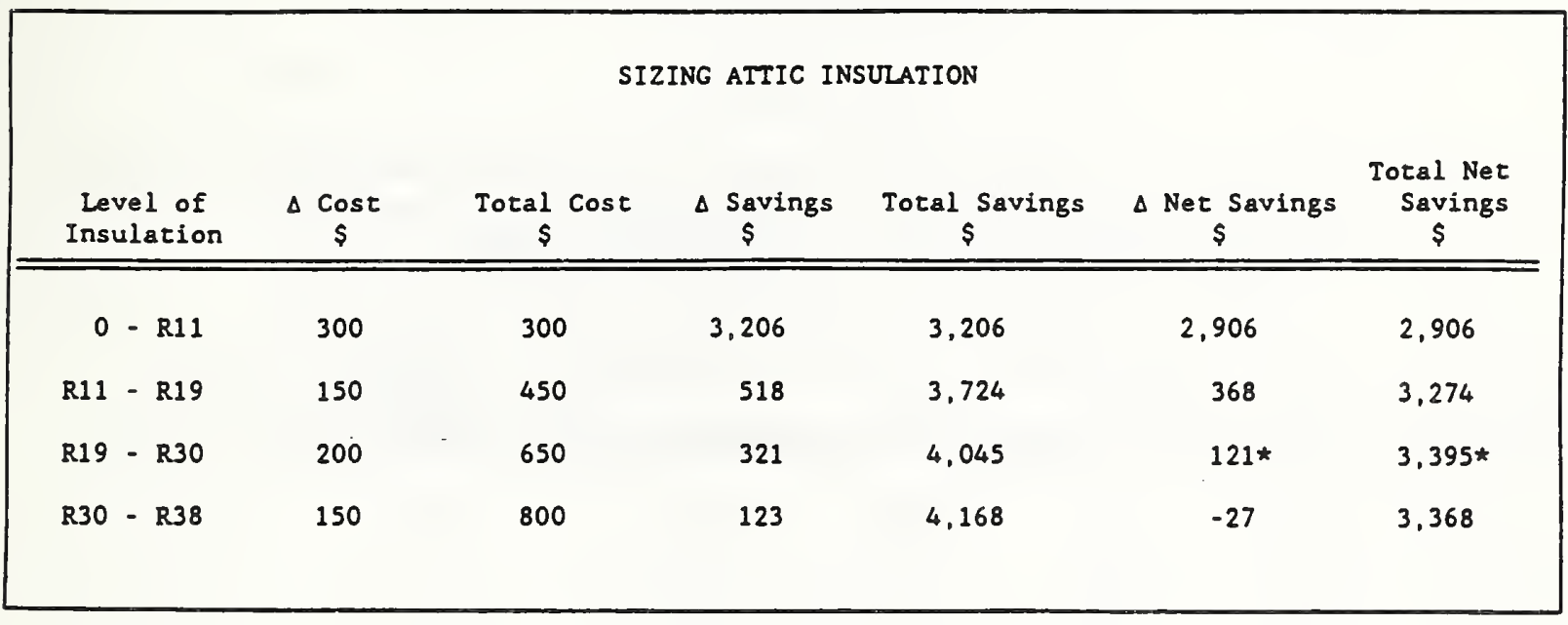

NOTES: 
MODULE F, CONTINUED

SLIDE F-9

\begin{tabular}{|c|c|c|c|c|c|c|}
\hline \multirow[b]{2}{*}{$\begin{array}{l}\text { Level of } \\
\text { Insulation }\end{array}$} & \multicolumn{6}{|c|}{ INCREMENTAL SIR - - NOT TOTAL SIR - - MUST BE USED TO SIZE! } \\
\hline & $\begin{array}{c}\Delta \text { Cost } \\
\$\end{array}$ & $\begin{array}{c}\text { Total Cost } \\
\$\end{array}$ & $\begin{array}{c}\Delta \text { Savings } \\
\$\end{array}$ & Total Savings & $\begin{array}{l}\text { Incremental } \\
\text { SIR }\end{array}$ & $\begin{array}{l}\text { Total } \\
\text { SIR }\end{array}$ \\
\hline $0-\mathrm{R} 11$ & 300 & 300 & 3,206 & 3,206 & 10.7 & 10.7 \\
\hline R11 - R19 & 150 & 450 & 518 & 3,724 & 3.5 & 8.3 \\
\hline R19-R30 & 200 & 650 & 321 & 4,045 & $1.6 *$ & 6.2 \\
\hline R30-R38 & 150 & 800 & 123 & 4,168 & 0.8 & 5.2 \\
\hline & & & & $\begin{array}{c}\text { No Indicat } \\
\text { of } \\
\text { Optimal }\end{array}$ & & \\
\hline
\end{tabular}

NOTES: 
MODULE F, CONTINUED

SIIDE $F-10$

REPLACE ELECTRIC RESISTANCE FURNACE

WITH HEAT PUMP?

Assumptions

electric furnace efficiency (EFF) $=1.0$

purchase and installation cost for $\mathrm{HP}=\$ 2,500$

heating seasonal perf. factor for HP (HSPF) $=1.0$

annual maintenance contract for HP $=\$ 100$

study period $=25$ years (same as insulation)

no replacement

no residual value

cooling savings not included in example

NOTES : 
MODULE F, CONTINUED

SLIDE F-11

NET SAVINGS FROM REPLACING EXISTING HEATING SYSTEM

Present value over 25 years

CASE 1: NO ATTIC INSULATION

$N S=(A H L / E F F-A H L / H S P F) \times$ Price/MBtU $\times$ UPW $-I-M \times U P W$

$\mathrm{NS}=(50 \mathrm{MBtu} / 1.0-50 \mathrm{MBEu} / 1.8) \times \$ 21.75 / \mathrm{MBtu} \times 11.34$

$-\$ 2,500-\$ 100 \times 11.65$

$=\$ 5,481-\$ 3,665=\$ 1,816$

NOTES: 
MODULE F, CONTINUED

SIIDE F-12

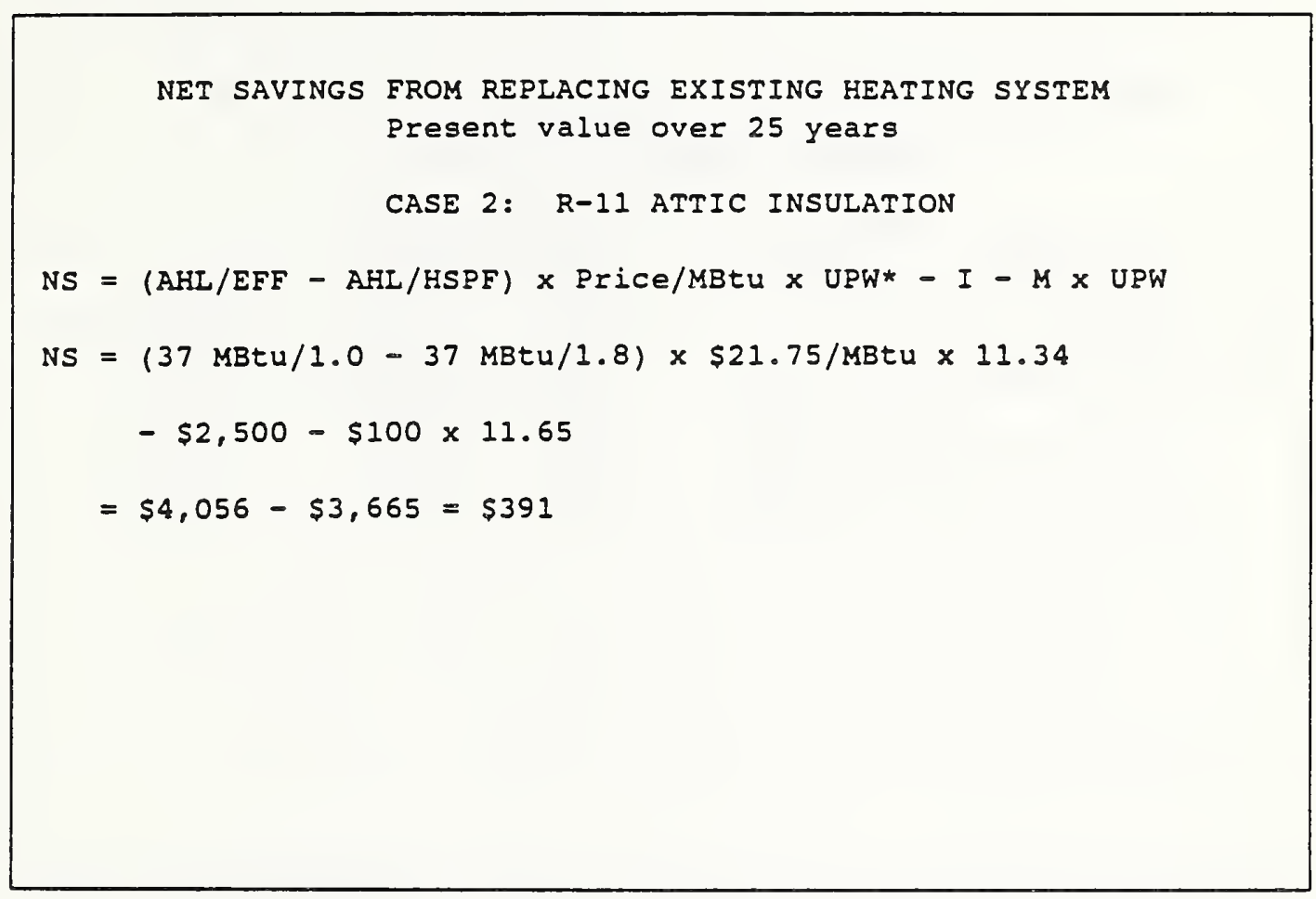

NOTES: 
MODULE F, CONTINUED

SLIDE $F-13$

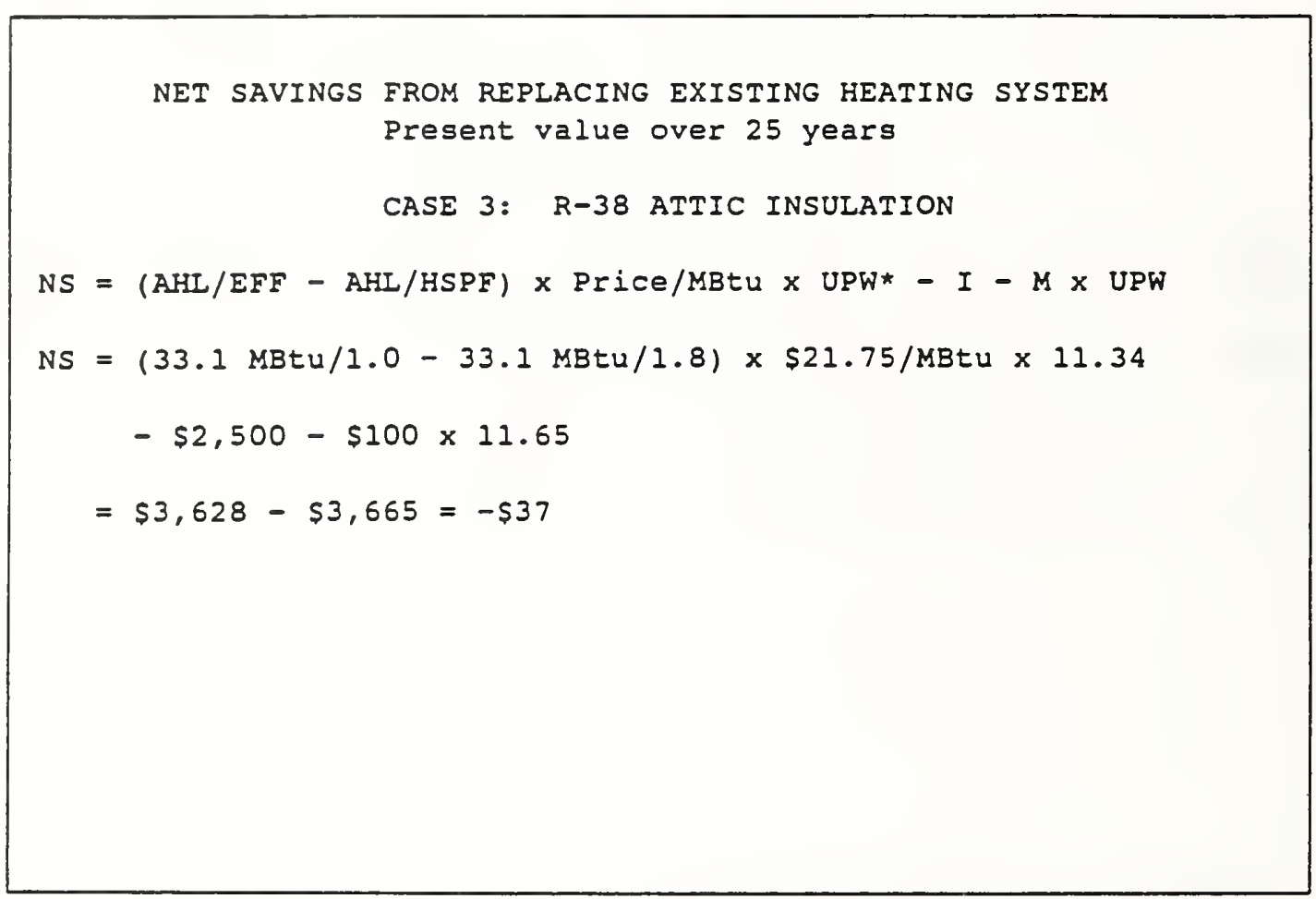

NOTES: 
MODULE F, CONTINUED

SLIDE F-14

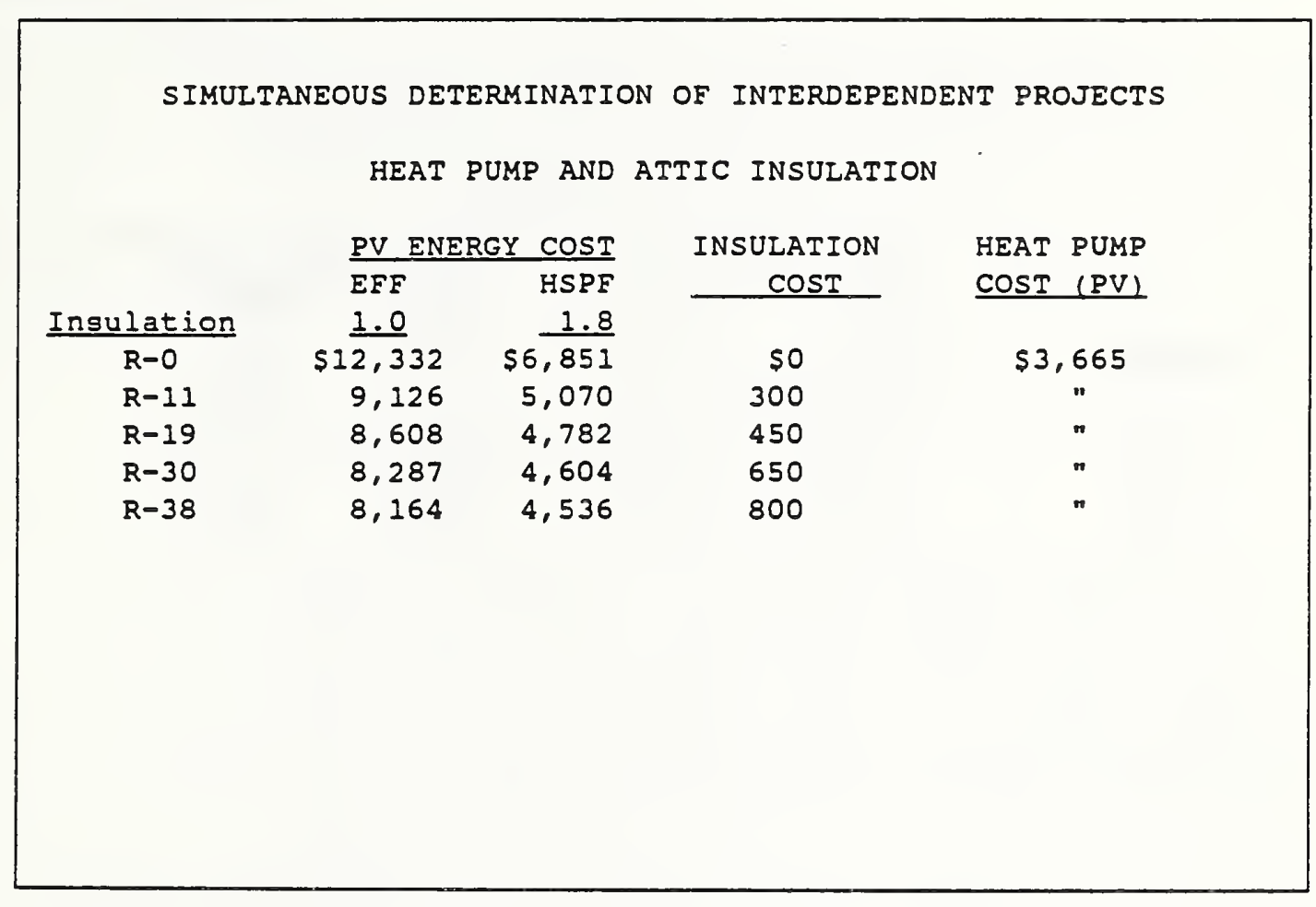

NOTES: 
MODULE F, CONTINUED

SIIDE $F-15$

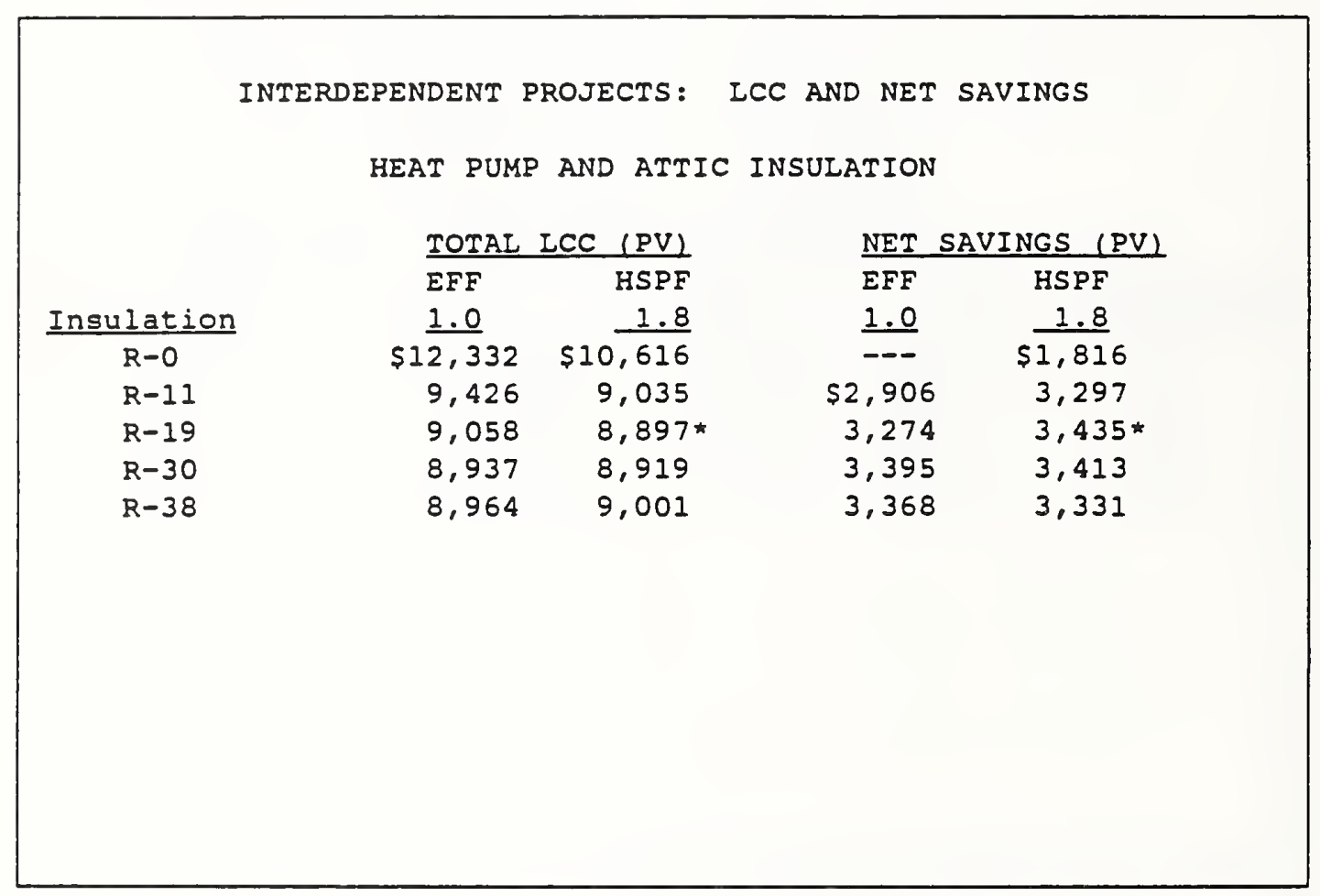

NOTES: 
MODULE F, CONTINUED

\section{INDEPENDENT SYSTEMS}

Slides F-2 through F-8 show how to find the cost-effective level of insulation in a house on a military base in ohio using the Ns method. The Ns method is convenient to use because the energy data are expressed as load reductions or savings. But the ICC method could also easily be used by starting with the base AHL and subtracting from it the reduction for each increment in insulation to derive AHIs for each level of insulation.

- Slide F-2 gives data.

- Slide $\mathrm{F}-3$ shows that the annual energy requirement is calculated as the annual heating load divided by the efficiency of the heating system. This means there will be interdependence between actions taken on the envelope to reduce the load and actiong taken to raise the heating system's efficiency.

- Slides F-4 through F-7 show how to calculate net savings (NS) from each additional increment of insulation. Slide $F-8$ summarizes the results of slides $F-4$ through $F-7$ and shows the level of insulation which maximizes net savings. It is R30. Past that point, additional increments result in net losses. Note that the level of energy conservation which provides the greatest Btu energy gavings may not be the level which provides the greatest dollar net savings. Also note the correspondence between results of the incremental NS approach and the total NS approach. 
MODULE F, CONTINUED

\section{INDEPENDENT SYSTEMS}

If there is no budget constraint, $\mathrm{R} 30$ is the cost-effective sizing choice. A budget less than $\$ 650$ would make it necessary to cut back to an affordable level.

- Slide F-9 demonstrates that the SIR based on total costs and savings is not for sizing. However, used incrementally, the SIR gives results consistent with the ICC and NS methods. Size increments having SIRs greater than 1.0 are costeffective.

\section{INTERDEPENDENT SYSTEMS}

Replacing the electric resistance heating system with a heat pump having a seasonal coefficient of performance of 1.8 , would reduce the annual kwh consumption of the house. Slide F-10 states assumptions. Slide F-11 shows the cost, savings, and net savings of replacing the heating system, assuming the insulation has not yet been added.

- Slides F-12 and F-13 show net savings of heat pump replacement with $\mathrm{R} 11$ and $\mathrm{R} 38$ attic insulation. Heat pump is not cost effective when $R 38$ attic insulation is present.

- Slide F-14 shows present value costs of energy, insulation, and heat pump at each insulation level.

- Slide F-15 shows LCC and net savings for each combination of insulation and heating system. Heat pump and RI9 has the lowest LCC and highest NS.

NOTE: Pages 189 to 196 have been deleted. 


\section{PROBLEM F-1}

Use LCC or NS to Choose Among Single-, Double-, and Triple-Glazed Windows

Assumptions:

$\begin{array}{cccc}\begin{array}{c}\text { Purchase } \\ \text { \& Installation }\end{array} & & \text { Annual } & \Delta \text { Annual } \\ \text { Cost } & \Delta \text { Cost } & \text { Heating } & \text { Load } \\ (S) & (S) & \text { Heating } & \text { Load } \\ & \end{array}$

Single-Glazed Windows

$\begin{array}{rrrr}2,000 & 2,000 & 60 & \\ 2,800 & 800 & 50 & -10 \\ 3,400 & 600 & 48 & -2\end{array}$

Furnace efficiency:

0.75

Fuel:

Distillate 0il

Initial Price of 0il: $\quad \$ 8.00 / \mathrm{MBtu}$

Location:

Vermont

Type of Building:

Park Service, Ranger's House (Commercial Pricing)

All costs other than purchase and installation and energy are identical.

Estimated life:

Indefinite 


\section{DETERMINING PROJECT PRIORI TY}

MODULE G 60 Minutes
Lecture, Illustration, and Exercise

OBJECTIVES

At the conclusion of this module, you are expected to be able to

- use the SIR method to allocate a budget among independent projects. 
MODULE G; CONTINUED

\section{SIR USEFUL FOR ASSIGNING PRIORITY}

SLIDE G-1

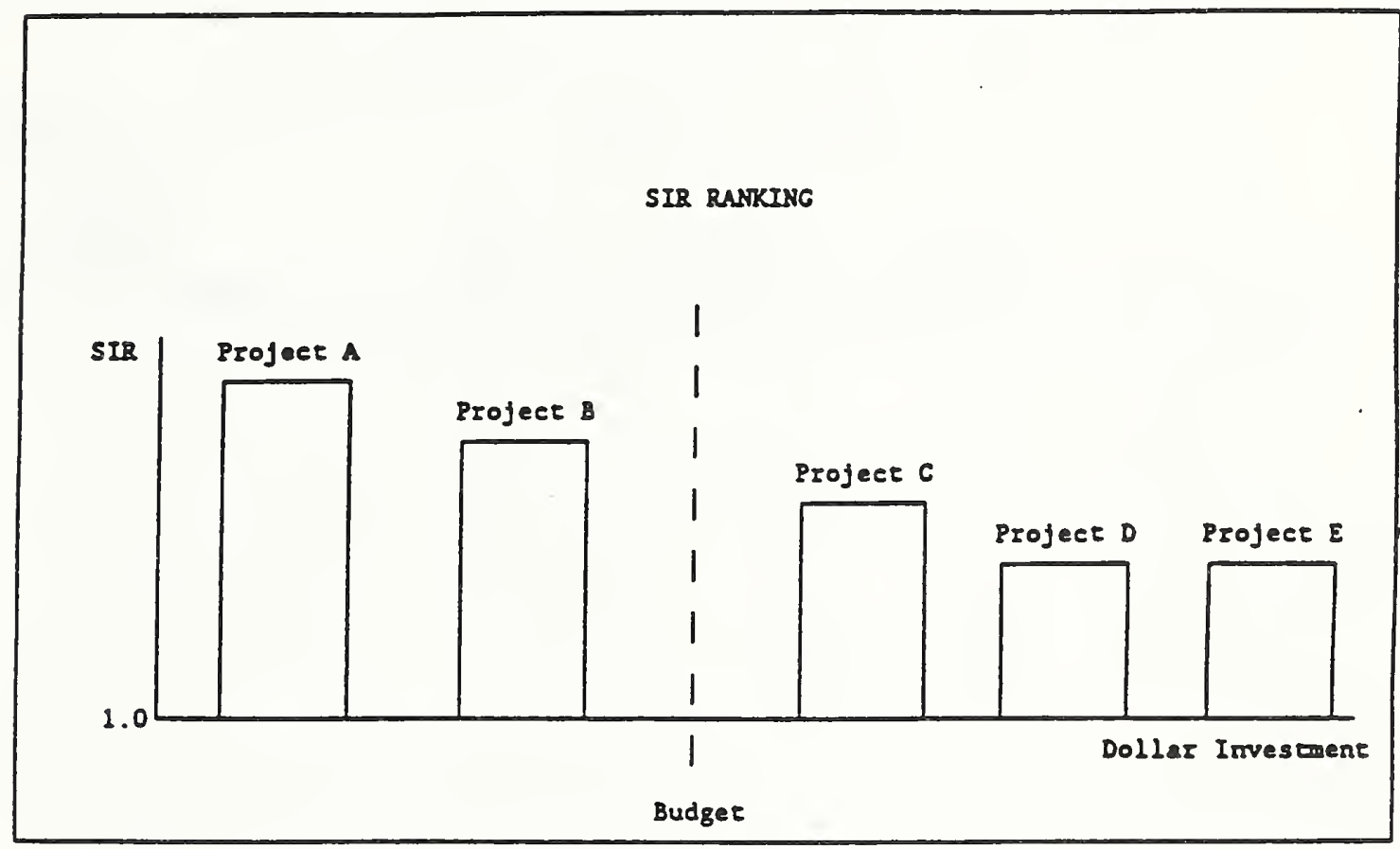

NOTES : 
MODULE G, CONTINUED

SLIDE G-2

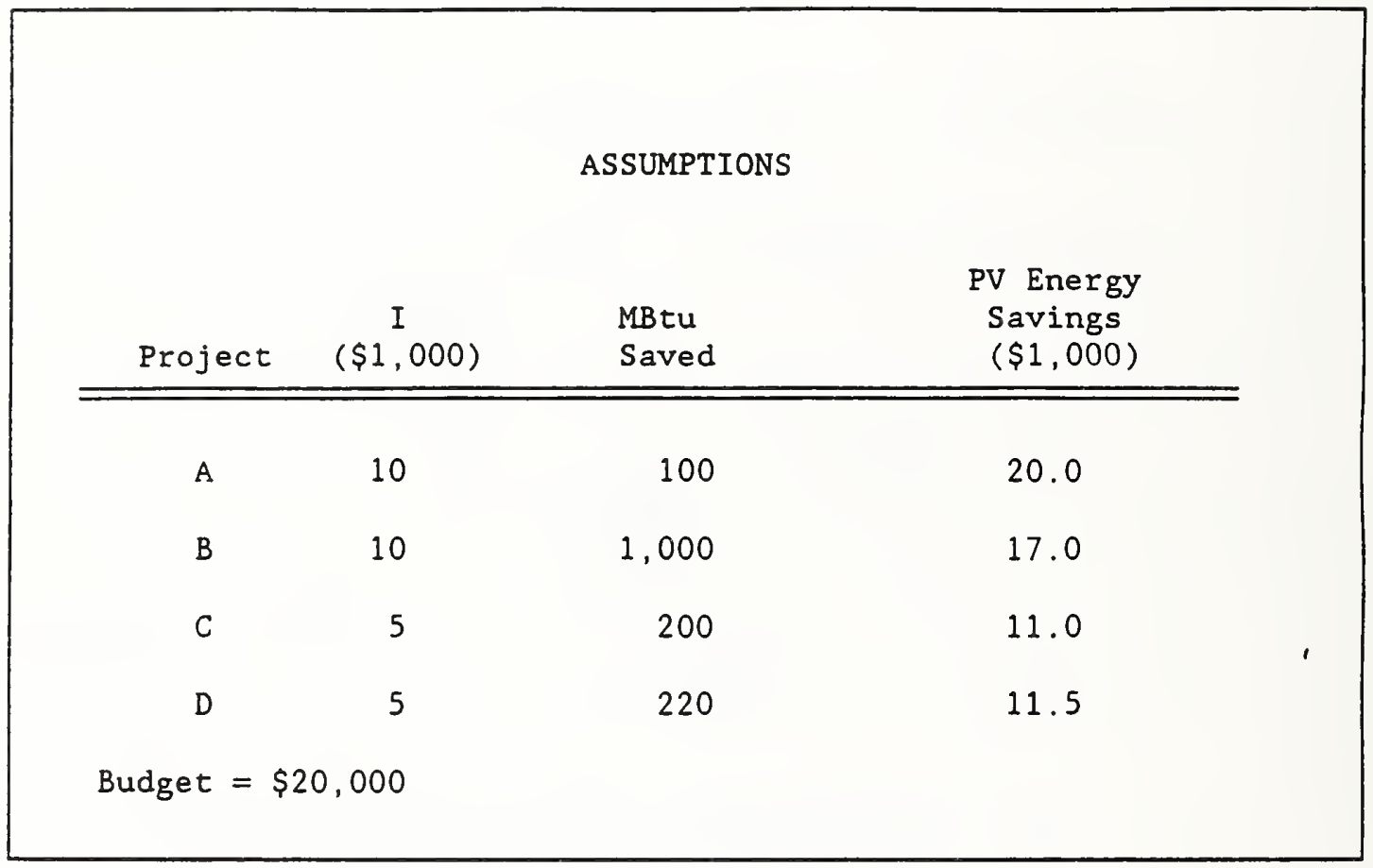

NOTES: 
MODULE G, CONTINUED

SLIDE G-3

\begin{tabular}{|c|c|c|c|c|c|}
\hline \multicolumn{6}{|c|}{ RANKING BY BTU/I } \\
\hline Project & $\begin{array}{c}I \\
(\$ 1,000)\end{array}$ & $\begin{array}{l}\text { MBtu } \\
\text { Saved }\end{array}$ & $\begin{array}{l}\text { MBtu/ } \\
1,000\end{array}$ & Rank & \\
\hline A & 10 & 100 & 10 & 4 & \\
\hline B & 10 & 1,000 & 100 & 1 & \\
\hline C & 5 & 200 & 40 & 3 & ' \\
\hline$D$ & 5 & 220 & 44 & 2 & \\
\hline
\end{tabular}

NOTES: 
MODULE G, CONTINUED

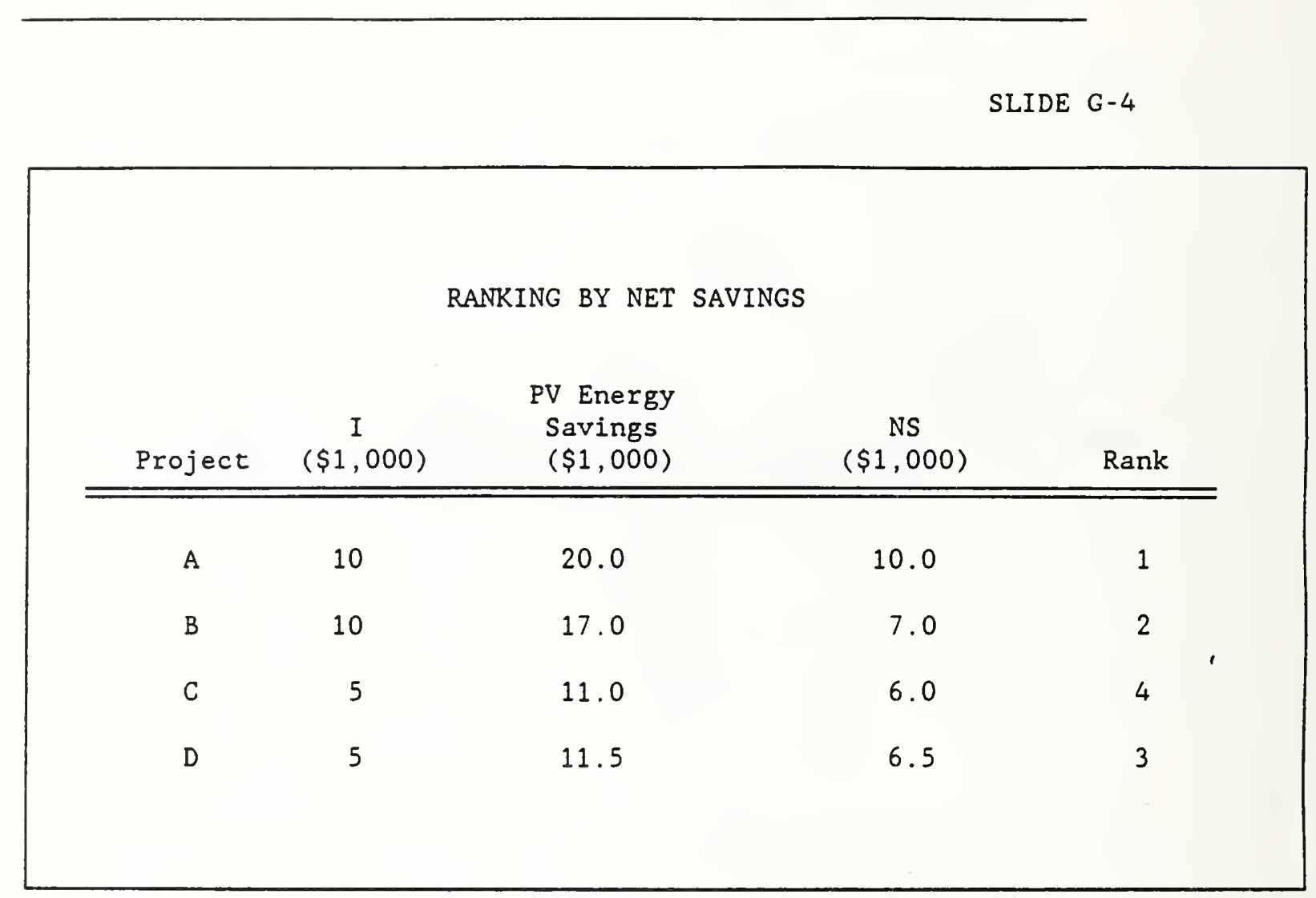

NOTES : 
MODULE G, CONTINUED

SLIDE G-5

\begin{tabular}{|c|c|c|c|c|c|}
\hline & & RANKING BY SIR & & & \\
\hline Project & $\begin{array}{c}I \\
(\$ 1,000)\end{array}$ & $\begin{array}{l}\text { PV Energy } \\
\text { Savings } \\
(\$ 1,000)\end{array}$ & SIR & Rank & \\
\hline A & 10 & 20.0 & 2.0 & 3 & \\
\hline B & 10 & 17.0 & 1.7 & 4 & \\
\hline C & 5 & 11.0 & 2.2 & 2 & ' \\
\hline$D$ & 5 & 11.5 & 2.3 & 1 & \\
\hline
\end{tabular}

NOTES : 
MODULE $G_{\bar{i}} \cdot$ CONTINUED

SLIDE G-6

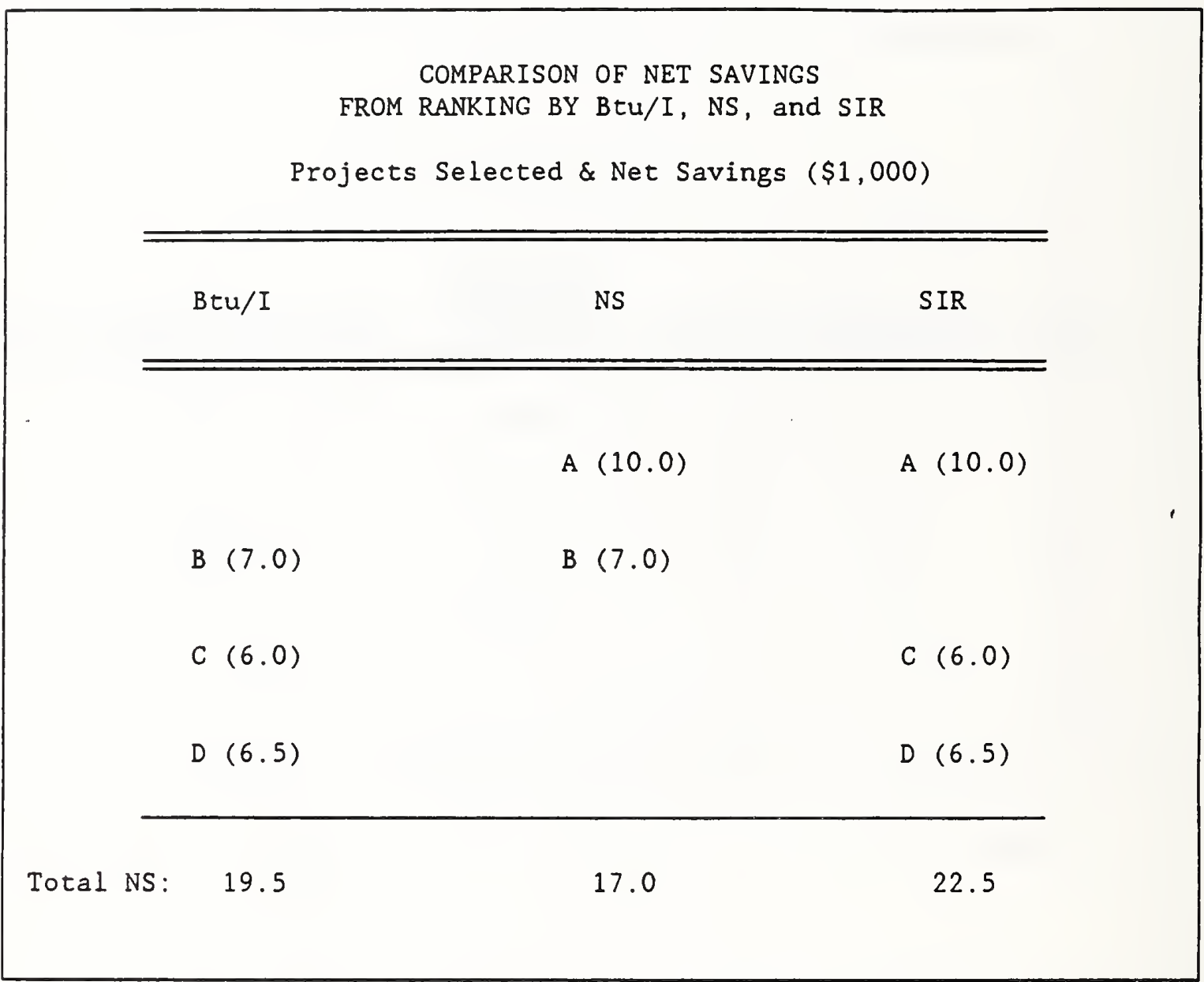

NOTES : 


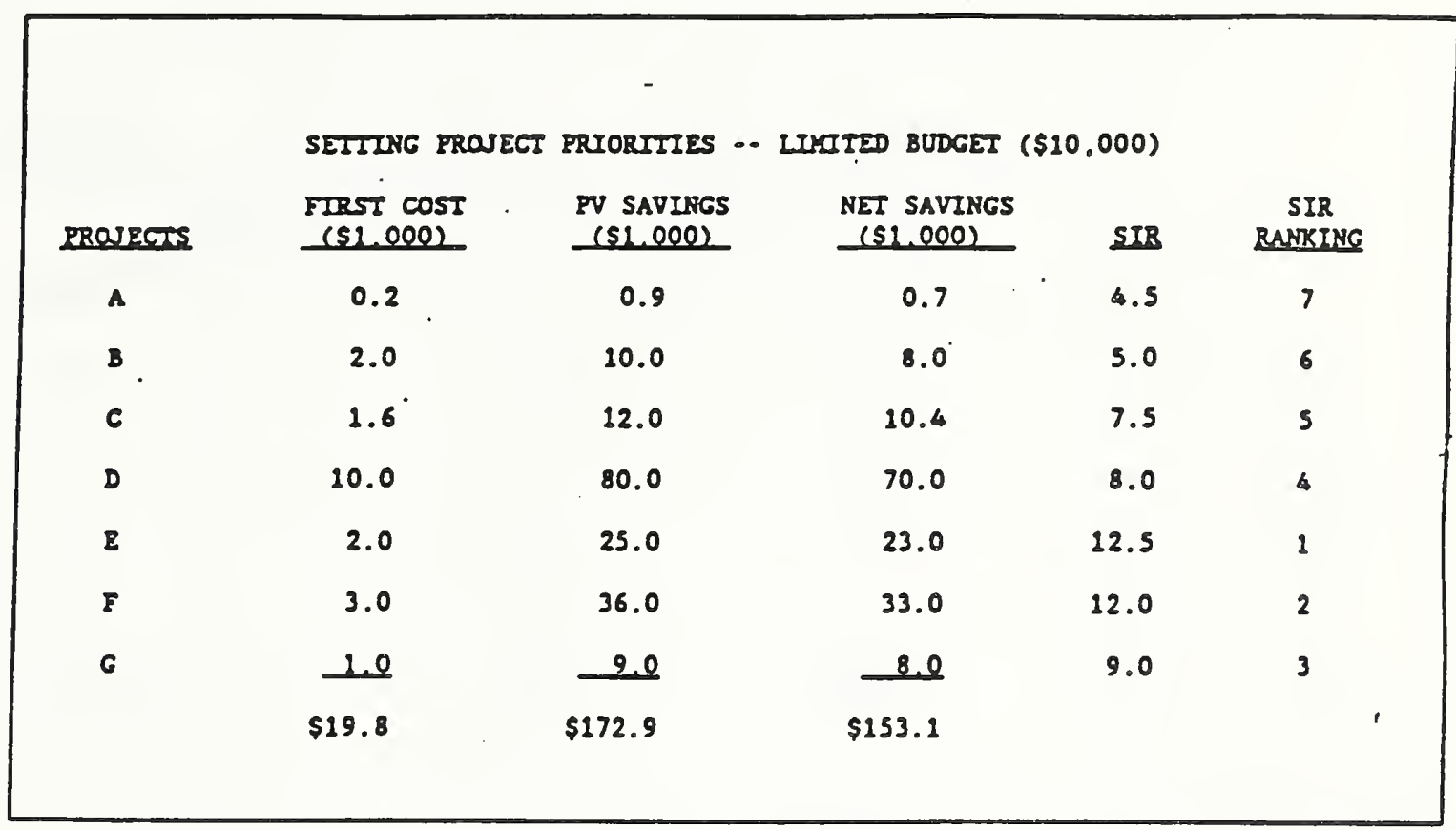

NOTES: 
MODULE G, CONTINUED

$=0$

SLIDE G-8

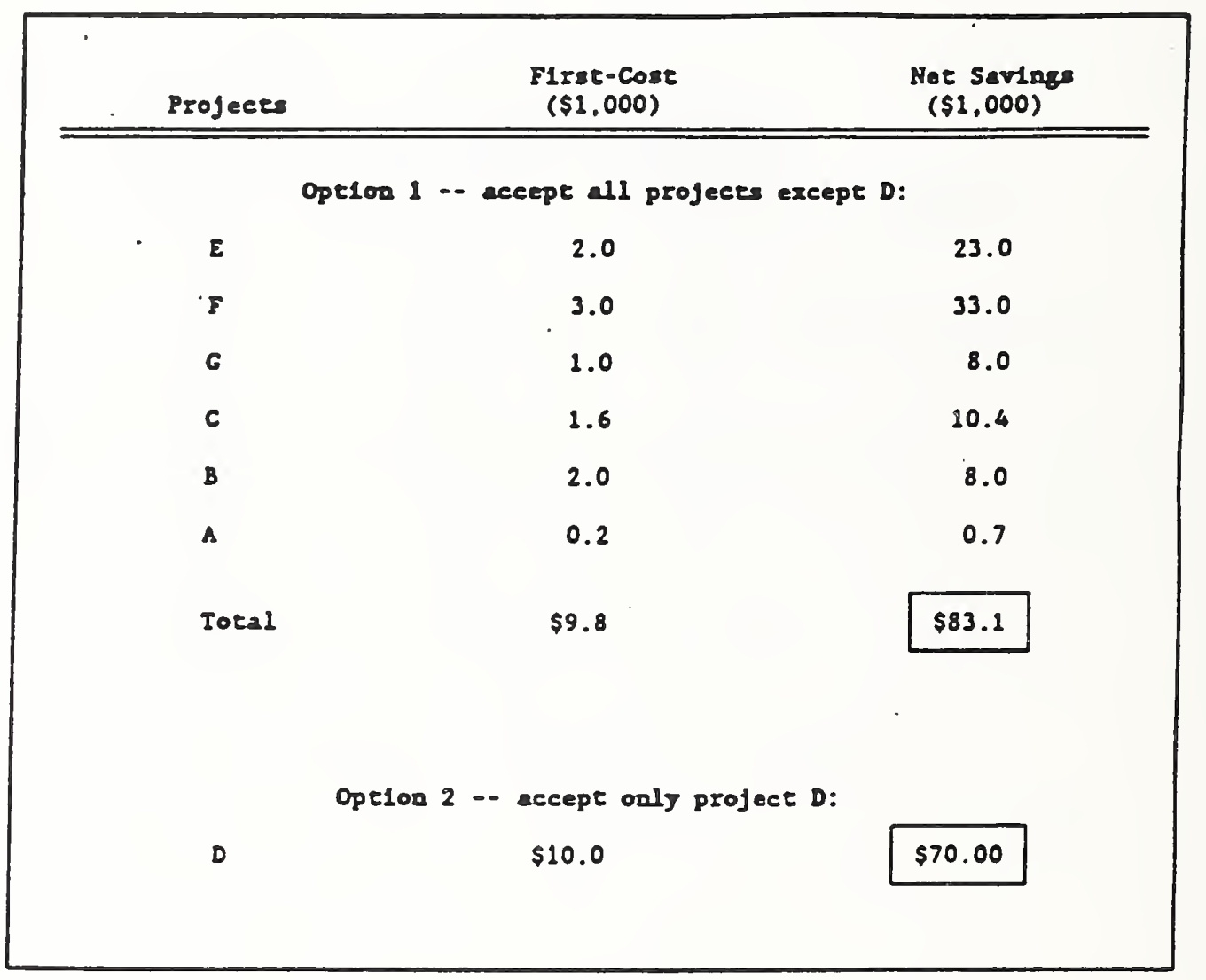

NOTES : 
SIIDE G.9

\begin{tabular}{|c|c|c|c|}
\hline \multicolumn{2}{|c|}{ Alocerlag a Budget Among } & \multirow{2}{*}{$\begin{array}{l}\text { of Variable S1ze } \\
\text { Fv Sevings } \\
(\$)\end{array}$} & \multirow{2}{*}{$\begin{array}{l}\text { Deen } \\
\text { RS } \\
(\$)\end{array}$} \\
\hline $\begin{array}{c}\text { Project } \\
\text { Altermetives }\end{array}$ & $\begin{array}{l}\text { Flrse Cose } \\
(\$)\end{array}$ & & \\
\hline$\Delta$ & 12,000 & 60,000 & 48,000 \\
\hline$B(1)$ & 5,000 & 15,000 & 10,000 \\
\hline$B(2)$ & 6,000 & 17,000 & 11,000 \\
\hline c & 6,000 & 5,000 & $-1,000$ \\
\hline D & 3,000 & 12,000 & 9,000 \\
\hline $\mathbf{E}$ & 8,000 & 12,000 & 4,000 \\
\hline$F$ & 5,000 & 14,500 & 9,500 \\
\hline
\end{tabular}

NOTES : 
MODULE $G$, CONTINUED

SLIDE G-10

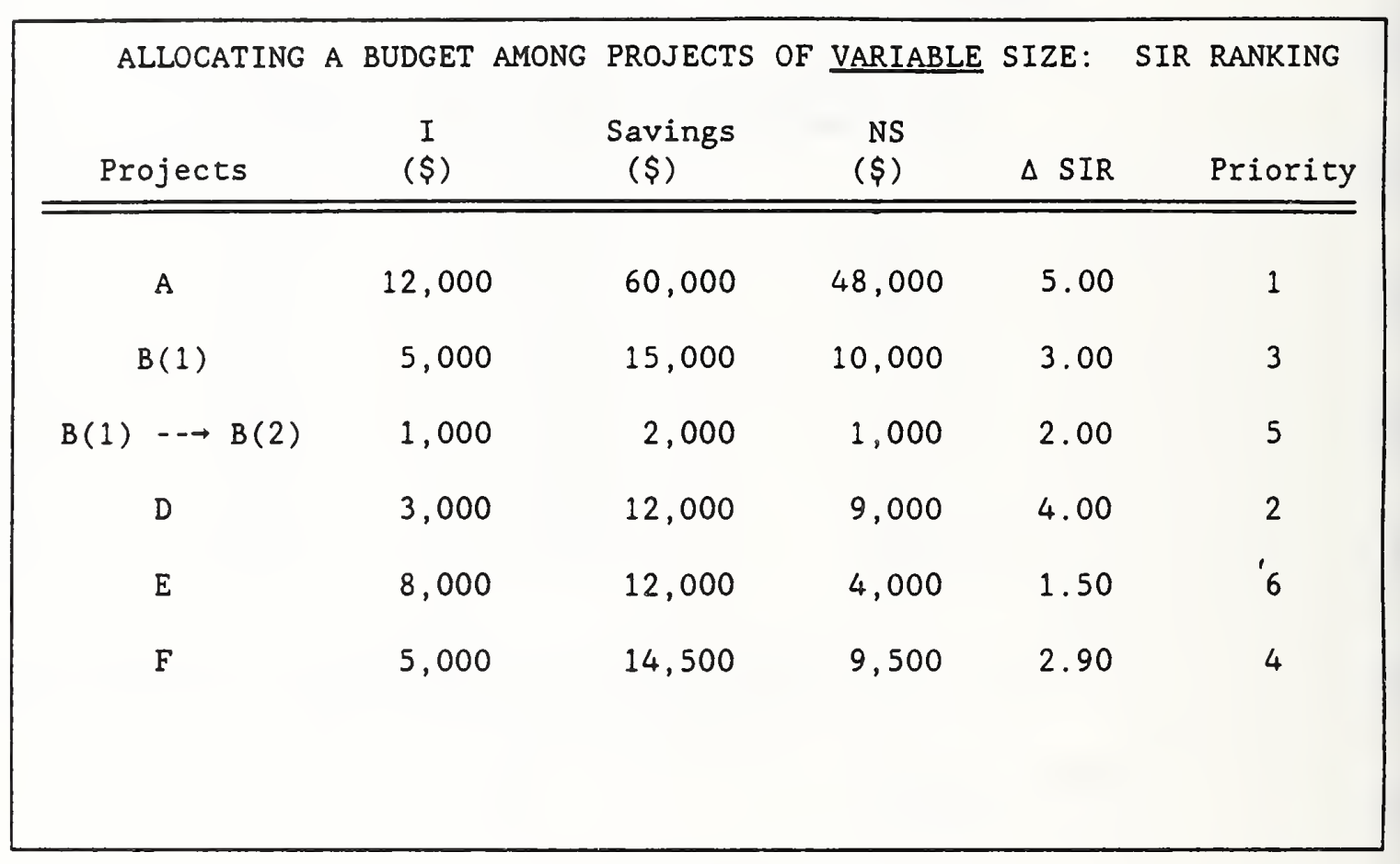

NOTES : 
MODULE $G$, CONTINUED

SLIDE G-11

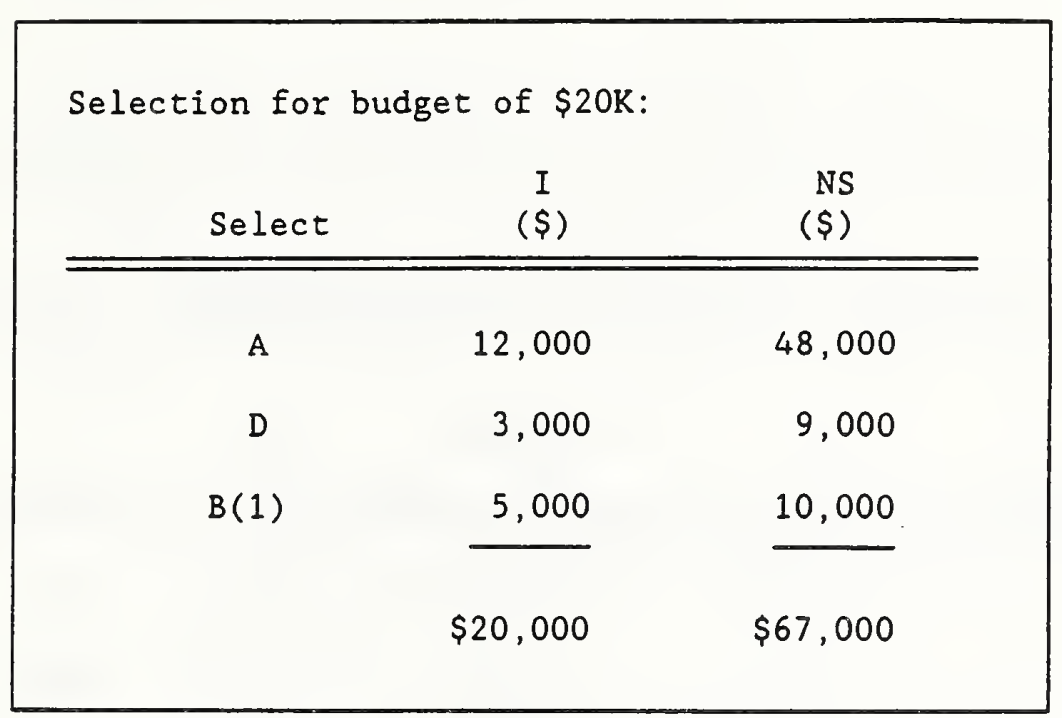

NOTES: 
MODULE G, CONTINUED

SLIDE G-12

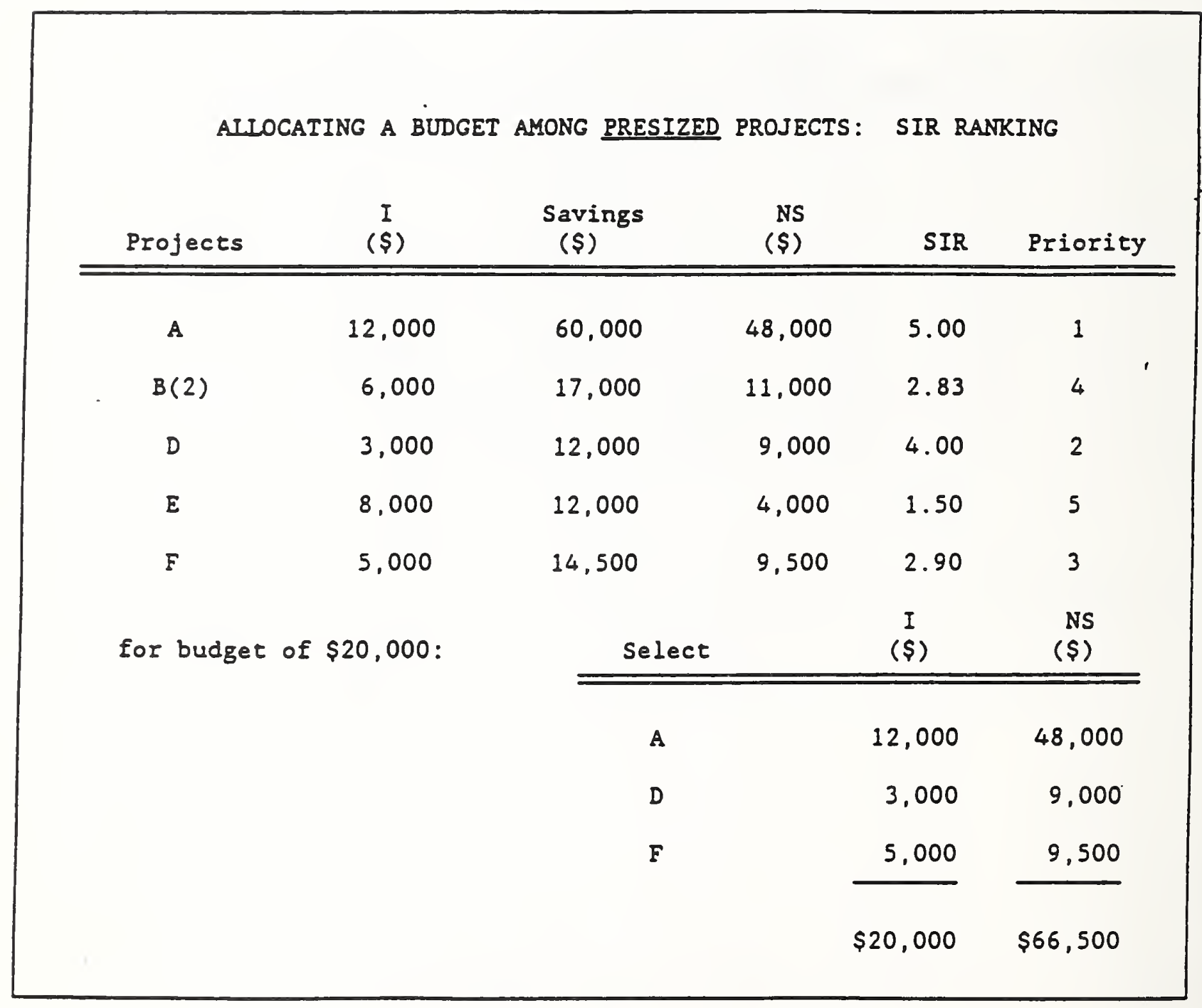

NOTES: 
MODULE G, CONTINUED

\section{SIR USEFUL FOR ASSIGNING PRIORITY}

The Savings-to-Investment Ratio (SIR) is useful for assigning priority to cost-effective projects when the budget is limited. ${ }^{1}$ Selecting projects in descending order of their SIRs can be relied on to maximize total net savings for the budget, provided the budget can be fully expended without departing from the SIR ranking.

- Slide G-1 depicts how projects are ranked in descending order of their SIRs and selected until the budget is exhausted.

The LCC and NS methods are not appropriate for assigning funding priority to individual projects. It may seem a paradox that assigning highest priority to projects with the greatest individual net savings will usually not maximize total net savings for the budget.

Furthermore, assigning highest priority to projects with the greatest Btu savings per investment dollar (Btu/I) will usually not maximize total net savings for the budget. The Btu/I measure treats all Btus as equal, ignoring that it is more economic to save expensive electricity Btus in New York City than inexpensive coal Btus in Ohio.

${ }^{1}$ The Adjusted Internal Rate of Return (AIRR) is also appropriate for assigning priority to cost-effective projects when the budget is limited. It may be used as an alternative ranking method. 
MODULLE G, CONTINUED

\section{SIR USEFUL FOR ASSIGNING PRIORITY, continued:}

- Slide G-2 gives investment cost, annual quantity of energy savings, and present value energy savings for four independent projects, A, B, C, and D. Project A saves electricity in New York City. Project B saves coal in West Virginia. Project $C$ saves natural gas in Iowa. Project $D$ saves distillate oil in Alaska.

- Slide G-3 shows project ranking by Btu/I. Note that B is ranked first; $D$, second; $C$, third; and $A$, fourth.

- Slide G-4 shows project ranking by NS. Note that $A$ is now first ranked; $B$ is second; $D$, third; and $C$, fourth.

- Slide G-5 shows project ranking by SIR. Note that $D$ is now first ranked; $C$ is second; $A$, third; and $B$, fourth.

- Slide G-6 compares total net savings resulting from each of the three rankings, assuming a total budget of $\$ 20 \mathrm{~K}$. Note that ranking by SIR gives a higher total NS $(\$ 22.5 \mathrm{~K})$ than ranking by Btu/I $(\$ 19.5 \mathrm{~K})$ or NS (\$17.0K).

\section{LIMITATIONS OF SIR FOR ASSIGNING PRIORITY}

"Lumpiness" in project costs may cause it not to be possible to fully exhaust the budget by taking projects exactly in descending order of their SIRs (or AIRRs). In this case, ranking by SIR may 
MODULE G, CONTINUED

LIMITATIONS OF SIR FOR ASSIGNING PRIORITY, continued

fail to identify the group of projects which will maximize overall net savings for the budget. Slides G-7 and G-8 illustrate this problem.

- Slide G-7 lists for seven independent projects, A through G, first cost, present value savings, net savings, SIR, and SIR ranking. Project costs total nearly $\$ 20,000$. Assume the available budget is only $\$ 10,000$. According to the SIR ranking, project E (SIR $=12.5$ ) is first chosen for an expenditure of $\$ 2,000$.

Next, project $F(S I R=12.0)$ is chosen for a total expenditure of $\$ 5,000$. Project $G(S I R=9.0)$ is chosen for a total expenditure of $\$ 1,600$. The next ranked project is project $D(S I R=8.0)$, but its cost, $\$ 10,000$, drives total cost over the budget.

The options are to (1) drop projects E, F, and G, and take only project $D$; or (2) take projects $E, F$, and $G$, skip over project $D$, and take the remaining projects, $C$, $B$, and $A$.

- Slide G-8 compares total net savings of option 1 (\$83.1) and option $2(\$ 70.0)$, and finds the former to be higher and, hence, preferable.

(Note that any funds left uninvested, such as the $\$ 200$ left uninvested by choosing alternative 1, are assumed 
MODULE G, CONTINUED

LIMITATIONS OF SIR FOR ASSIGNING PRIORITY, continued

to earn a rate of return equal to the discount rate, and, hence, add nothing to net savings.)

When it is necessary to depart from the SIR ranking to fully allocate the budget, a comparison of total NS of the various possible combinations of projects must be made to ensure that the combination which maximizes net savings is selected.

\section{ALLOCATING A BUDGET AMONG PROJECTS OF VARIABLE DESIGN/SIZE}

To maximize total net savings from investing in a group of projects of variable design and size, design/size decisions must be made jointly with budget allocation decisions. Slides G-9 through G-11 show how this can be done.

- Slide G-9 lists for six independent projects, A through $F$, first cost, present value savings, and net savings. One of the projects, $B$, can be done in a small size, designated $B(1)$, or in a larger size, designated $B(2)$. Size $B(2)$ costs $\$ 1,000$ more than $B(1)$ and saves $\$ 2,000$ more, which means that its net savings are $\$ 1,000$ higher than $B(1)$. If there is no budget limitation, clearly it pays to choose the larger size $B(2)$ over the smaller size $B(1)$. But if there is a budget constraint, the increment to project $B$ may be less worthwhile than a competing use of funds. 
MODŪLE G, CONTINUED

ALLOCATING A BUDGET AMONG PROJECTS OF VARIABLE DESIGN/SIZE, continued:

- Slide G-10 ranks the increment to project B (designated $B(1) \longrightarrow B(2)$ ) relative to the competing projects. It ranks fifth. For a budget of $\$ 15,000$, projects $A$ and $D$ are chosen. For a budget of $\$ 20,000$, projects $A, D$, and $B$ in its smaller size are chosen. For a budget of $\$ 25,000$, project $F$ is added. Only if the budget reaches $\$ 26,000$, is project $B$ selected in its larger size.

- Slide G-11 shows the budget allocation/sizing for a budget of $\$ 20,000$. Net savings are $\$ 67,000$.

- Slide G-12, for comparison, shows how net savings are less if project $B$ is sized first, without regard to the budget limitation. Project $B$ in its larger size is ranked fourth. For a budget of $\$ 20,000$, Projects A, D, and $F$ are selected, resulting in net savings of $\$ 66,500$. Note that net savings are lower than those obtained from the joint size/allocation solution.

When there is a single budget to be allocated, it is important to make design/size increments of projects compete for funding. But when there are a series of budgets to be allocated, it may be better, as a rule-of-thumb, to predesign/size projects as though there were no budget limitation, and then let those projects compete for funding as it becomes available. This approach will tend to result in slightly oversized projects, but ignoring future budgets will result in undersized projects. The economic 
$\therefore$

MODULE $G$, CONTINUED

ALLOCATING A BUDGET AMONG PROJECTS OF VARIABLE DESIGN/SIZE, continued:

efficiency loss will tend to be less by predesigning/sizing projects when there are a series of budgets. 


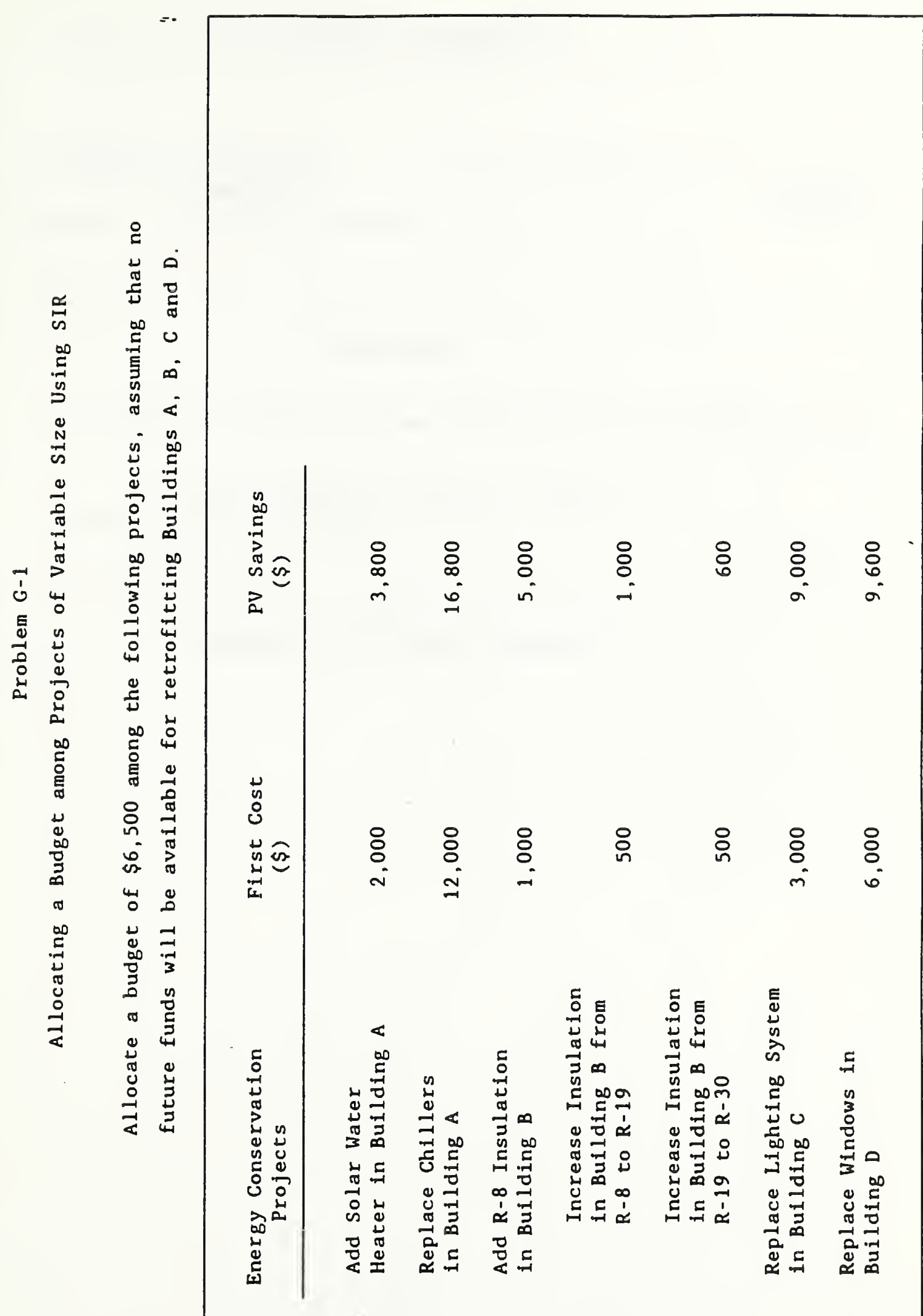

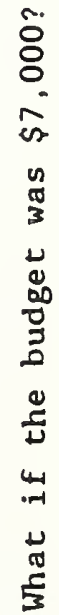




\section{UNCERTAINTY}

MODULE H

60 MINUTES

Lecture, Discussion, Class Problem

\section{OBJECTIVES}

At the conclusion of this module, you are expected to be able to

- perform sensitivity analysis; and

- make a decision under uncertainty in accordance with Federal criteria. 
MODULE $\mathrm{H}$, CONTINUED

SOURCES OF UNCERTAINTY

NOTES :

CONSEOUENCES OF UNCERTAINTY

NOTES : 
MODULE $\mathrm{H}^{\sim}$, CONTINUED

WHAT TO DO ABOUT UNCERTAINTY

NOTES : 
MODULE H-- CONTINUED

SLIDE H-1

TECHNIQUES THAT ACCOUNT FOR UNCERTAINTY,

RISK, OR BOTH

1. conservative benefit and

6. input estimate using cost estimating expected values

2. breakeven analysis

7. mean-variance criterion and coefficient of variation

3. sensitivity analysis

8. decision analysis

5. certainty equivalent technique

9. simulation

10. mathematical/analytical technique

NOTES : 
MODULE $\mathrm{H}$, CONTINUED

SLIDE $\mathrm{H}-2$

SENSITIVITY ANALYSIS IS PERFORMED --
by repeating an economic evaluation
with one or more input values changed.

(It may be used with any of the five evaluation methods.)

NOTES: 
MODULE H, CONTINUED

SLIDE $\mathrm{H}-3$

\section{SENSITIVITY ANALYSIS}

used to --

(1) identify critical data inputs

(2) estimate range of results

(3) answer "what if" questions

NOTES : 
MODULE $\mathrm{H}$, CONTINUED

SLIDE $\mathrm{H}-4$

\section{IDENTIFY CRITICAL INPUTS}

108 change in input

input 1

input 2

* input 3
8 change in output

2

10

20

Conclusion: devote more resources to improving data estimates for input 3 than input 1.

NOTES: 
MODULE H, CONTINUED

SLIDE $H-5$

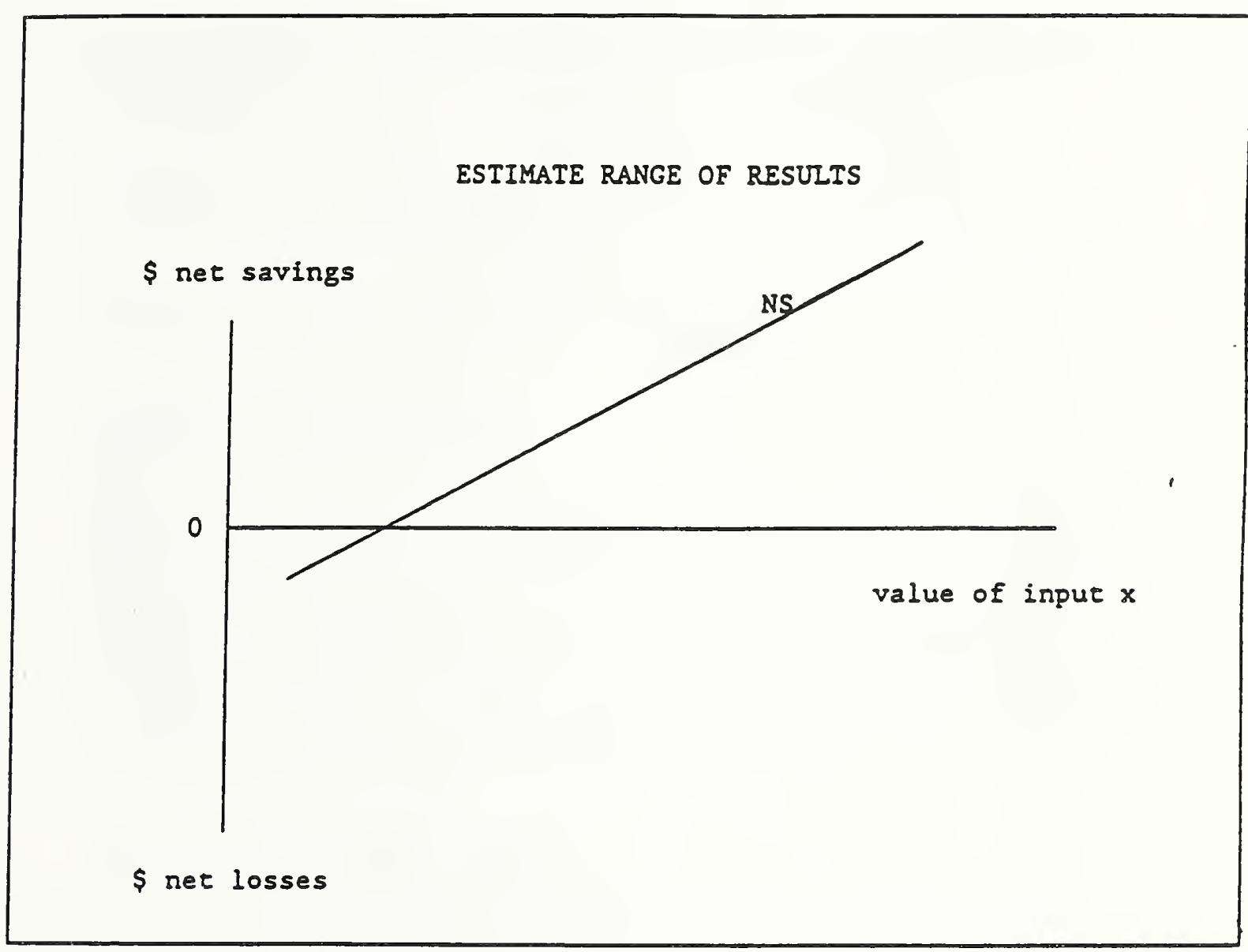

NOTES : 
MODULE H, CONTINUED

SLIDE H-6

"WHAT IF?"

scenario

1

2

3

4
$\underline{\mathrm{NS}}$

$\$ 10,000$

5,000

$-1,000$

3,000

NOTES: 
MODULE H, CONTINUED

\section{SOURCES OF UNCERTAINTY}

Economic evaluations which take a life-cycle perspective are based on projections and are, by nature, subject to uncertainty. There are usually uncertainties, for example, about the costs of constructing or purchasing and installing energy conservation systems, the quantity of energy saved, the time over which savings will continue, the future price of energy, and the costs of operating and maintaining systems over time.

\section{CONSEOUENCES OF UNCERTAINTY}

Uncertainty in input values means that actual outcomes may differ from estimated outcomes. Uncertainty may cause us to reject cost-effective projects, or accept projects that result in lower net savings than estimated or incur net losses. In short, uncertainty in input values creates risk that a decision will have a less favorable outcome than what is expected.

\section{WHAT TO DO ABOUT UNCERTAINTY}

The Presence of Uncertainty is not Cause to Abandon a Life-Cycle Approach:

Uncertainty in life-cycle cost analysis may cause you to think it is better to base decisions on first costs only, because they tend to be more certain. Consider, however, that a first-cost approach to decision making has in it the implicit assumption that future costs are zero. This is a poor assumption. Usually we can 
MODULE H, CONTINUED

Deterministic Approaches to Economic Evaluation Ignore Dncertainties:

Deterministic life-cycle cost analysis provides the decision maker with no information about the degree of uncertainty and associated risk. Using "best-guess estimates" as single input values to life-cycle costs and ignoring that the values are uncertain result in a single-value output.

Techriques for Treating Uncertainty and Risk:

There are a variety of techniques for treating uncertainty and risk which can improve decision making with life-cycle cost analysis. Slide $\mathrm{H}-1$ lists 10 techniques. These techniques are described and their use illustrated in a 1988 report. (See H. E. Marshall, Iechniques for Ireating Uncertainty and Risk in the Economic Evaluation of Building Investments, National Institute of Standards and Technology, NIST Special Publication 757.)

In the limited time of the course, we will focus on one of the rechniques:

Sensitivity Analysis. It is easy to perform, easy to use, is practical, and can aid in making decisions in the face of uncertainty. Sensitivity analysis requires no additional methods of computation beyond those already treated in the course. Slides H-2 through $H-6$ describe sensitivity analysis.

- Slide H-2 explains how to perform sensitivity analysis. 
MODULE H, CONTINUED

Techniques for Treating Dncertainty and Risk, continued:

- Slide H-3 lists three purposes for which sensitivity analysis is performed:

(1) To identify critical data inputs, test the percentage change in the output value in response to a specified percentage change in each input value; e.g., the percentage change in ICC in response to a 108 increase in residual value.

(2) To estimate the range within which an output will occur, calculate a lower bound for the output value based on pessimistic input values and an upper bound based on optimistic input values.

(3) To answer "what if" questions, calculate output values based on different scenarios which a decision maker, or those with review responsibility, wight have.

- Slide H-4 illustrates the use of sensitivity analysis to identify critical input values.

- Slide H-5 illustrates using sensitivity analysis to estimate the range within which the output will occur. Input $x$ might, for example, be the quantity of energy saved each year and the lower and upper boundaries might be high and low construction cost, respectively.

- Slide H-6 illustrates using sensitivity anslysis to provide answers to "what if" questions. 
MODULE H, CONTINUED

$=$.

Federal Criteria Regarding Oncertainty:

If uncertainty analysis casts substantial doubt on the results of life-cycle cost analysis, Federal agencies are advised to obtain more reliable inpur data, or eliminate the project.

Federal agencies are directed to use the DOE energy price projections and discount rate as published, without testing for sensitivity. 
MODURE H, CONTINUED

PROBLEM H-1

Taking Into Account Uncertainties

Use ICC with sensitivity analysis to evaluate the cost-

effectiveness of retrofitting a computer room with a waste heat recovery system to supply part of the heating load of the building.

$\underline{\text { Date }}$

Location:

Wyoming

Building:

Federal Building

Installed Cost of Waste Heat

Recovery System:

$\$ 6,000$

Yearly Maintenance and Repair

Cost of Waste Heat Recovery

System:

$\$ 500$

Heating Load:

900 MBEL

Existing Fuel:

Natural Gas

Today's Price:

$\$ 5.15 /$ MBtu (Commercial Pricing)

Efficiency of Existing System:

0.65

Contribution of Waste Heat

Recovery System to Building's

Heating Load:

258 (Best Guess)

108 (Worst Case)

Expected Period of Use:

Indefinite 


\section{REVIEW}

MODULE I

60 MINUTES

Questions and Answers

\section{OBJECTIVES}

In this review, you are expected to be able to

- summarize how to perform an economic evaluation; and

- answer correctly selected questions about the evaluation process. 
MODULE I, CONTINUED

NOTES: 


\section{COMPUTER LAB: USING BLCC (Revised*)}

MODULE J

75 minutes

computer lab

objectives

By the end of this module, you are expected to be able to

- use BLCC to find the economic size of a building system

- combine interdependent systems in a BLCC analysis

- This revised module supersedes module J in the "Life-Cycle Costing for Energy Conservation in Buildings: Students Manual," NISTIR 89-4130, National Institute of Standards and Technology, Gaithersburg, MD, August 1989 


\section{BLCC Lab Problem J-1 (revised)}

\section{Sizing Attic Insulation}

Use BLCC to determine the level of attic insulation with the lowest life-cycle cost for a federally-owned, single-family house with electric resistance heating, located in the suburbs of Washington, D.C. (Census Region 3). Assume a life of 25 years, and no resale value. Use the following insulation cost and space heating load schedule:

Attic Insulation

Level Total Cost

$\begin{array}{ll}R-0 & \$ 0 \\ R-19 & \$ 440 \\ R-30 & \$ 650 \\ R-38 & \$ 800\end{array}$

Annual space Heating kWh

Baseboard $\operatorname{COP}=1.0$

Current electricity cost (residential rates) $=\$ 0.075 / \mathrm{kWh}$

Energy conversion efficiency $=100 \%(\operatorname{COP}=1.0)$

Suggested Approach:

Create an input data file (suggested filename $=R 0$ ) for the zero insulation case. This base case will have no investment cost (i.e., no capital component), no maintenance, and no resale value, but will have annual energy consumption based on the space heating requirements shown above. This base case file can then be modified to create files for each insulation level, based on the insulation costs and corresponding space heating requirements. Remember, you must have a separate data file for each level of insulation. LCC output files will automatically be created when each input data file is saved. Use "Lowest LCC" from main menu to determine which $\mathrm{R}$-value has the lowest LCC. 
Combining Heating System Replacement

with Attic Insulation

Use BLCC to evaluate the cost effectiveness of replacing the electric resistance heating system in the house described in Problem J-1 with a heat pump having a seasonal COP of approximately 2.0. Use the new space heating $\mathrm{kWh}$ data shown below. Then determine the economic level of insulation for the house with the heat pump. Since there are two components in this new case (insulation and heating system), you should create a new base case file (suggested name ROHP) that includes both R-0 insulation and a heat pump. Create separate files for each additional level of insulation to be evaluated. Use "Lowest LCC" function from main menu to determine which combination has the lowest overall LCC.

\begin{tabular}{cc} 
Attic & Insulation \\
\cline { 1 - 1 } Level & Total Cost \\
R-0 & $\$ 0$ \\
R-19 & $\$ 440$ \\
R-30 & $\$ 650$ \\
R-38 & $\$ 800$
\end{tabular}

Annual Space Heating kWh

Heat pump $C O P=2.0$

Cost of Heat Pump Installed:

7354

5157

4952

4878

Seasonal Coefficient of Performance of Heat Pump (Heating)

Annual Maintenance cost of Heat Pump:

$\$ 3,000$

2.0

Annual Maintenance cost of

Electric Resistance System

Expected System Lives:

$\$ 100$

Resale value

$\$ 0$

25 years

\$0 


\section{APPENDIX A}

ADDITIONAL PROBLEMS

Appendix Problem 1: Design Problem

Appendix Problem 2: Sizing and Ranking Problem

Appendix Problem 3: Deciding Whether a Building Investment is Subject to FEMP Guidelines and Taking into Account a Delay in Construction 
$=$ 
APPENDIX PROBLEM 1

Building Design Problem

An energy-conserving building design ( $A$ ) is being considered as an alternative to a conventional building design (B) for a Federal office building in Madison, Wisconsin (Census Region 2). The two designs are approximately equivalent in total assignable and auxiliary spaces and in functional performance with respect to the purpose of the building. Each has two underground levels for parking and seven office floors, plus a mechanical house. Each has a floor area of approximately $176,000 \mathrm{ft}^{2}$ (gross).

The two designs differ primarily in the envelope, building configuration, orientation, and lighting systems. The energyconserving design is slightly elongated on the east-west axis for greater exposure of the south side to solar radiation. The window area of the energy-conserving side is 258 of the wall area and most of that is located on the south side; in the conventional building, it is $40 \%$. More massive exterior surfaces are used and insulation is increased, reducing the wall $U$ value from 0.16 to 0.06 and the roof $U$ value from 0.15 to 0.06 . Horizontal window fins reduce the summer cooling load of the energy-conserving design. The north wall of the first floor of the energy-conserving design is earth-bermed. It is assumed that both designs will last at least 25 years, and they are both assumed to have no salvage value remaining at the end of the 25 -year study period.

Based on the data given on the following page, determine which design has the lowest life-cycle cost. 
APPENDIX PROBLEM 1, continued

Energy-Conserving Conventional

Design

Design

(A)

(B)

(a) Site acquisition costs:

(To ensure adequate exposure

of south-facing windows, an

additional acquisition cost of

$\$ 100,000$ is necessary for the

energy-conserving design.

Other site costs are assumed $\$ 2,100,000$

$\$ 2,000,000$

to be identical for the two

designs, and hence, are not shown. )

(b) Architectural and Engineering

Design Fees and Construction

Costs

$\$ 9,780,000$

$\$ 9,130,000$

(c) Annual Energy Consumption:

Natural Gas

Electricity

2,290 MBtu

3,886 MBtu

(d) Energy Prices:

Natural Gas

Electricity

(e) Nonfuel O\&M Costs:

Recurring Annual Cost: $\$ \$ 70,000$

Repairs to External

Surfaces Every 10

Years
$\$ 5.49 / \mathrm{MBtu}$

$\$ 21.21 / \mathrm{MBtu}$

$\$ 60,000$
$\$ 90,000$

4,980 MBtu

7,277 MBtu

$\$ 5.49 / \mathrm{MBtu}$

$\$ 21.21 / \mathrm{MBtu}$

$\$ 100,000$ 
Approximately $100 \mathrm{ft}$ of hot water pipes running through the basements of each of 10 buildings of a Federal laboratory facility in Massachusetts have been found to be uninsulated. Data and assumptions are as follows:

Footage of Uninsulated Pipe: $100 \mathrm{ft} / \mathrm{Bldg} \times 10 \mathrm{Bldgs}=1,000 \mathrm{ft}$ Required Water Temperature: $180^{\circ}$

Pipe Size: $11 / 2$ " Diameter

Operation: $4 \mathrm{hr} /$ day $\times 260$ days $/ \mathrm{yr}=1,040 \mathrm{hrs} / \mathrm{yr}$

Type of Energy: Distillate Oil

Agency Base-Year Price of Distillate: $\$ 7.00 / \mathrm{MBtu}$

Plant Efficiency: 0.55

Remaining Building Life: Indefinite

Insulation Life: Indefinite

Study Period: 25 years

Available Insulation Choices: 1" or 2" of Fiberglass

Heat Loss Rates ${ }^{1}$-. Uninsulated 1 1/2" Pipe: $150 \mathrm{Btu} / \mathrm{hr} / \mathrm{ft}$

1" Insulated 1 1/2" Pipe: $20 \mathrm{Btu} / \mathrm{hr} / \mathrm{ft}$

2" Insulated 1 1/2" Pipe: $12.5 \mathrm{Btu} / \mathrm{hr} / \mathrm{ft}$

Pipe Insulation Costs -- 1" Insulation: $\$ 3.60 / \mathrm{ft}$ installed cost 2" Insulation: $\$ 6.00 / \mathrm{ft}$ installed cost

The following questions are to be answered:

(1) Would it be cost-effective to insulate the pipes?

(2) How much insulation should be added, 1 or 2 inches?

${ }^{1}$ Estimated from U.S. Department of Energy, Architects and Engineers Guide to Energy Conservation in Existing Buildings, Heat Loss Rate Nomogram, Figure H-1. 
Sizing and Ranking Problem, continued

(3) What priority should this project receive relative to the following independent projects: Project A, SIR = 5.0;

Project B, SIR = 15.1; Project C, SIR = 1.7;

Project $D$, SIR $=2.8$ ? 
(Rov. 11/88)

\section{Energy Prices and Discount Factors for Life-Cycle Cost Analysis 1988 (s:MYlE)}

Annual Supplement to

NBS Handbook 135 and

NBS Special Publication 709
Barbara C Lippiatt Rosalie T. Ruegg

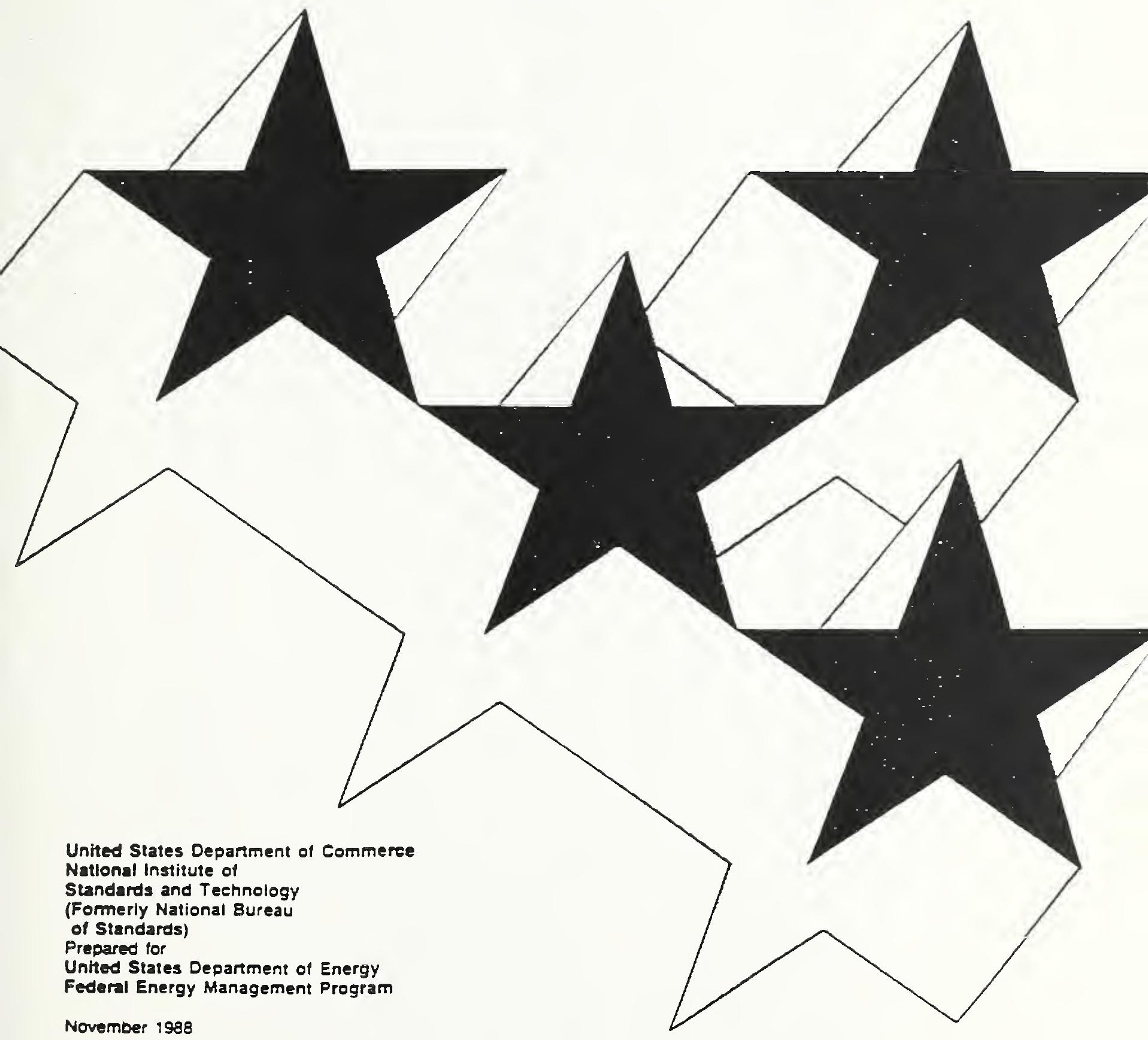


=。 
Table A-1. SFU Factors for Finding the Presext Value of Future Nonfund, Nonansually Recurring Amountes

Number of Years

Une11 Future Amount

Occurs (N)
SFW Factor

$(d=0.07)$
SPW Factor

$(d=0.10)$
1

2

3

4

5

6

7

8

9

10

11

12

13

14

15

16

17

18

19

20

21

22

23

24

25

26

27

28

29

30
0.93

0.87

0.82

0.76

0.71

0.67

0.62

0.58

0.54

0.51

0.48

0.44

0.41

0.39

0.36

0.34

0.32

0.30

0.28

0.26

0.24

0.23

0.21

0.20

0.18
0.91

0.83

0.75

0.68

0.62

0.56

0.51

0.47

0.42

0.39

0.35

0.32

0.29

0.26

0.24

0.22

0.20

0.18

0.16

0.15

0.14

0.12

0.11

0.10

0.09

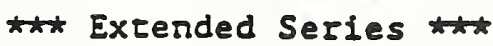

0.08

0.08

0.07

0.06

0.06 
Table A-2. UPW Factors for Flading the Present Value of Future Nonfual, Anmully Recurring Amountes

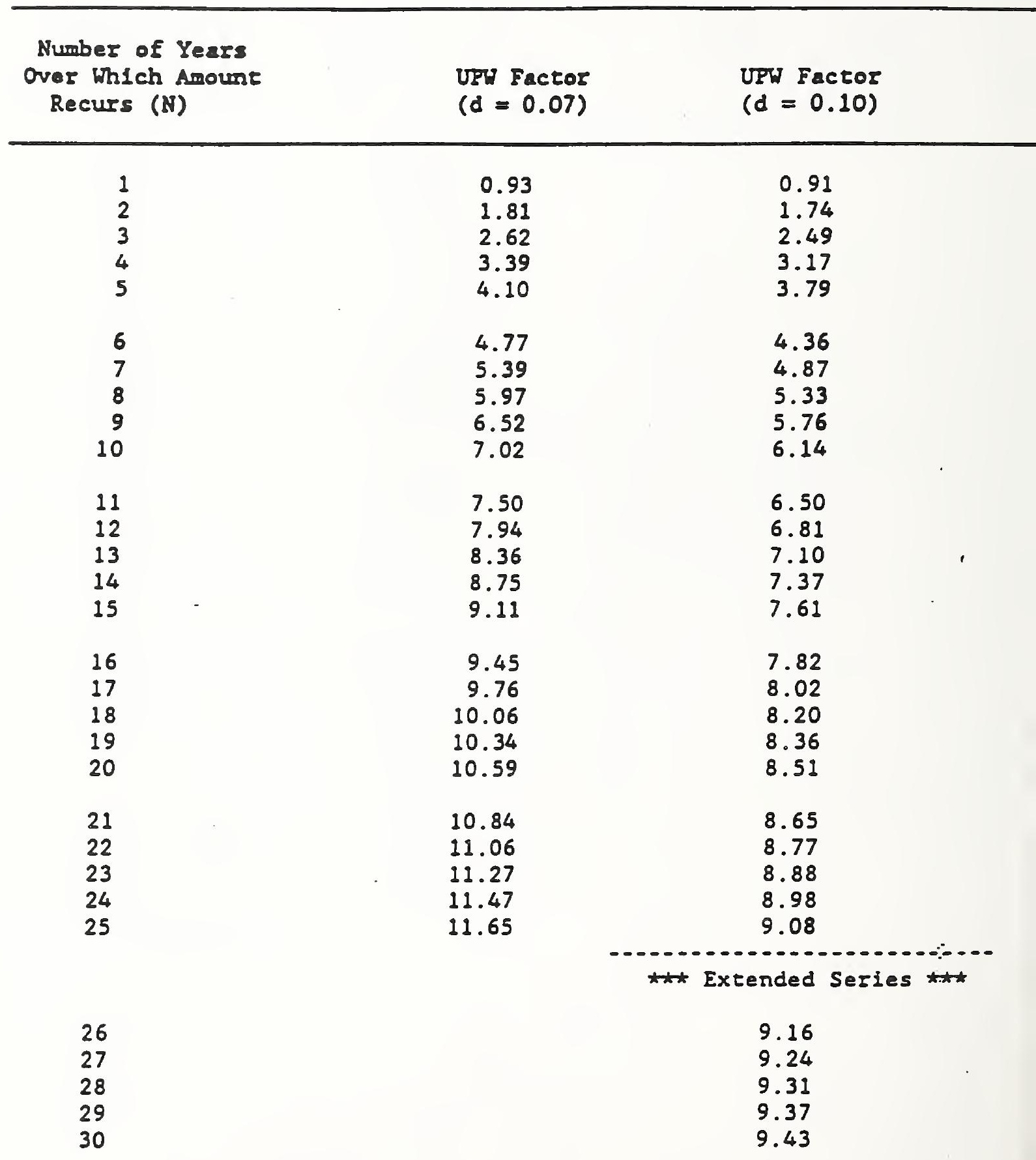




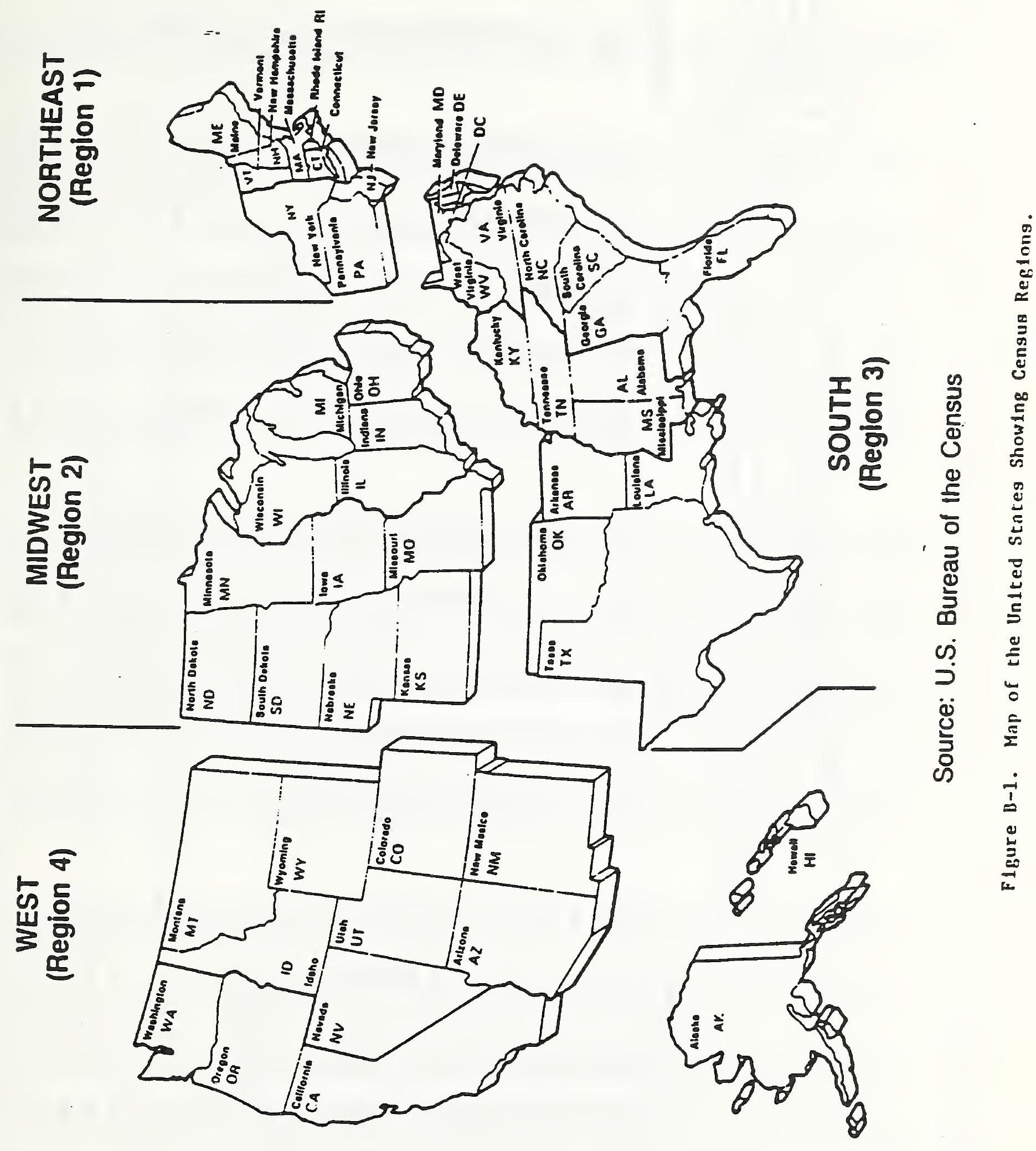








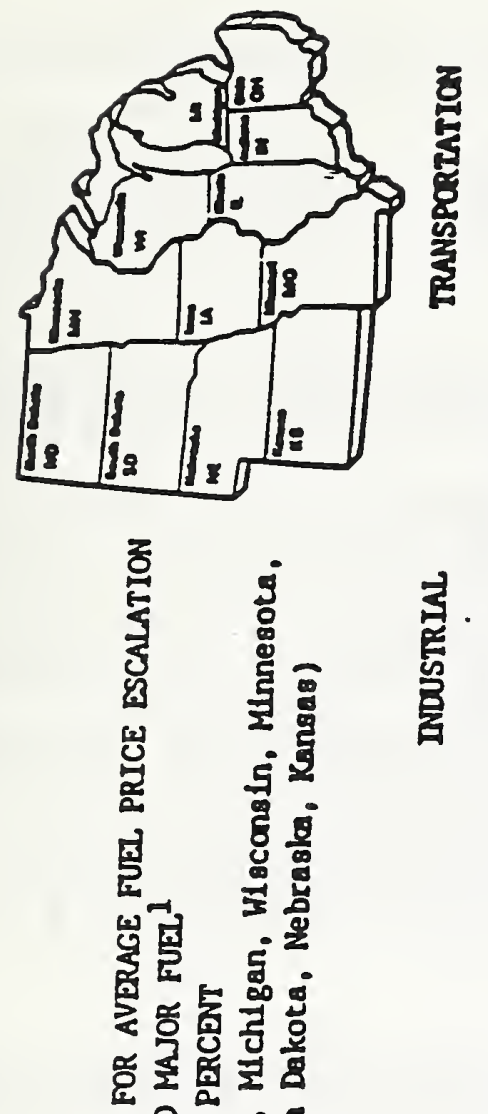

因是号官

哲

द胥点:

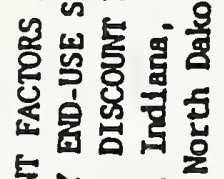

క్

家

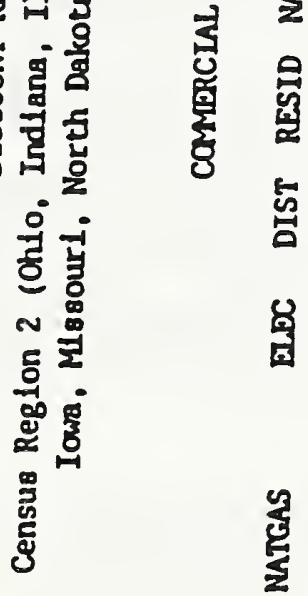

尔

ลี

है

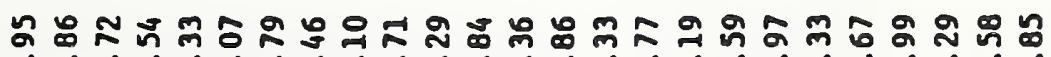
○ं山िं

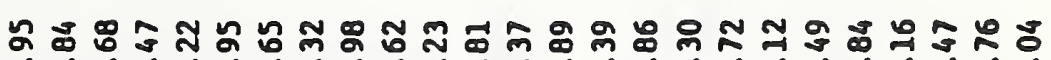

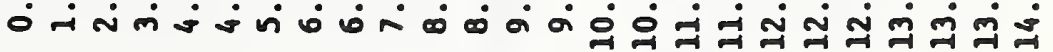

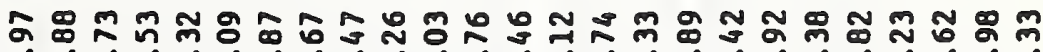

○ள

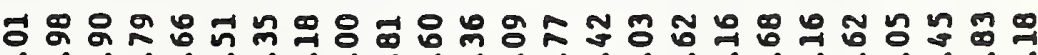
-

응ํำ -

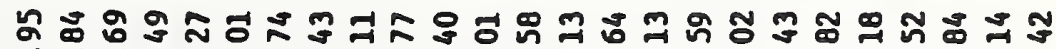
○ं

告

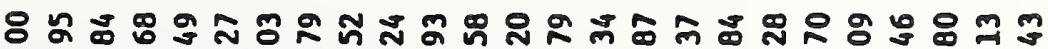
-

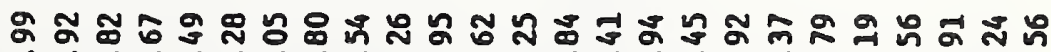

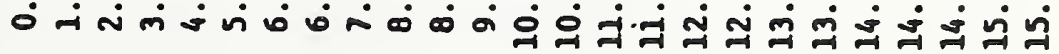

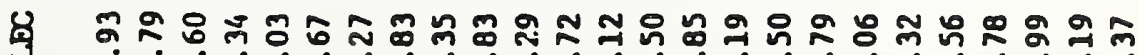

国

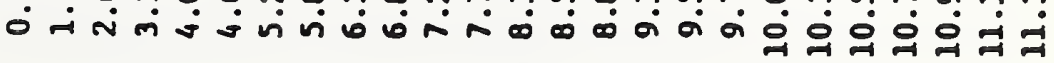




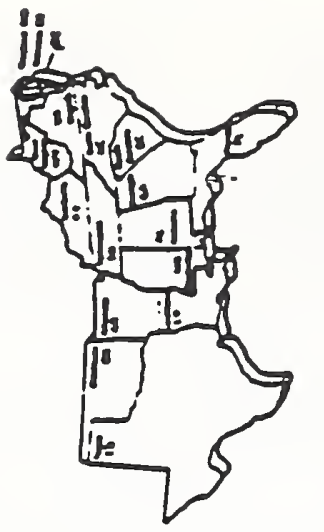

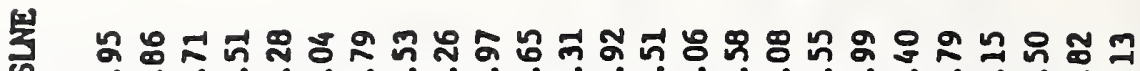

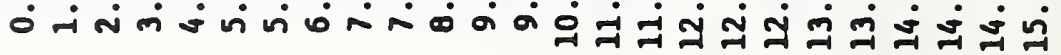

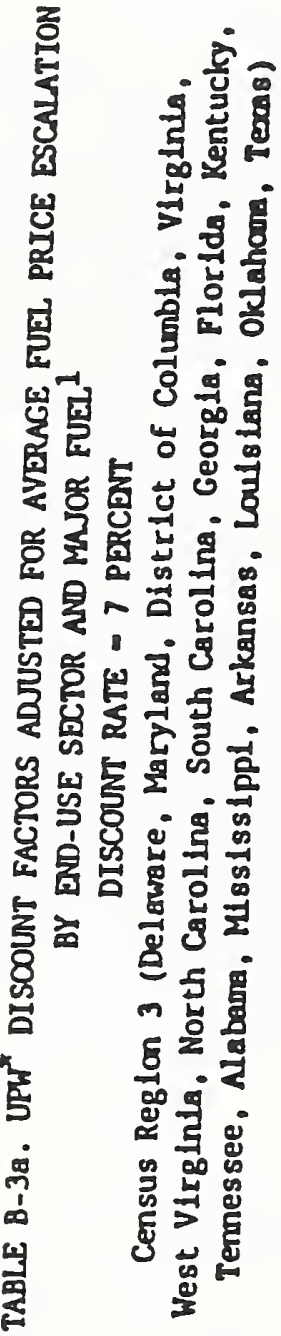

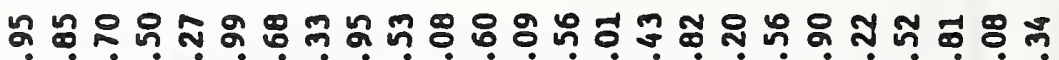

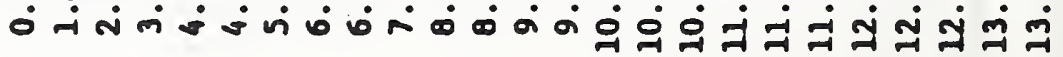

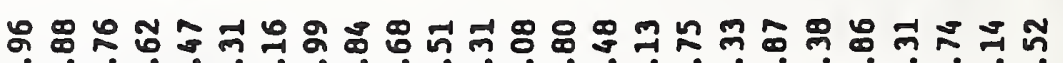

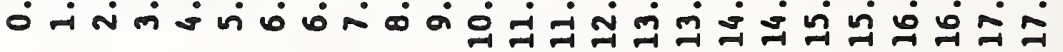

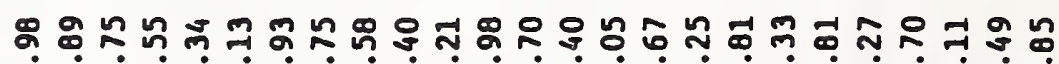
ல

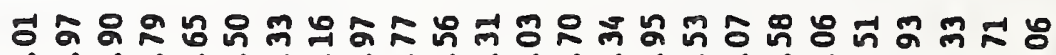

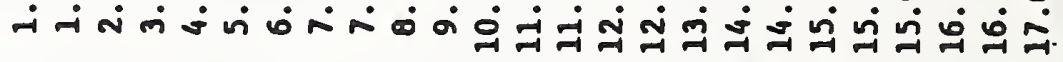

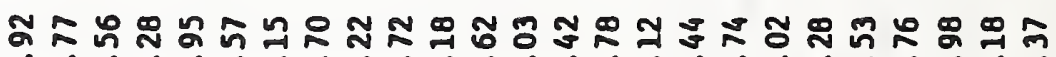

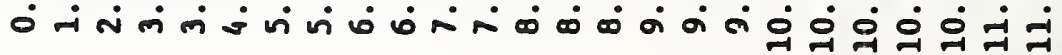

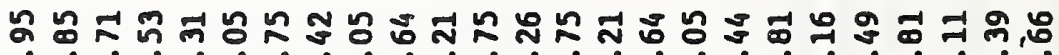
○ ณ ○ं

용ํำ

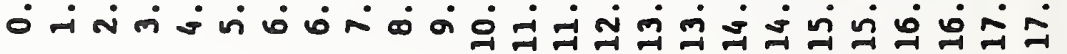

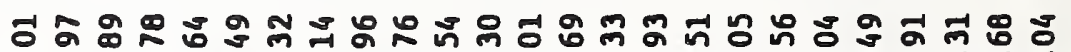
-

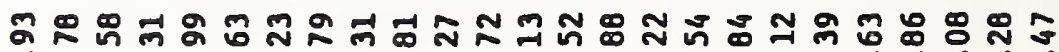

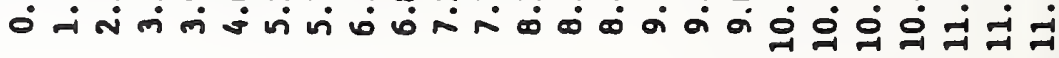

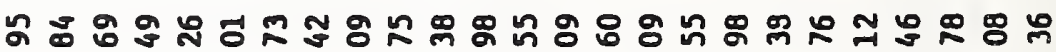

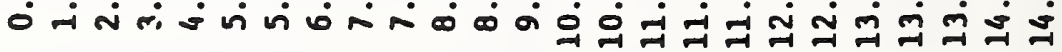

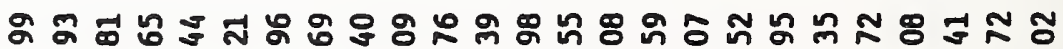

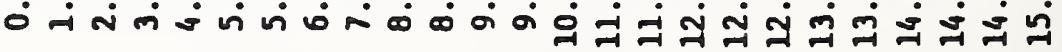

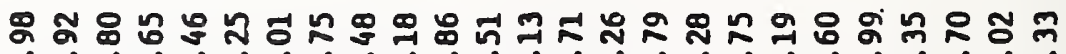

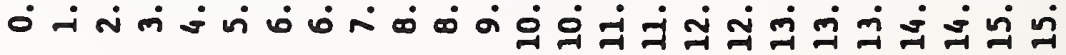

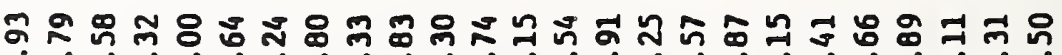
- - 

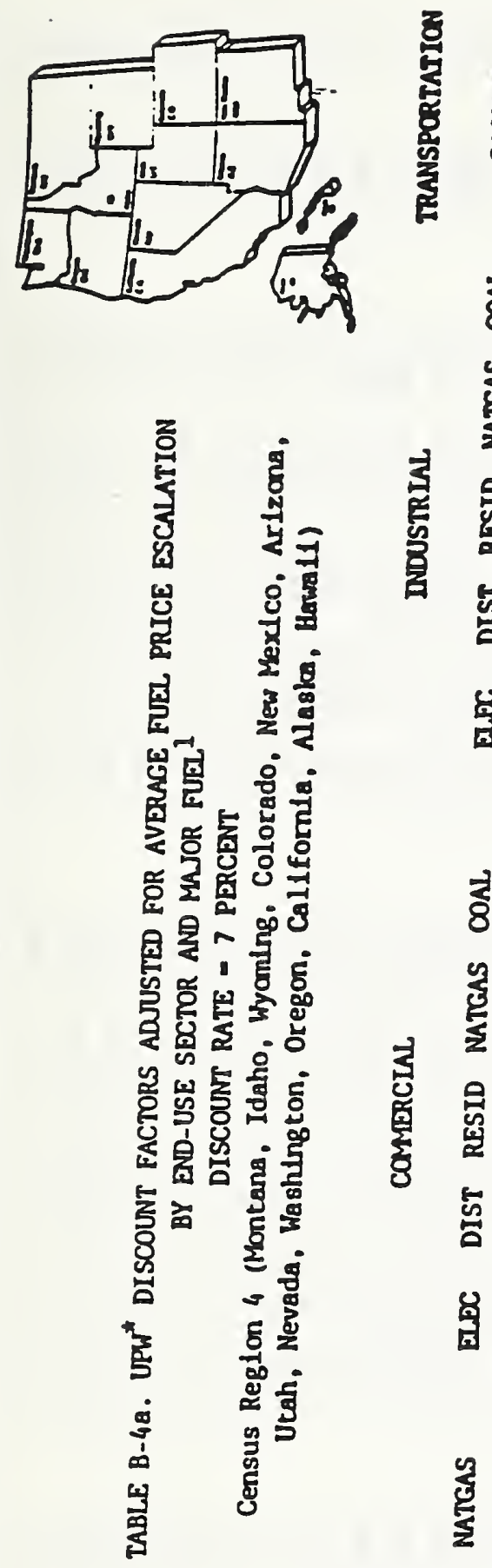

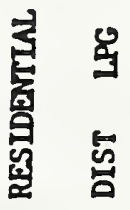

苜

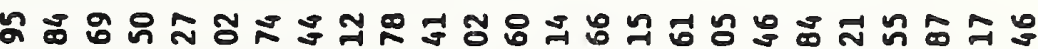

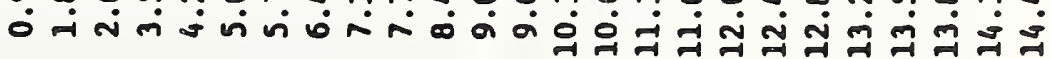

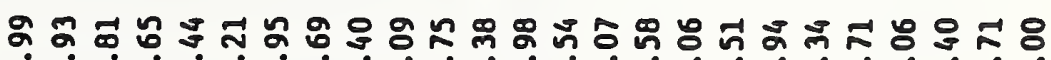

包

絪

¿े

है

昜

量

赵

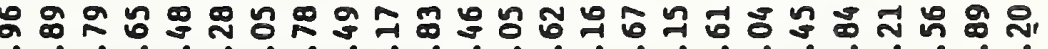

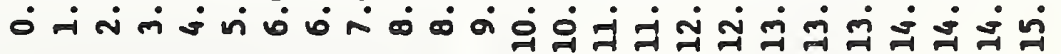

ณฐ์ -

ลํㅀ ○ न

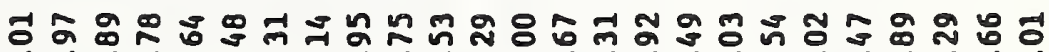

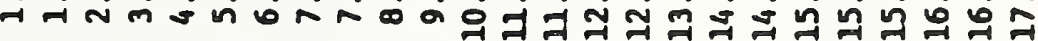

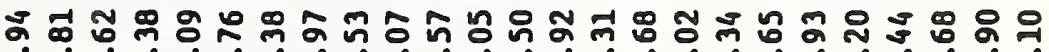
○

○ं

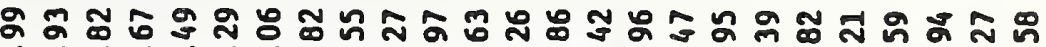

வ

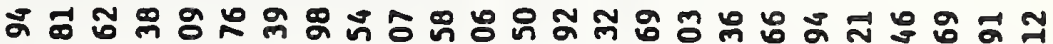

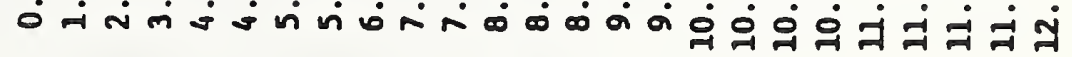




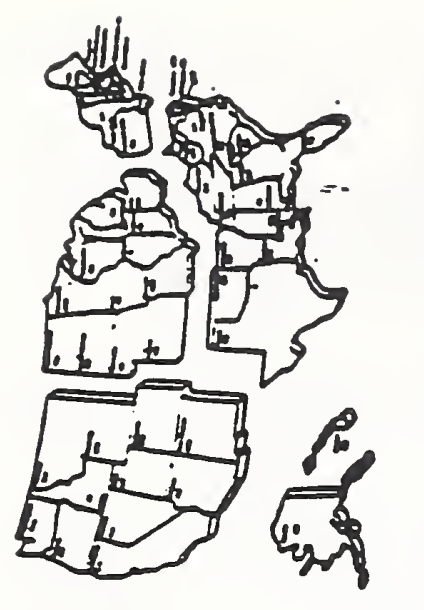

दे

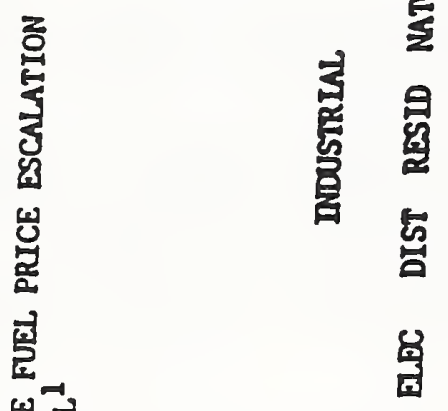

z -

题

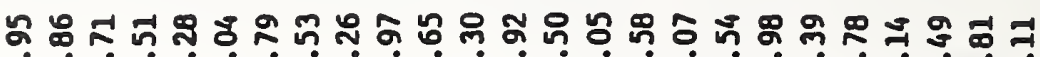
- -

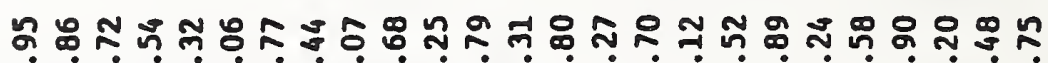
ல்

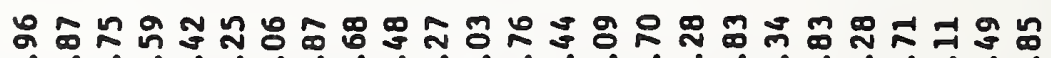

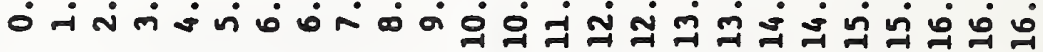

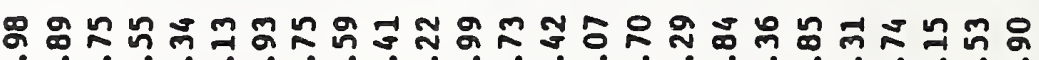

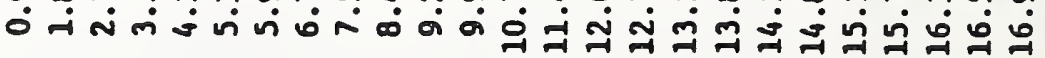

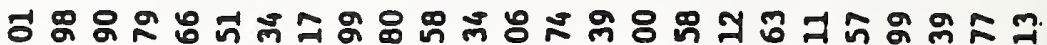
ㅇํำ

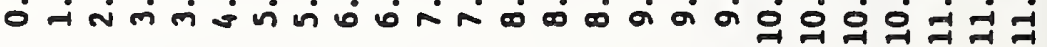

ङे

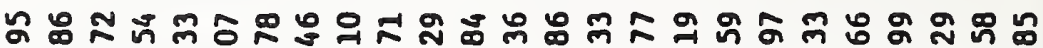

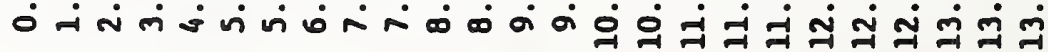

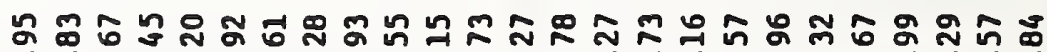
-

ลิ

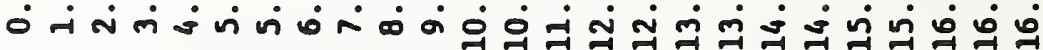

点

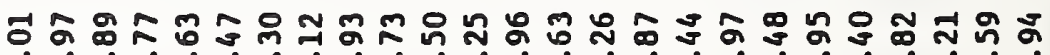
-

音

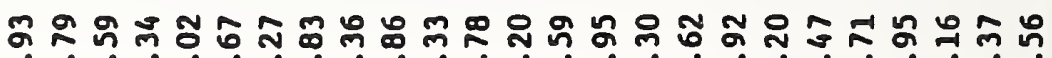
○ள

है

テั

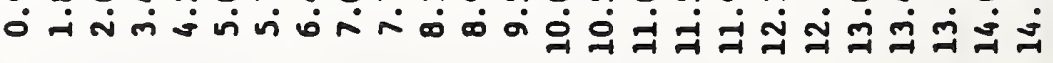

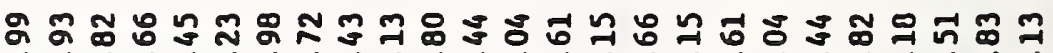

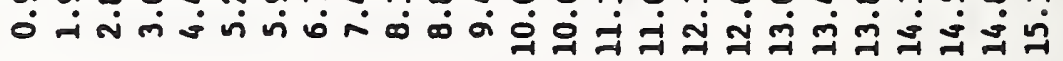

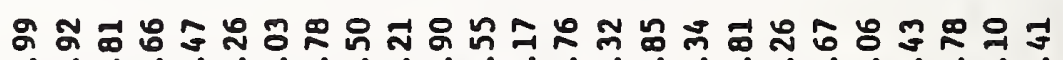
○ -

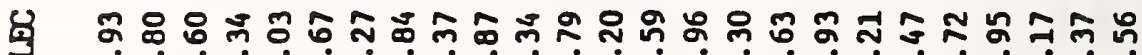

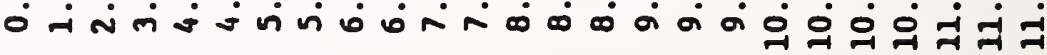


1988 Projected Average Fuel Prices Indices

(Tables $\mathrm{Ca}-1$ through $\mathrm{Ca}-5$ )

and

1988 Projected Average Fuel Price Escalation Rates

(Tables $\mathrm{Cb}-1$ through $\mathrm{Cb}-5$ ) 


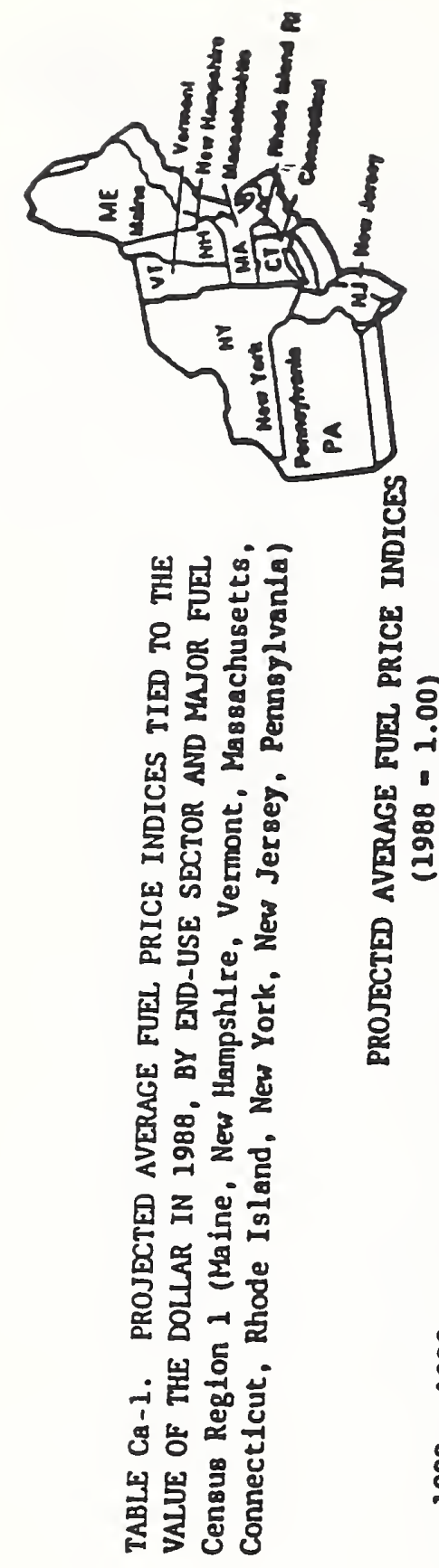

ठํำ

a

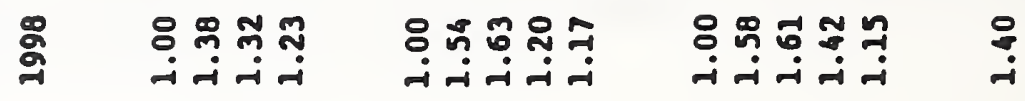

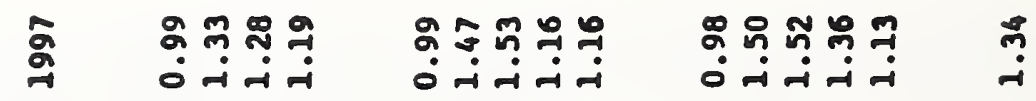

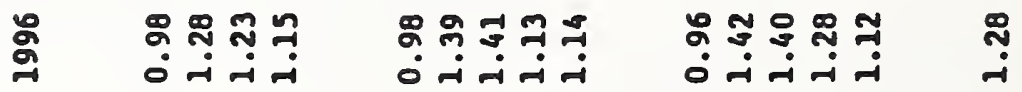

官焉焉

요 $\simeq$

园宅害

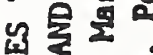

额

政

엉 के

品

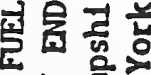

品 害

更

远

空焉

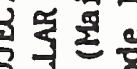

$8-7$

读

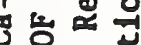

4. 닐 常

롤

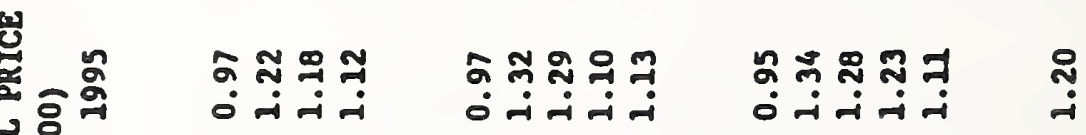

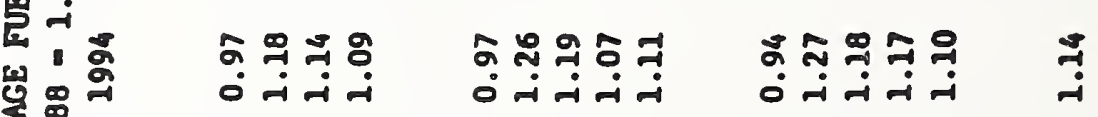

\%

ڤે

హे 界

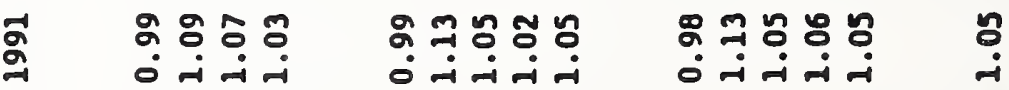

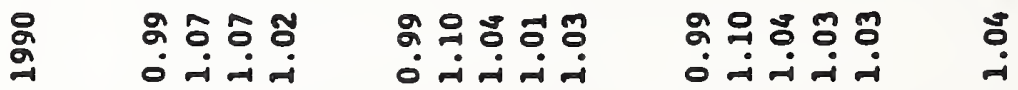

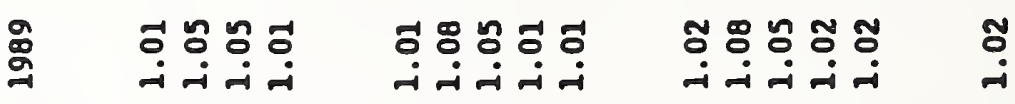

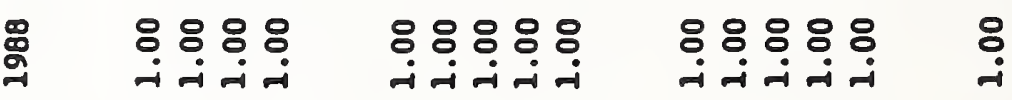

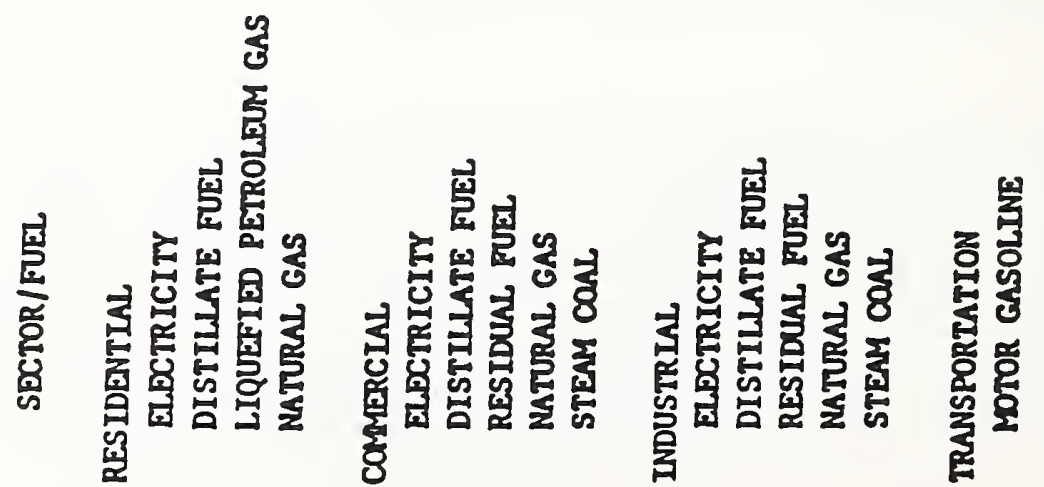




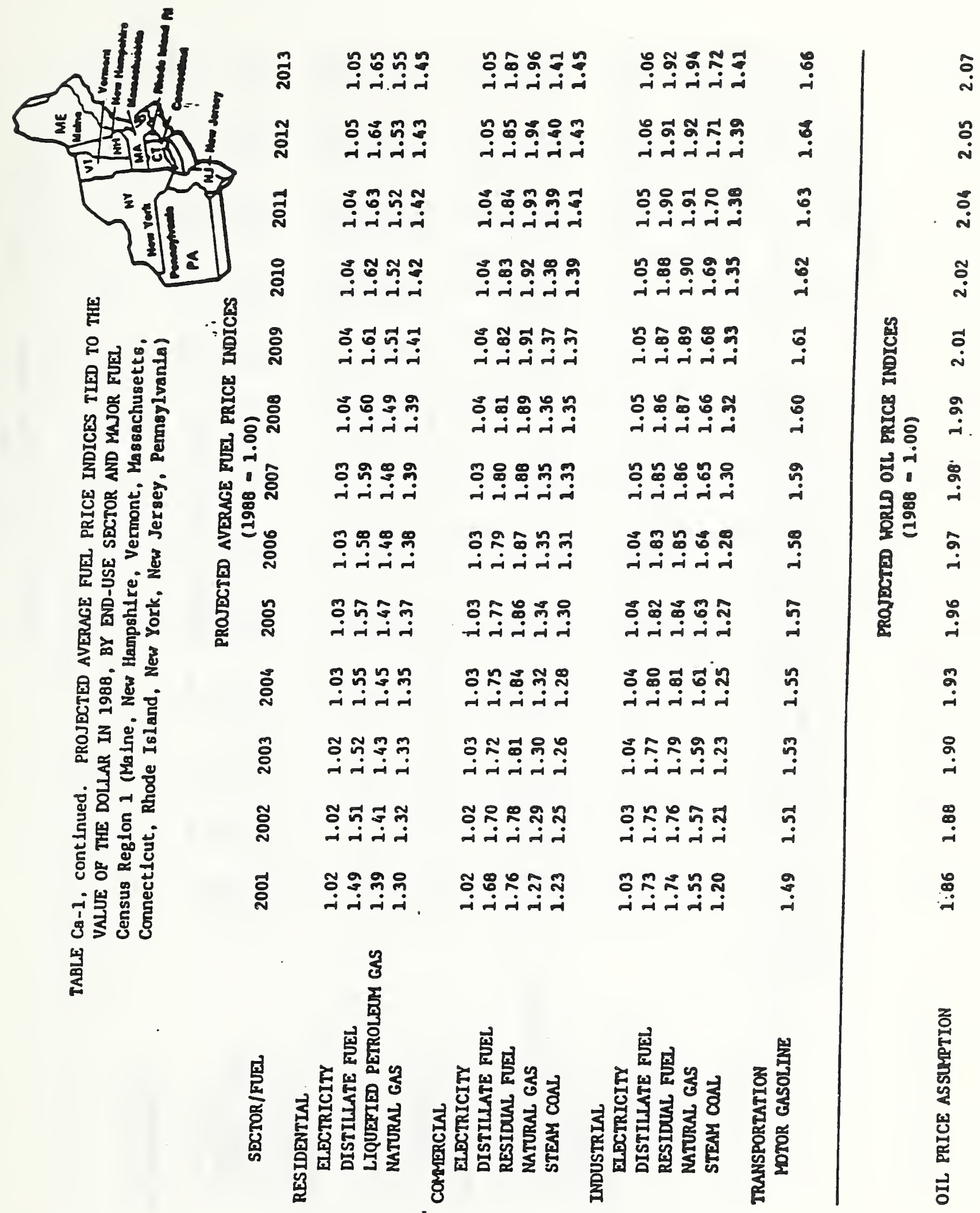




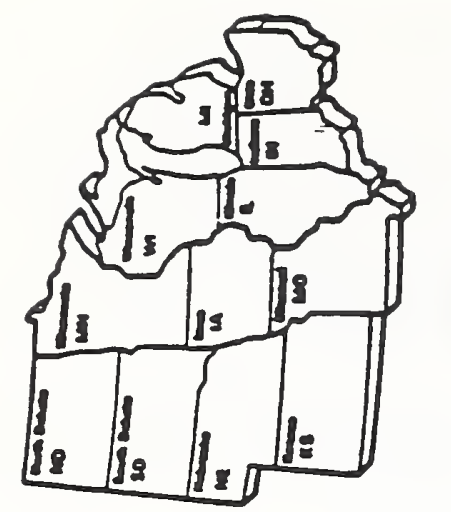

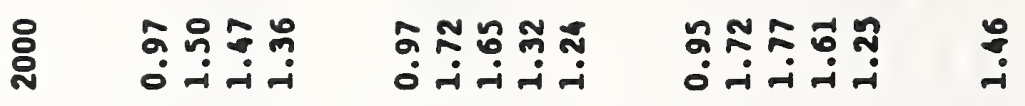

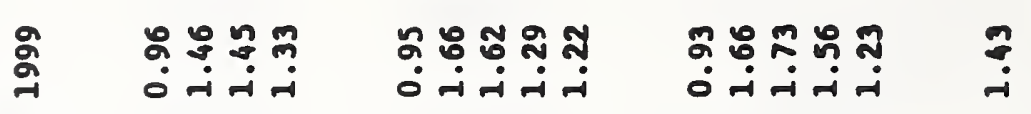

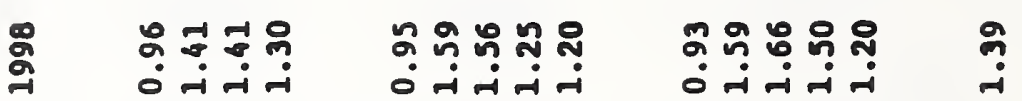

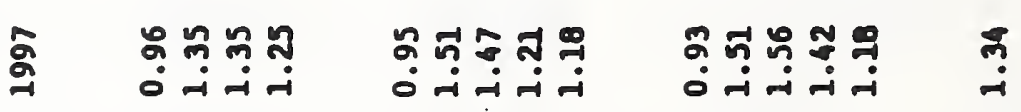

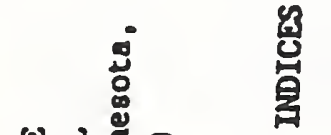

兽

:

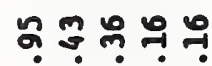

om $m$ m वन्नं

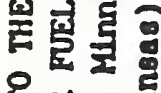

옹ํํㄹ

点运

뇽

응 옹

刍约

แู

엉 눙

잉

国家

承

素罗焉

过

음

종응

0 $\dot{-i} \dot{-1}$

ดักับำ구

ํำ유든

○ं $\dot{-1} \dot{-1}$

○ं $\dot{-1} \dot{-1}$

1.

욕

亩

$\sum_{1}^{1}=$

ต

是

$\stackrel{\text { g }}{\text { a }}$

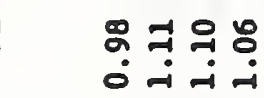

ลีส ㅇํㅇㅇㅜ

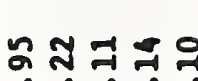

वन्त

$\triangle$ ำ

ลวะัะ

옥용웡

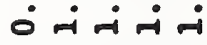

$0-i-i$

a

용웅무

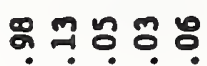

ล뒁ㅇㅇㅇㅇㅇ

\& 9 웅

족형

8 孚兵

운용억-

왿 을

बें

ठन न्म

ठ नंन न

역 å̃o :

옹웜ㄷㅇㅇㅎㅕ

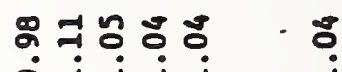

욤

ริ ะㅇํㅇ

$\circ-i-i$

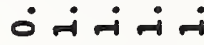

$\stackrel{\sim}{-1}$

约

3능 들 존

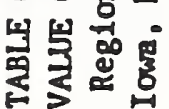

起

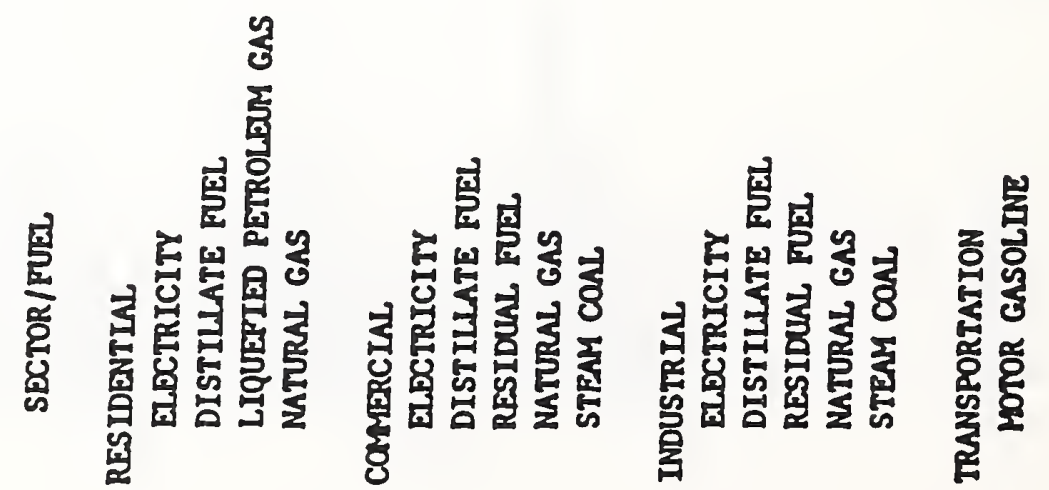

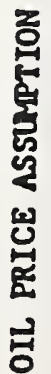




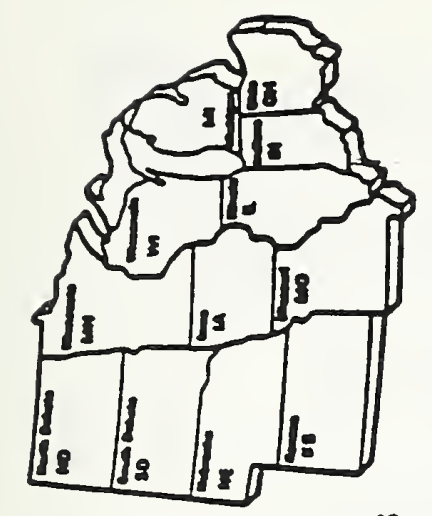

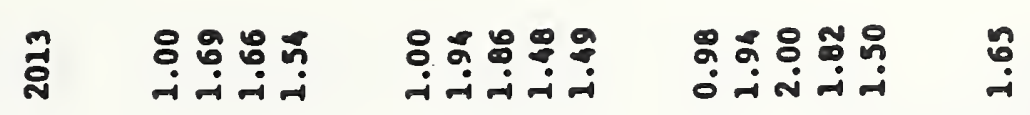

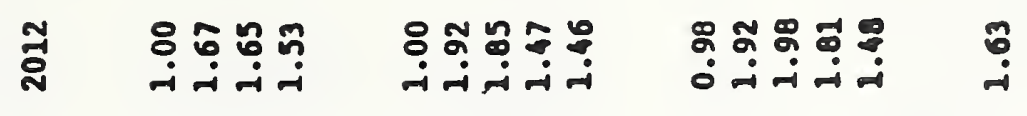

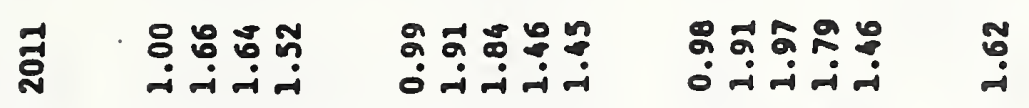

ปี

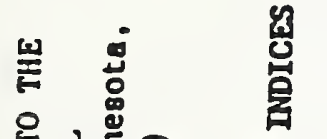

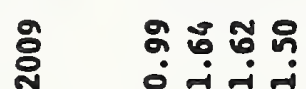

ละ $ळ:$

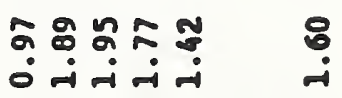

是宸害要

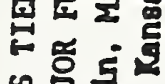

象农到

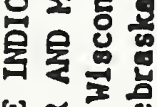

뉭 웅

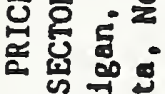

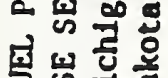

官岁空音

嵌富豆害

安它

目密范

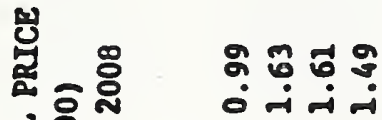

वंन्नं

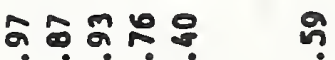

톡

हो

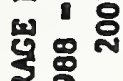

ơं

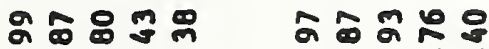

ठंनंन्न

० नंनं नं

ดั

因

量

ถ⿻ำ

क्षंत्र

ดัฒจฺุ

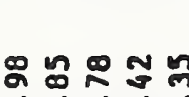

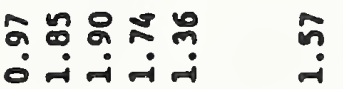

兽

客 $\quad$ :

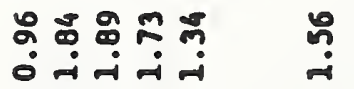

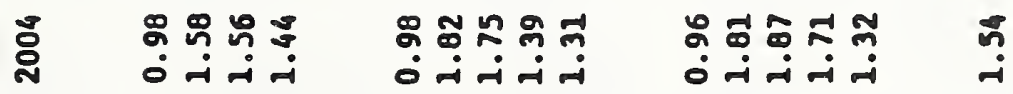

용

吾恶

这

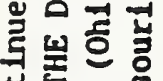

总密

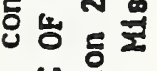

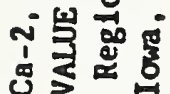

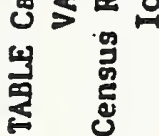

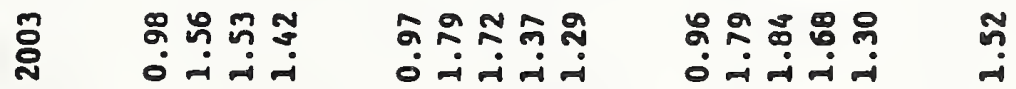

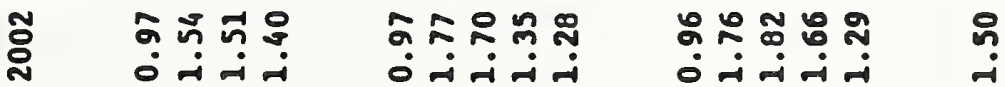

옹

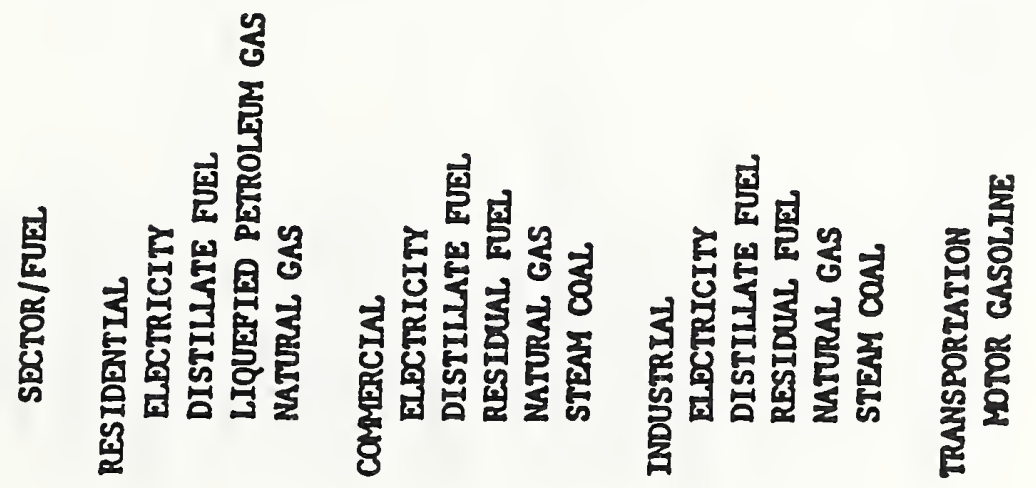

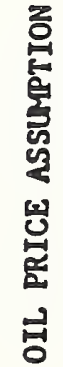




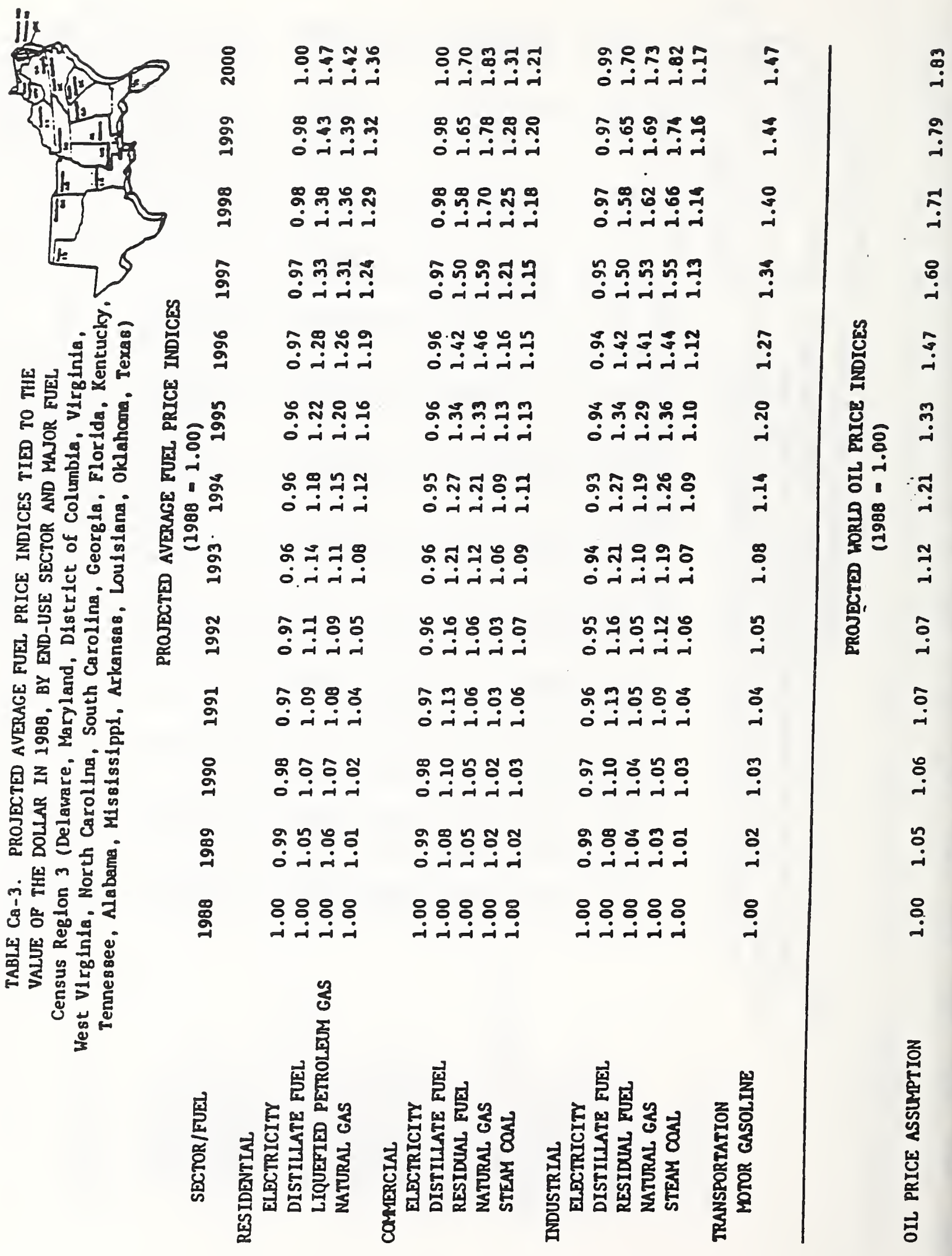




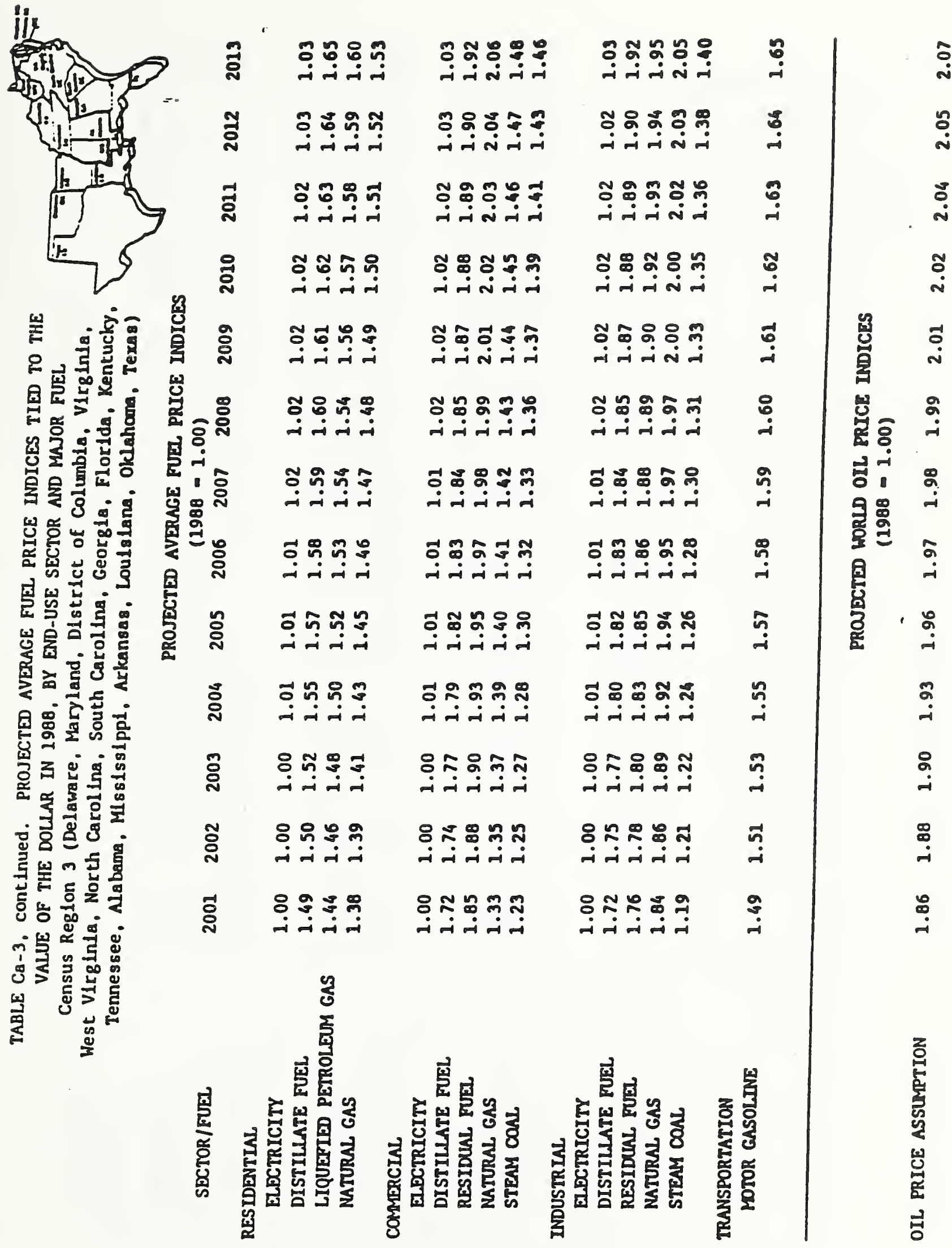




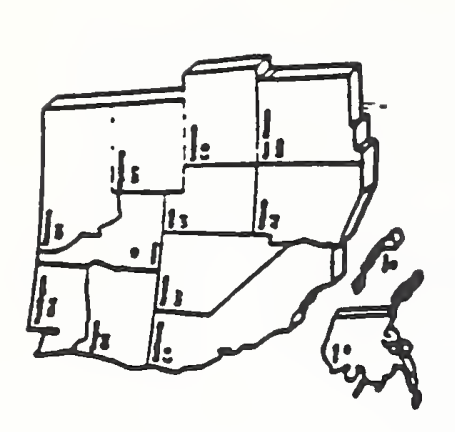

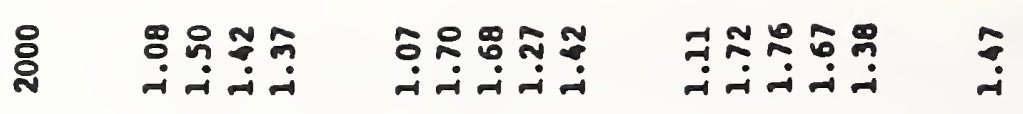

gి

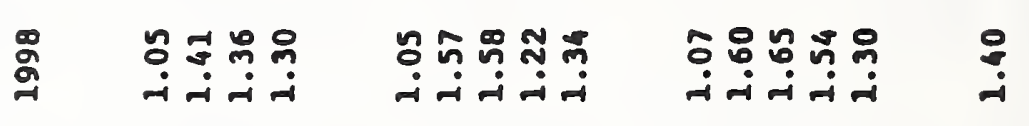

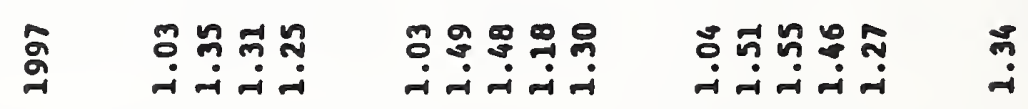

鄫

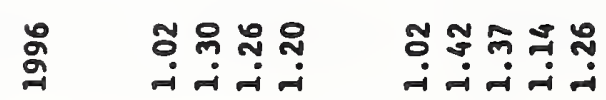

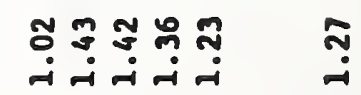

옹용

욜 过

\& 3 है

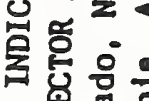

凶 8 品

ज幽

동

당 0

\& 2 ह

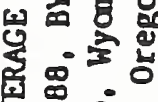

逻

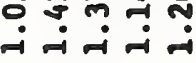

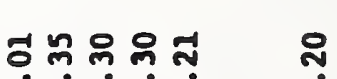

总哭哭

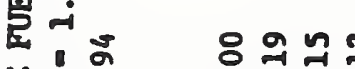

过咢

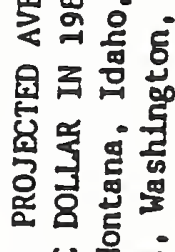

을 올

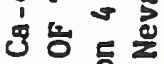

년 일 웅

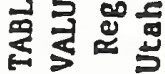

嵌

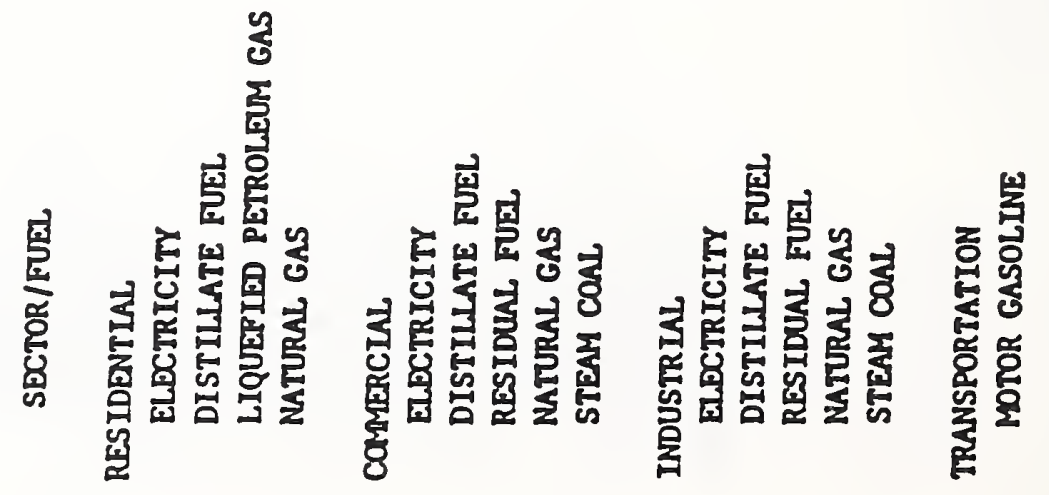

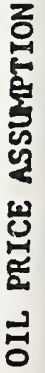




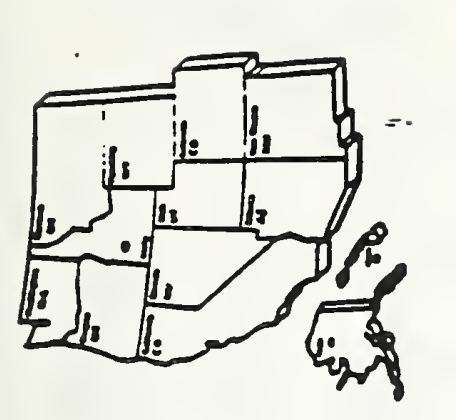

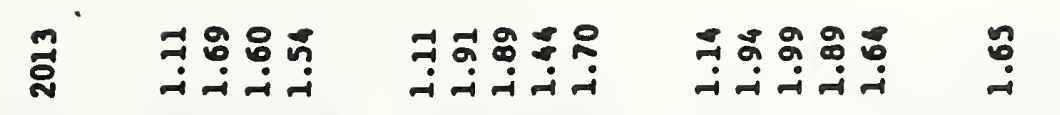

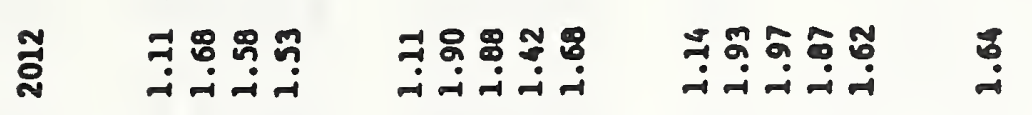

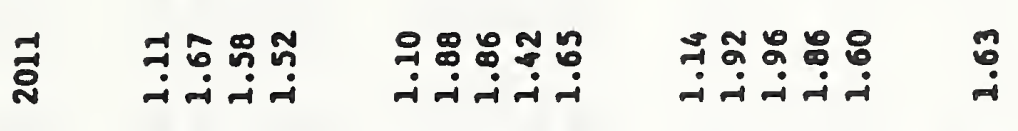

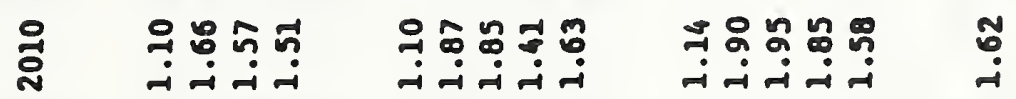

宸总兽

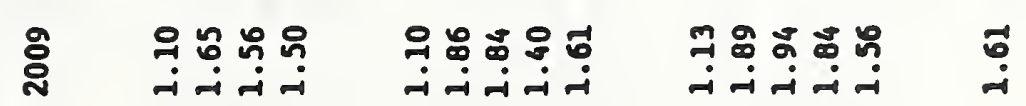

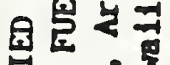

要要

这运

政

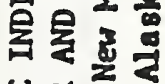

뱅뭉

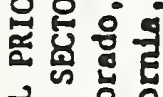

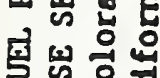

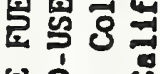

药

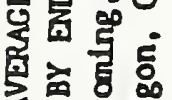

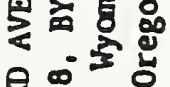

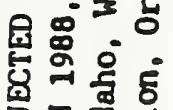

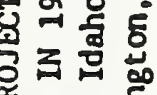

等空

这若

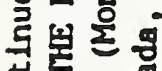

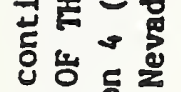

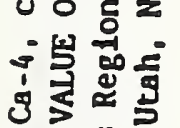

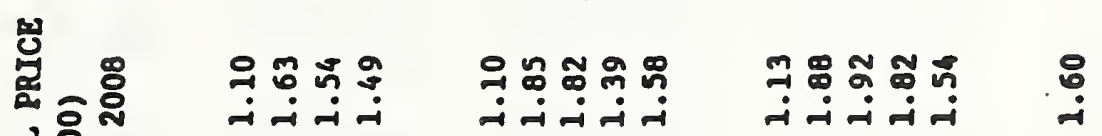

国家

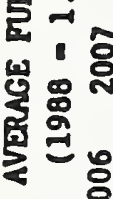

傿

:

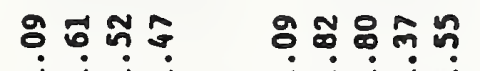

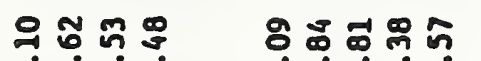

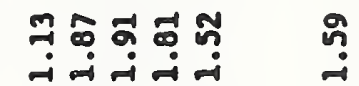

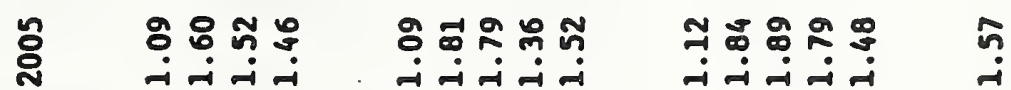

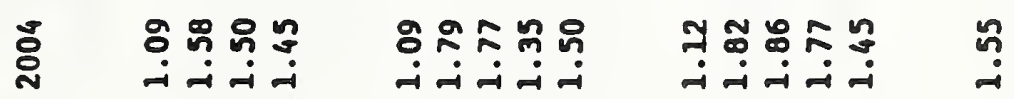

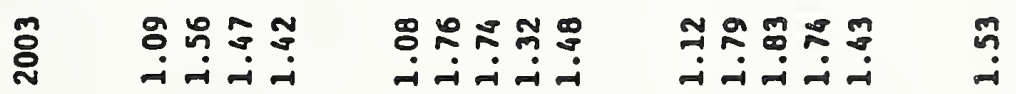

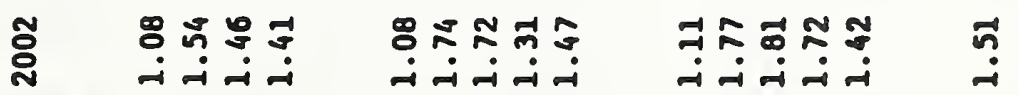

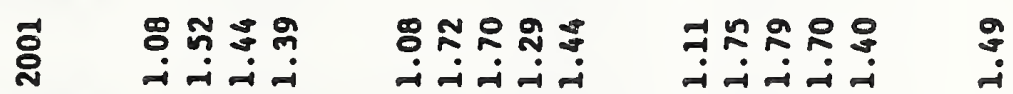

幽

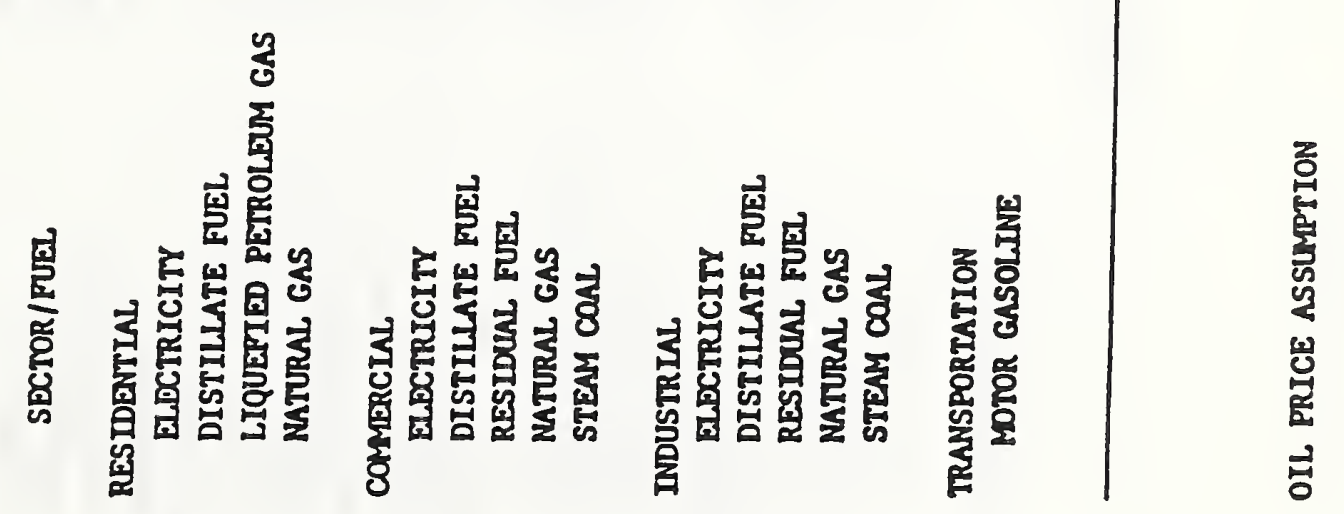




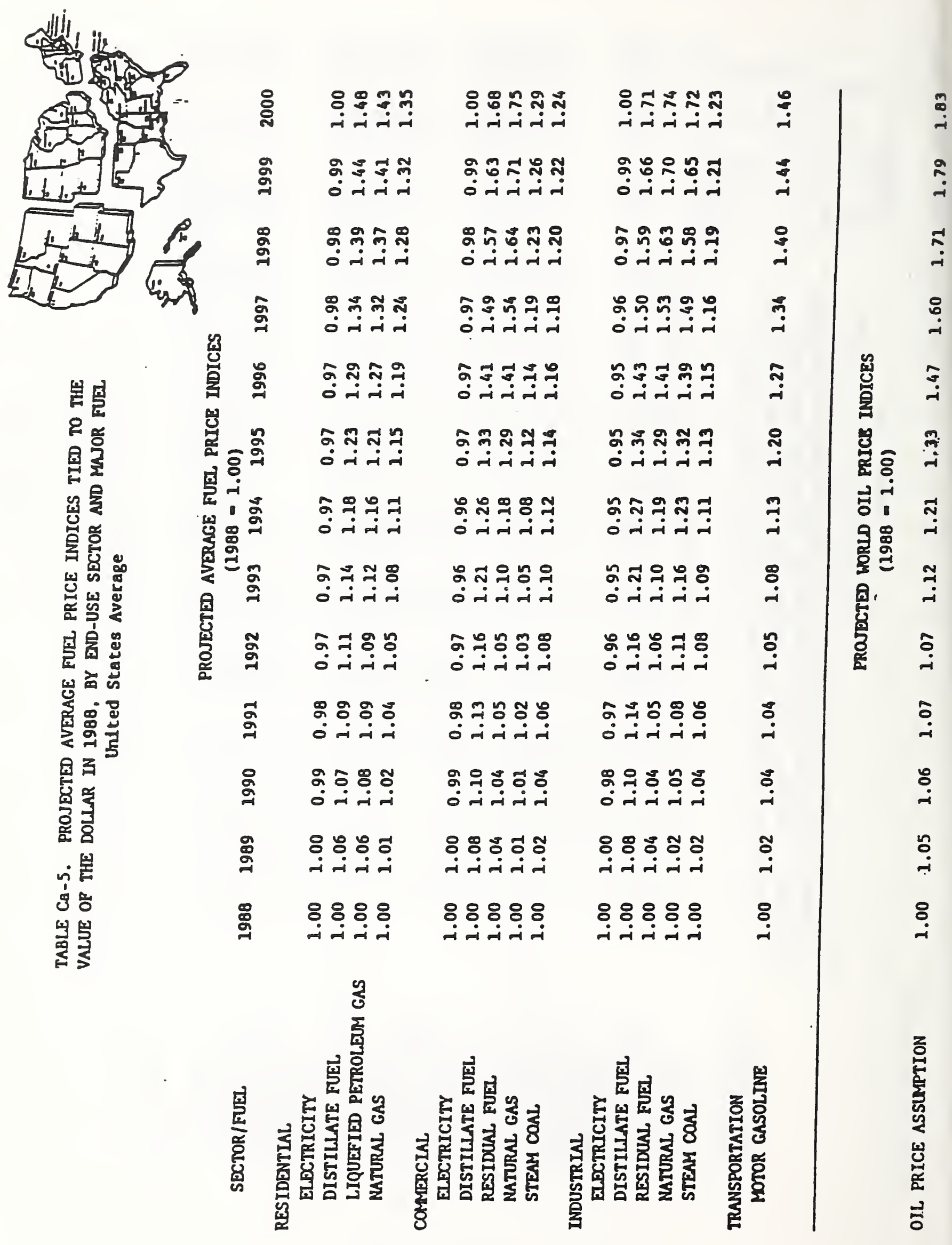




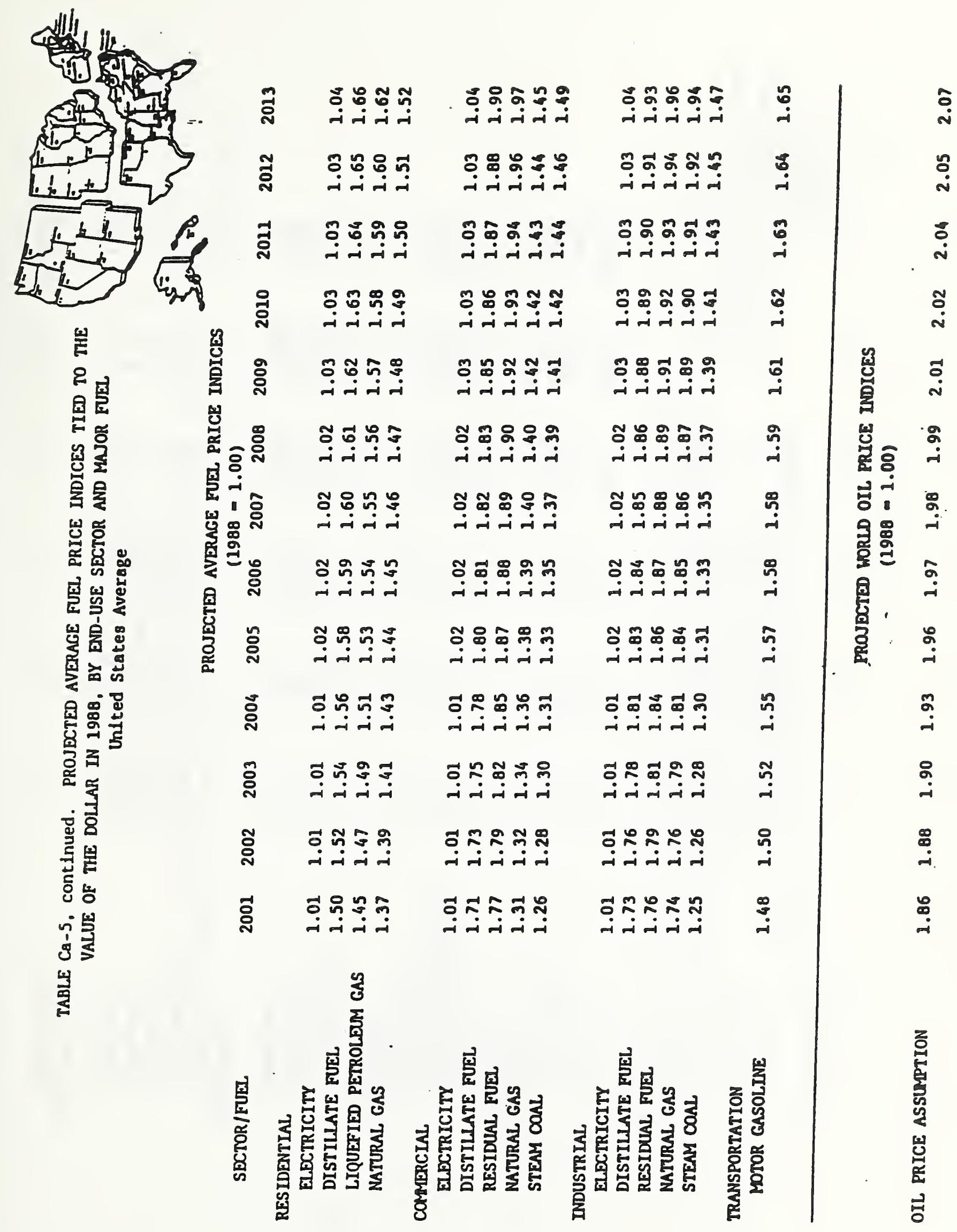




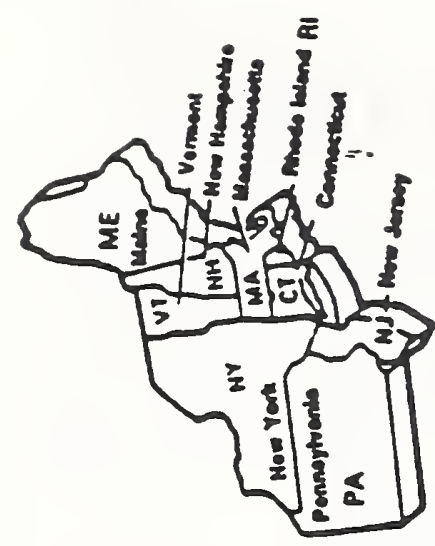

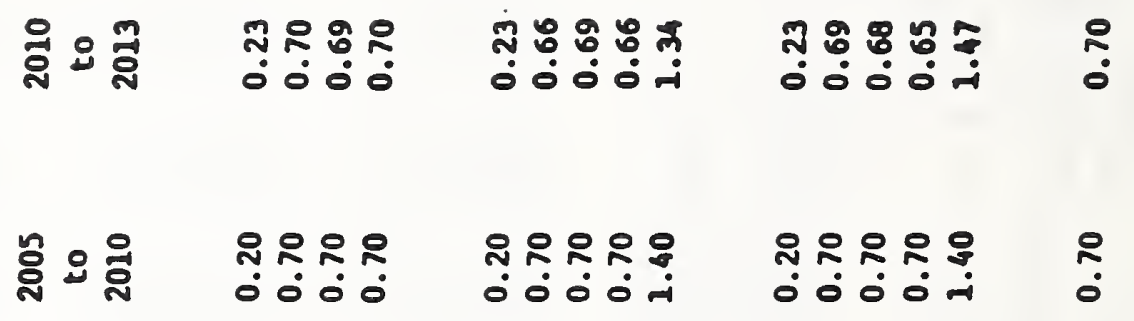

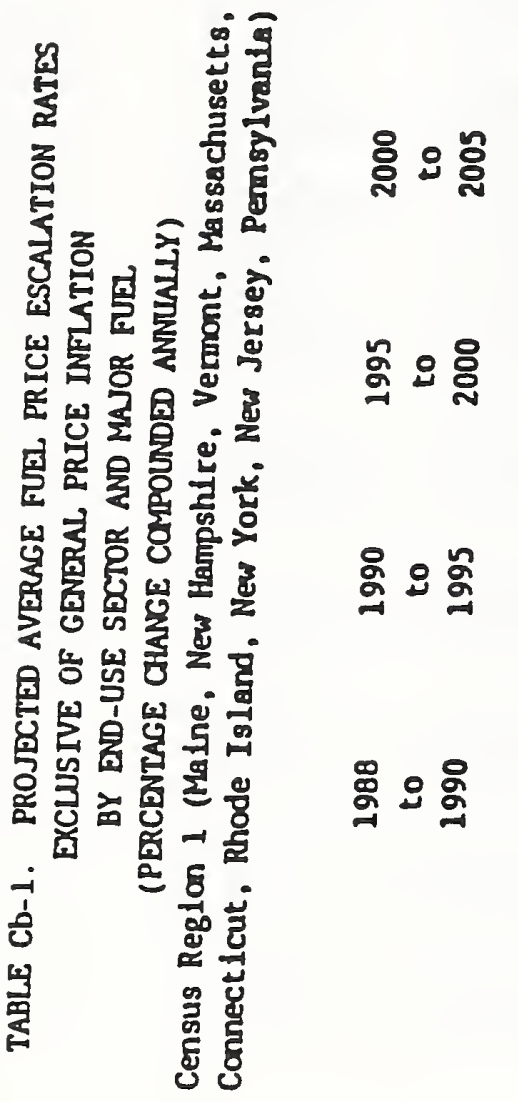

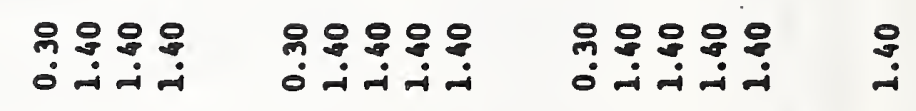

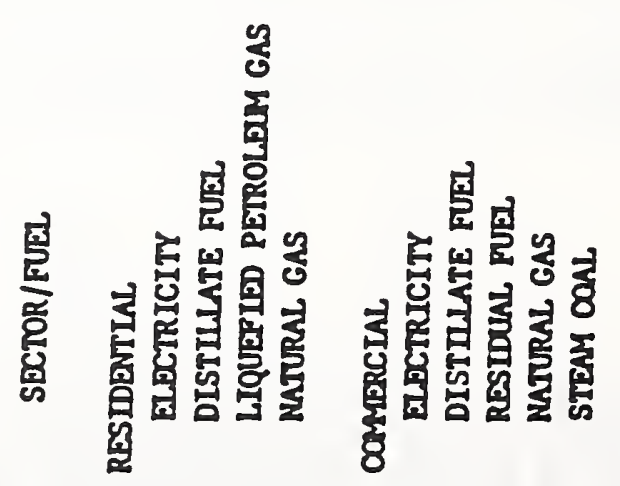

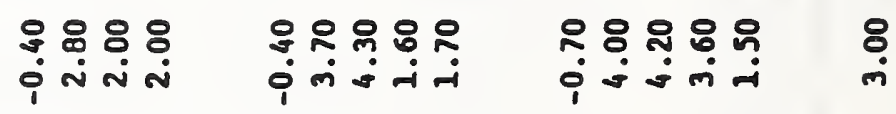

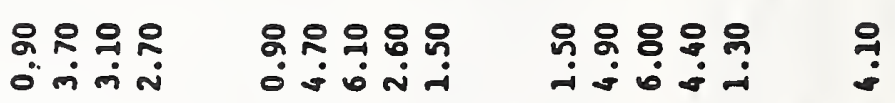
กำ $\stackrel{\circ}{\circ}$

它定

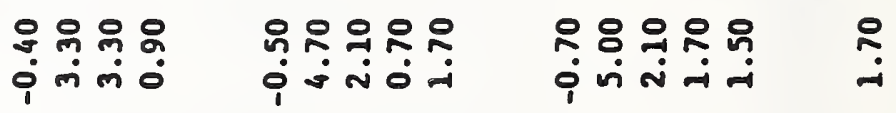

z: 


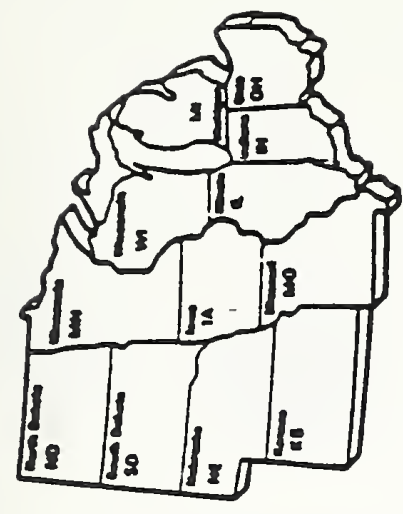

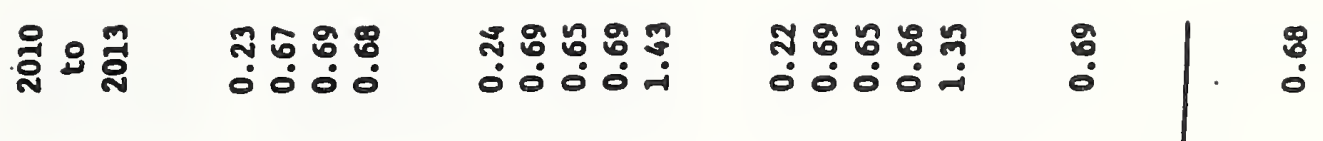

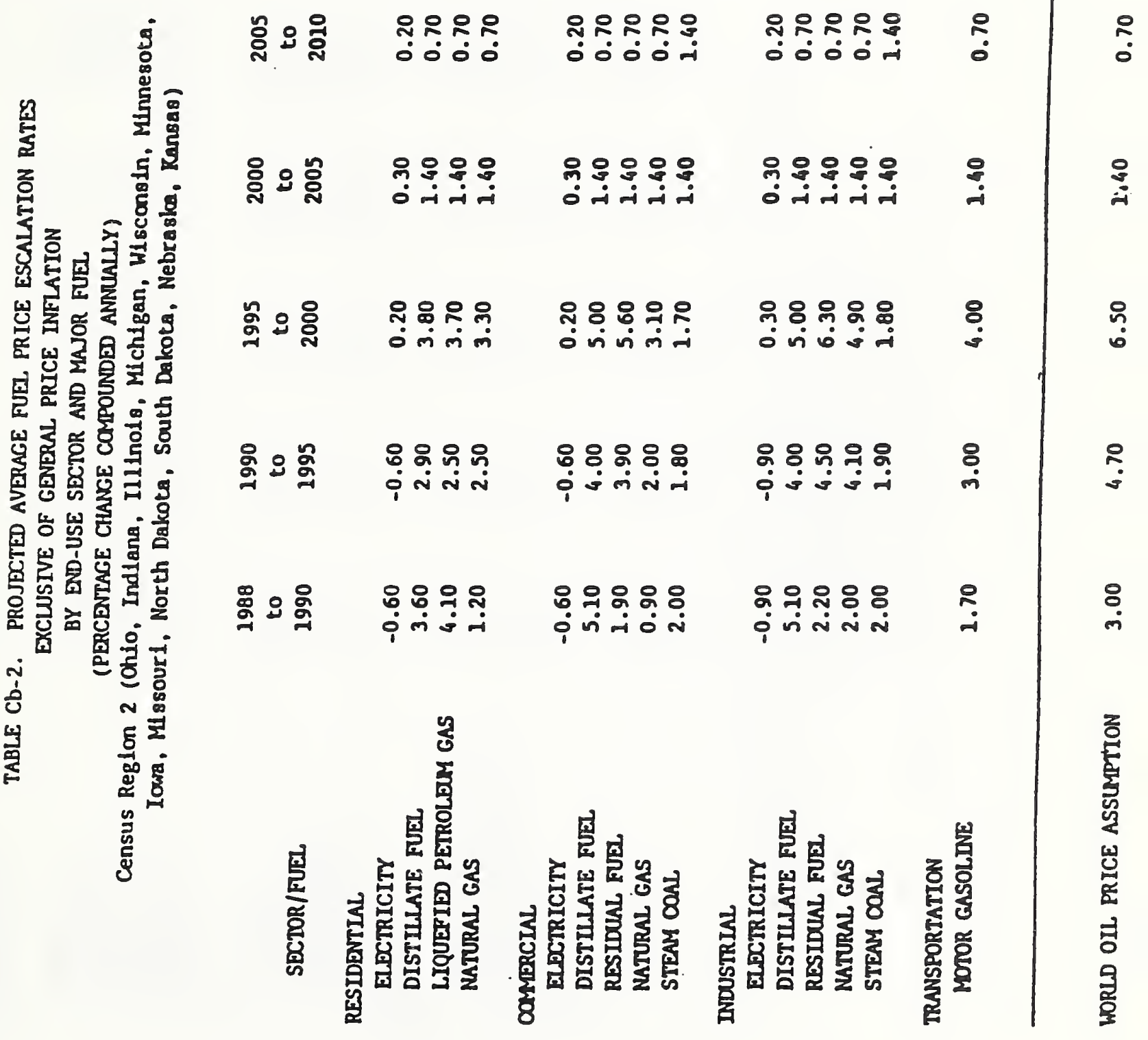




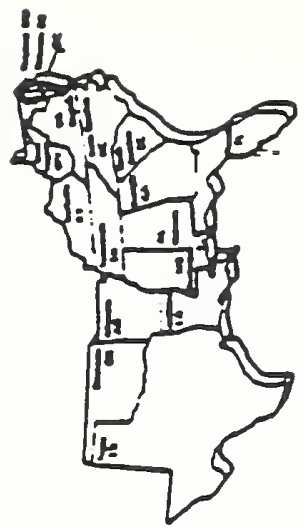

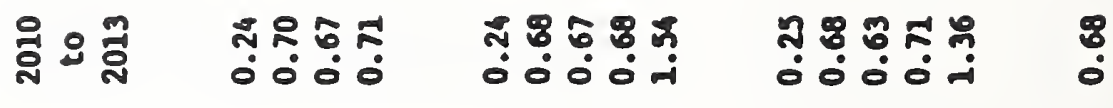

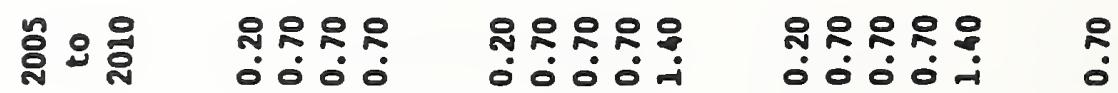

里

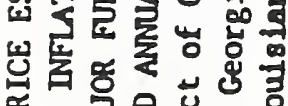

这娄苞

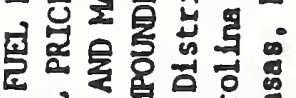

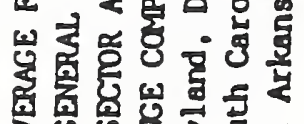

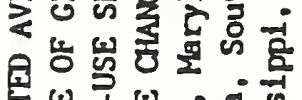

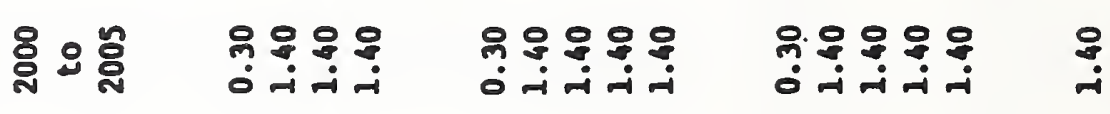

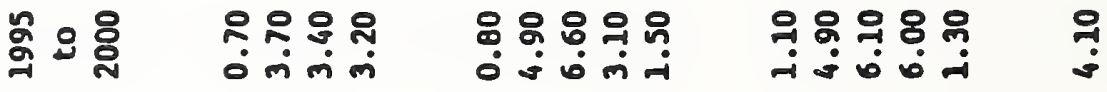

$\stackrel{8}{\circ}$

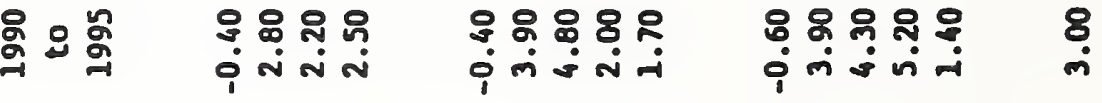

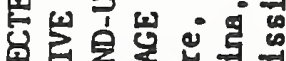

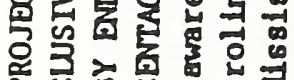

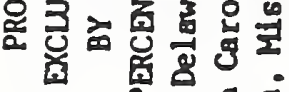

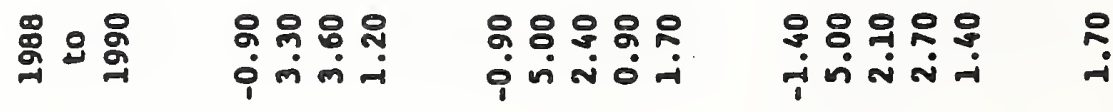

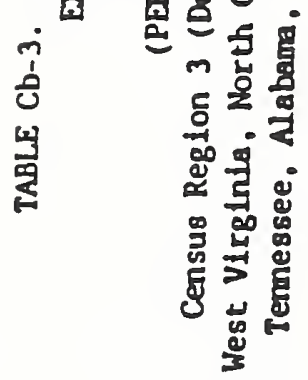

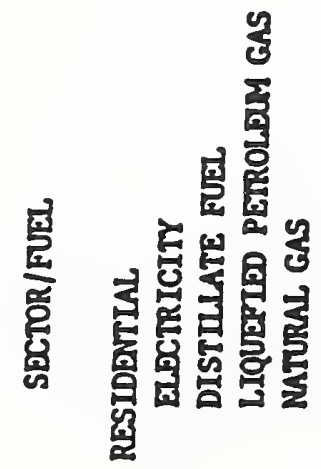

尊

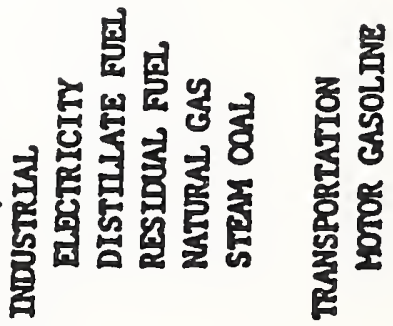

$\stackrel{8}{\dot{m}}$

을 


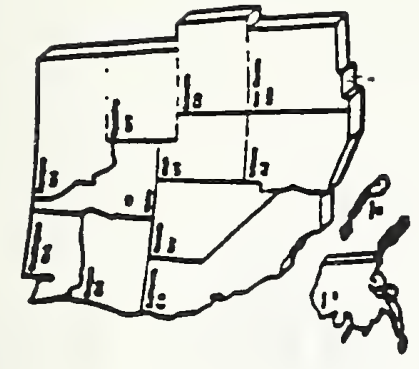

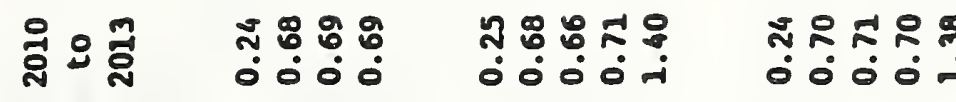

\begin{tabular}{l|l}
0 \\
0 & $:$ \\
0
\end{tabular}

舟

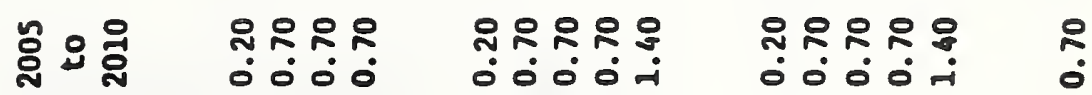

$\stackrel{?}{\circ}$

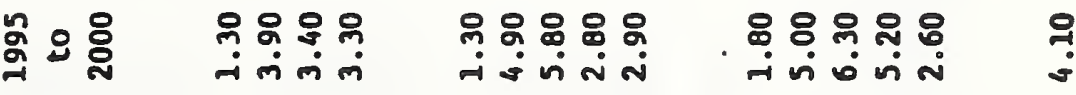

$\stackrel{?}{\circ}$

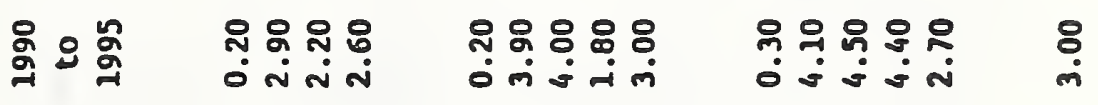

넝

产总此

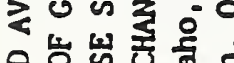

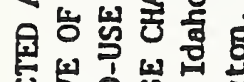

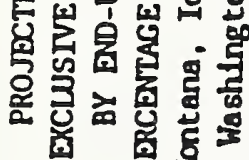

过

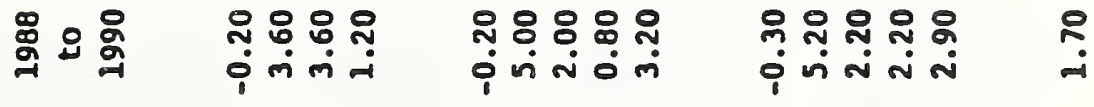
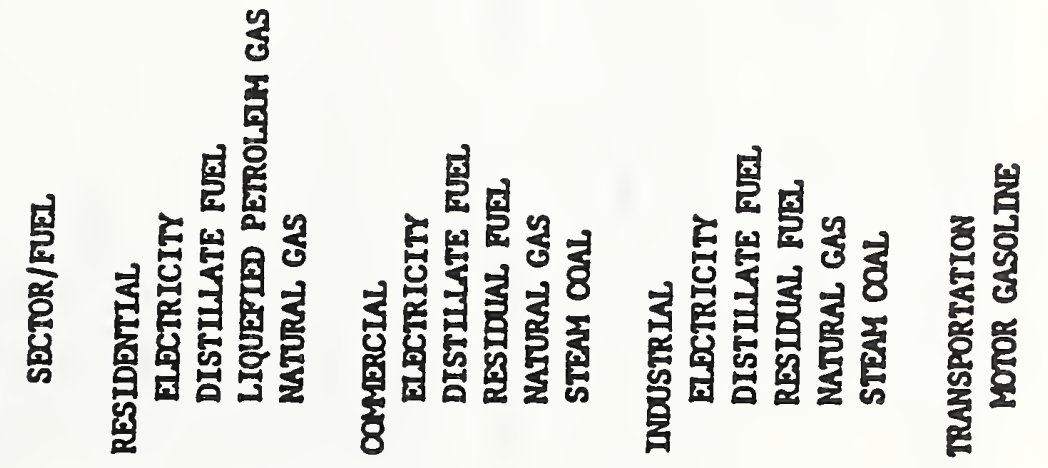

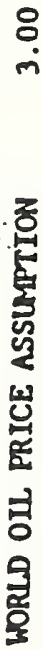




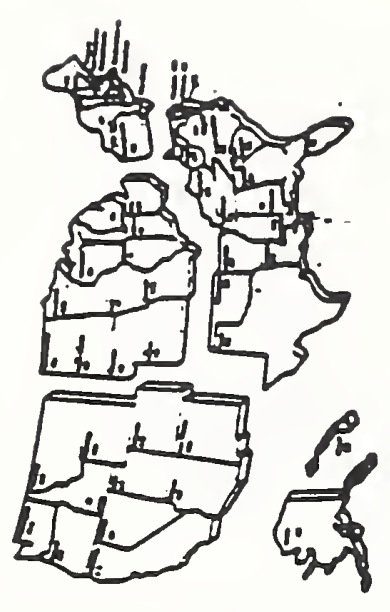

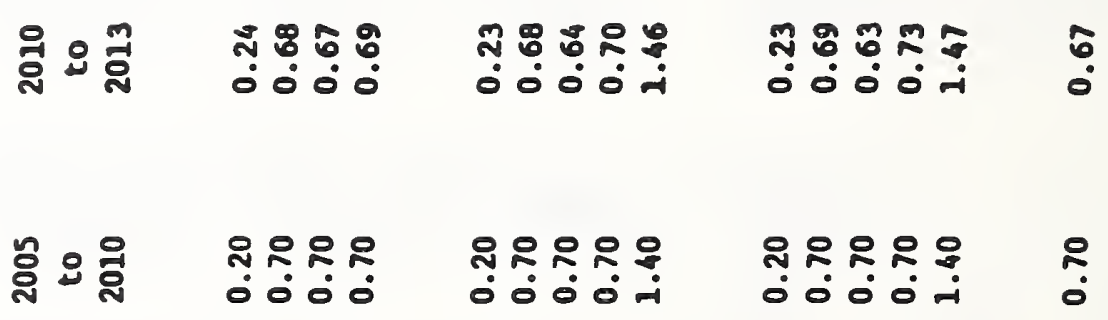

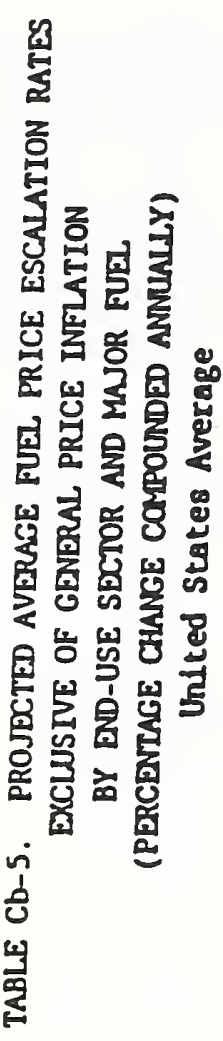

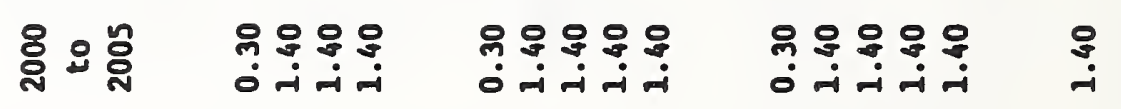

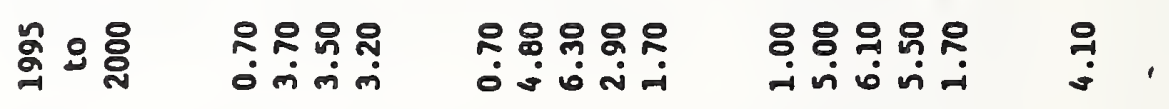

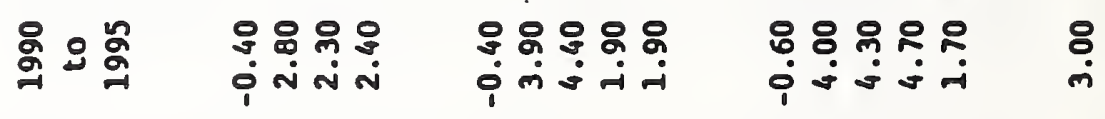

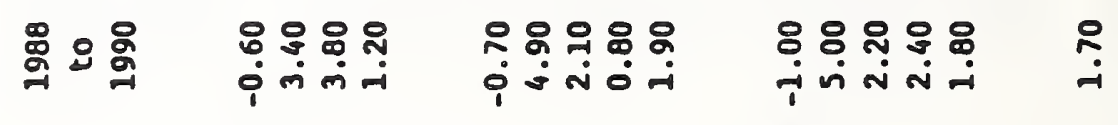
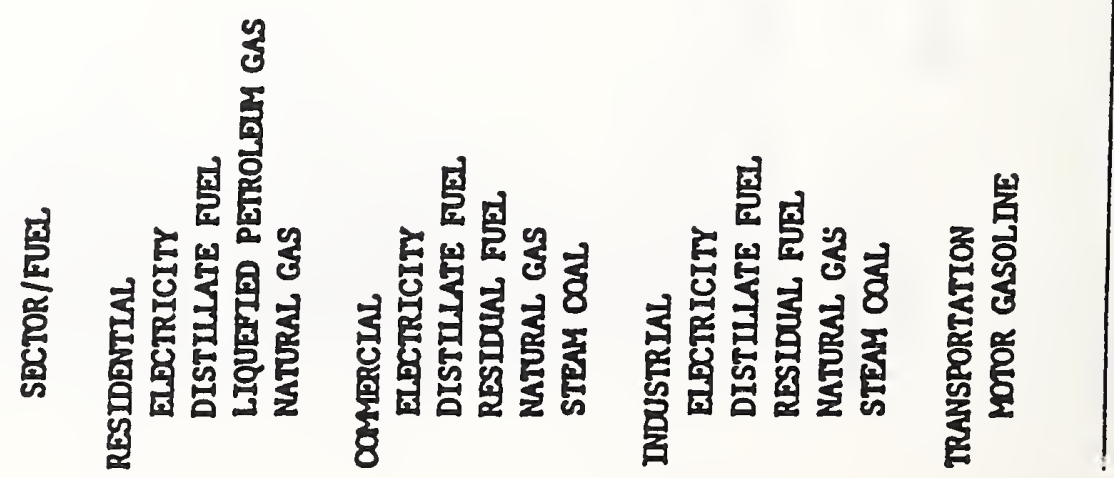

$\ddot{0}$

$\stackrel{8}{i}$

คి 


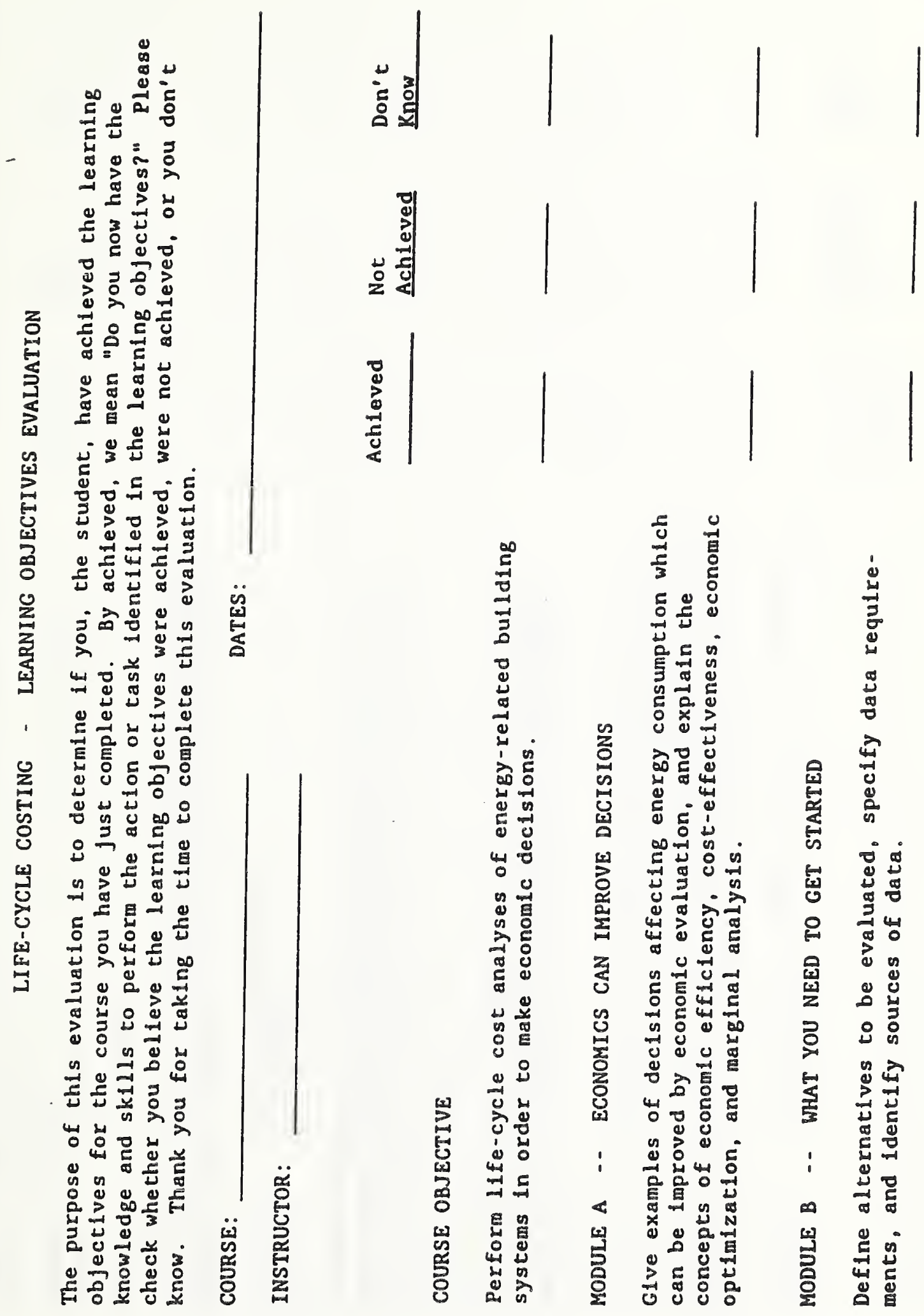




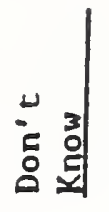
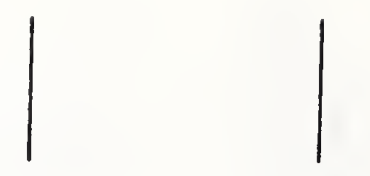

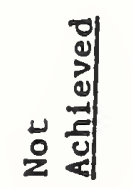
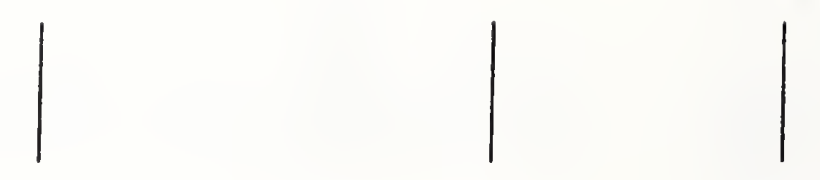

范

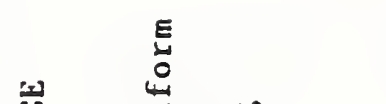


:
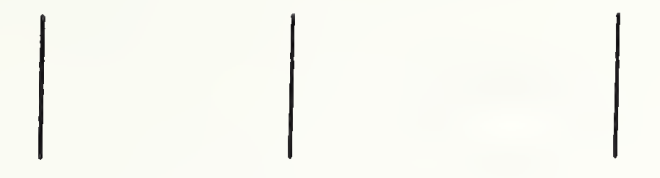

|
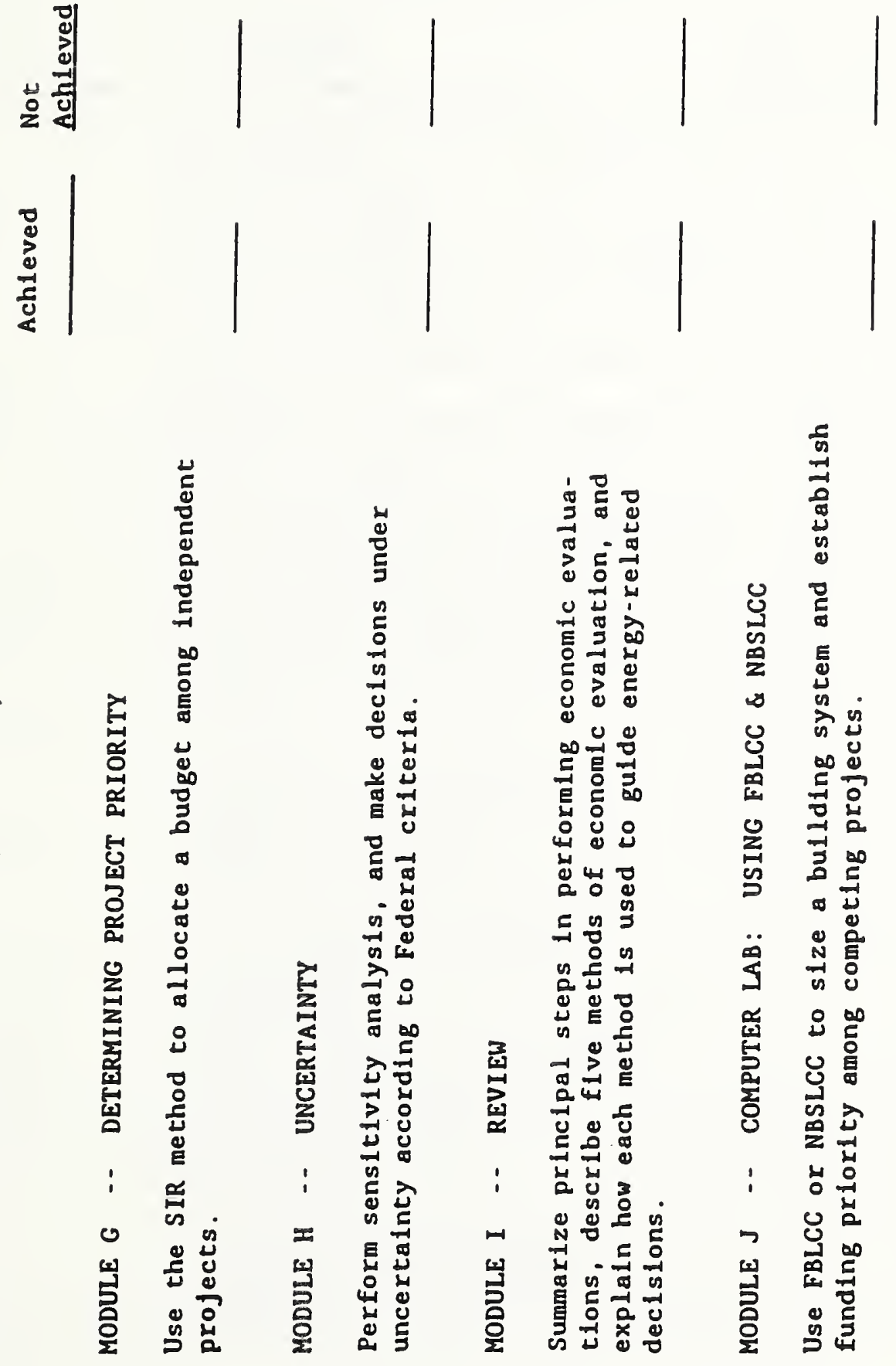


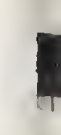




\section{COURSE EVALUATION}

PURPOSE: $n$ is our objecine io present useful and effecive trainng courses. You are ine final authorny on wheiner that objecive has been met. Your compleiton of inis form, inerefore, will play an mportani pari in our furure plannmg Please do not feel bound to imit your remarks to quesions ch inis form. Your pertment comments on any aspeci of the course will be appreciaied.

TITLE OF COURSE COURSE NO.

\section{LOCAIION}

IChock the response closest to your opinion

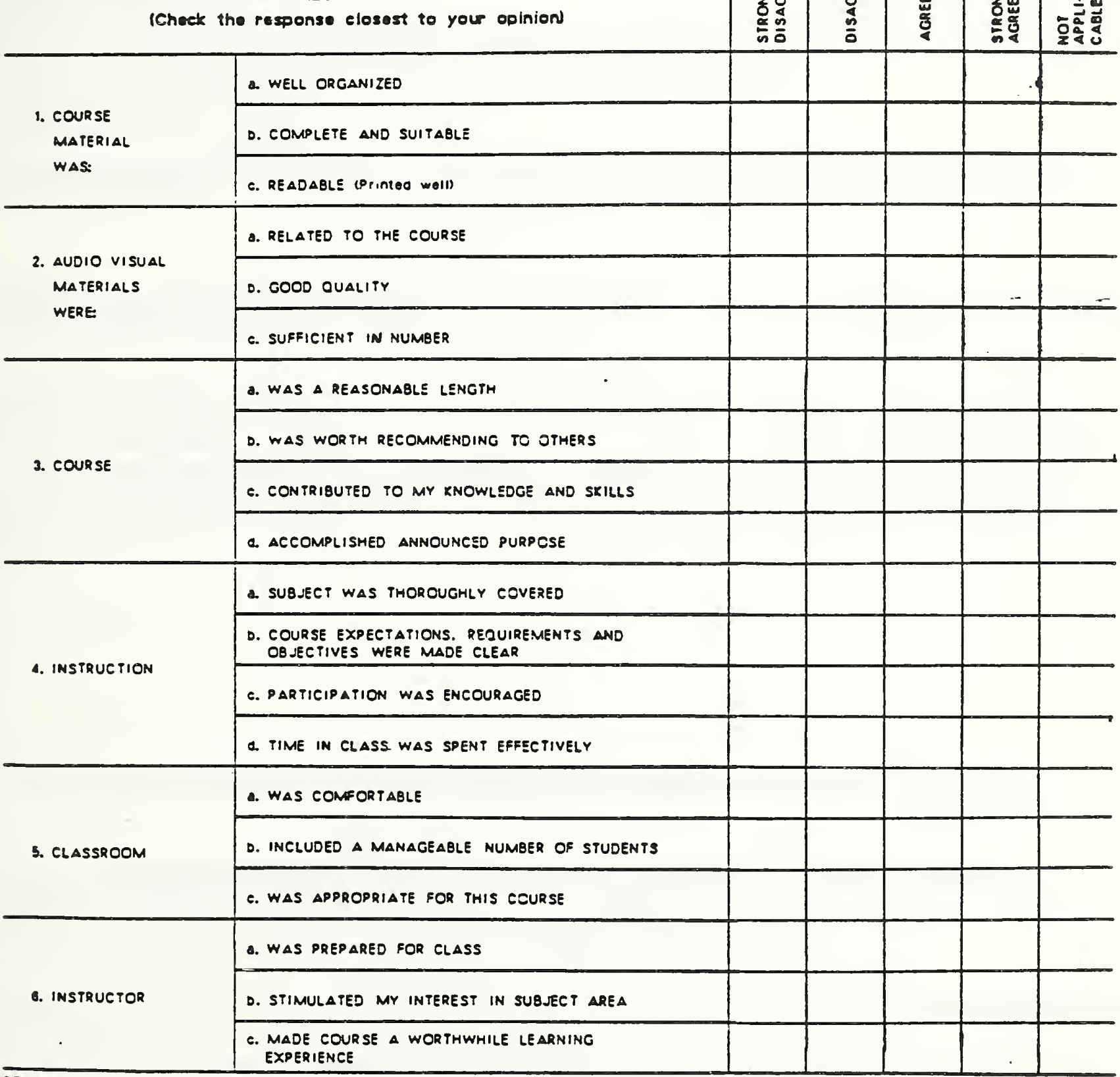

RESPONSES 
COURSE EVALUATION (ContInUEd)

3. OVERALL INSTRUCTOR EVALUATION ICHOCK YOM ODInION
a. KNOWLEDGe of tMe subject
$\square$ Excellent
$\square$ Good
$\square$ Fair
$\square$ Poor
D. ABILITY TO TEACH
Excoliont
$\square 6000$
foir
Poor

8. WOULD YOU AOD OR EMPHASIZE ANY SUBJECT MATTER AREAS IN SUBSEOUENT COURSE SESSIONS:

$\square$ YeS $\square$ NO. IF -YeS" lIST these AREAS AND GIVE YOUR REASONS.

9. WOULD YOU DELETE OR DE-EMPHASIZE ANY SUSJECT-MATTER AREAS?

$\square$ ves $\square$ no. if "yes" list these areas AND give rour reasons.

10. AS A RESULT OF YOUR PARTICIPATION IN THIS COURSE. WHAT AODITIONAL RELA TED TRAINING SHOULD BE MADE AVAILABLE ro rou?

11. OTMER COMMENTS. PLEASE PROVIDE ANY COMMENTS. EITMER GENERAL OR SPECIFIC. THAT YOU WOULD LIKE TO MAKE RELATIVE IO TMIS COURSE. 


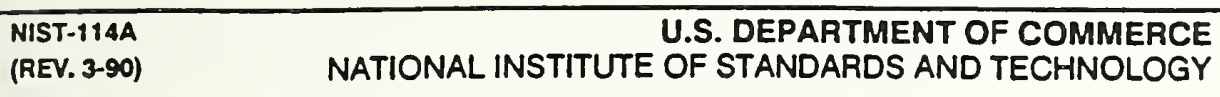

\section{BIBLIOGRAPHIC DATA SHEET}

\section{TITLEAND SUBTITLE}

Life-Cycle Costing for Energy Conservation in Federal Bulldings:- Student's Manual

5. AUTHOR(S)

Rosalie T. Ruegg and Stephen R. Petersen

6. PERFORMING ORQANIZATION (IF JOINT OA OTHER THAN NIST, SEE INSTRUCTIONS)

U.S. DEPARTMENT OF COMMEACE

NATIONAL INSTTTUTE OF STANDARDS AND TECHMOLOOY

CATTHERSBURG, MD 20890

9. SPONSOAING ORGANIZATION MAME AND COMPLETE ADDRESS (STREET, CITY, STATE, ZIP)

U.S. Department of Energy, Federal Energy Management Program

1000 Independence Avenue, S.W.

Washington, D.C. 20585

10. SUPPLEMENTARY MOTES

11. ABSTRACT (A 200-WORD OR LESS FACTUAL SUMMARY OF MOST SIGNIFICANT INFORMATION. IF DOCUMENT INCLUDES A SIOMIFICANT BIBLOGRAPMY OR UTERATURE SURVEY, MENTION TT HERE.)

This is the Student's Manual for an intensive two-day course on how to use life-cycle costing and related economic methods to make cost-effective decisions in designing and retrofitting Federal bulldings for energy conservation. The manual is designed to serve as an in class workbook and as a source for later reference and review. It contains 10 leaming modules the mastery of which will satisfy the course's goal of enabling and encouraging building professtonals to take into account long-run economic consequences of their decisions.

12. KEY WORDS (6 TO 12 ENTRIES; ALPMABETICAL ORDER; CAPITAUZE ONLY PROPER NAMES; AND SEPARATE KEY WORDS BY SEMICOLONS) building economics; capital investment; energy conservation; energy economics; engineering economics; Federal buildings; life-cycle costing; training courses

13. AVAILABIUT,

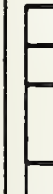

\section{UNUMITED}

FOR OFFICLLL DISTRIBUTION. DO NOT RELEASE TO MATIONAL TECHMICAL IMFORMATION SERVICE (MTIS).

ORDER FROM SUPERINTENDENT OF DOCUMENTS, U.S. GOVERMMENT PRINTIMG OFFICE, WASHINOTOH, DC 20402.

ORDER FROM HATIONAL TECHMICAL INFORMATION SERVCE (MTIS), SPRINGFIELO, VA 22161.

14. NUMBER OF PRINTED PACES

222

15. PAICE

A10

\section{ELECTRONIC FORM}





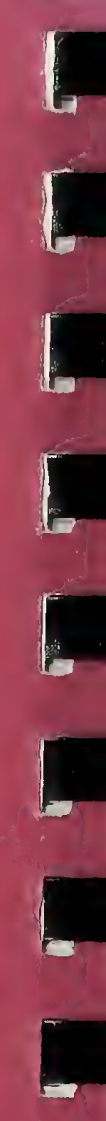

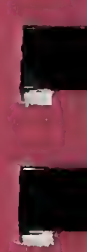

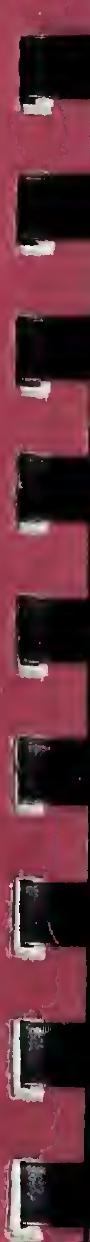

